INTERACTION BETWEEN CLOSTRIDIUM THERMOCELLUM ATCC 27405 AND THERMOANAEROBACTERIUM SACCHAROLYTICUM DSM 7060 ON CELLULOSIC AND LIGNOCELLULOSIC SUBSTRATES: SUBSTRATE ATTACHMENT, CONCENTRATION DYNAMICS, AND ETHANOL PRODUCTION

\author{
by
}

Dragan Miscevic,

Bachelor of Science Biology, Ryerson University 2012

A thesis

presented to Ryerson University

in partial fulfillment of the requirements for the degree of

Master of Applied Science

in the Program of Environmental Applied Science and Management

Toronto, Ontario, Canada, 2015

(C) Dragan Miscevic, 2015 


\section{AUTHOR'S DECLARATION}

\section{AUTHOR'S DECLARATION FOR ELECTRONIC SUBMISSION OF A THESIS}

I hereby declare that I am the sole author of this thesis. This is a true copy of the thesis, including any required final revisions, as accepted by my examiners.

I authorize Ryerson University to lend this thesis to other institutions or individuals for the purpose of scholarly research

I further authorize Ryerson University to reproduce this thesis by photocopying or by other means, in total or in part, at the request of other institutions or individuals for the purpose of scholarly research. 


\title{
INTERACTION BETWEEN CLOSTRIDIUM THERMOCELLUM ATCC 27405 AND THERMOANAEROBACTERIUM SACCHAROLYTICUM DSM 7060 ON CELLULOSIC AND LIGNOCELLULOSIC SUBSTRATES: SUBSTRATE ATTACHMENT, CONCENTRATION DYNAMICS, AND ETHANOL PRODUCTION
}

\author{
Dragan Miscevic \\ Master of Applied Science, Environmental Applied Science and Management, Ryerson \\ University, 2015
}

\begin{abstract}
Second generation biofuel research and bioethanol production via consolidated bioprocessing has the potential to become a viable alternative to finite fossil fuel reserves. Further advances have to be made in order to make this biotechnology more economically feasible. The focus of this study was to use cellulolytic $C$. thermocellum in a consortium with hemicellulolytic $T$. saccharolyticum to investigate the dynamics of their interaction with respect to cellulosic and lignocellulosic substrate attachment, respective numbers, and extent of solid substrate hydrolysis and desired end product formation. T. saccharolyticum's partial adherence to cotton and switchgrass has demonstrated limited need for substrate colonization and hence reduced competition with $C$. thermocellum. Real-time PCR analysis indicated that $T$. saccharolyticum can proliferate under low carbon supplementation, and efficiently utilize the metabolites produced from $C$. thermocellum's hydrolysis of cotton and switchgrass. The interaction between the two thermophiles on both substrates demonstrated a potential for increased bioethanol production.
\end{abstract}




\section{ACKNOWLEDGEMENTS}

First and foremost, I would like to sincerely thank my supervisor Dr. Gideon Wolfaardt for his continuous guidance and support throughout this project. Without his persistent help this thesis would not have been possible. Very special thanks have to be extended to the following people as well:

Dr. Alexandru Dumitrache, the techniques I have learned from him have helped me tremendously and his aid has structured the overall parameters of this study.

Dr. Richard Sparling and Alan Froese, University of Manitoba, their help with qPCR protocol, research analysis, and helpful criticism was truly appreciated.

The undergraduate and graduate students in Dr. Wolfaardt's and Dr. Gilbride's research group for great suggestions and the constant friendly environment in the laboratory was very helpful.

Finally, I would like to thank my family and friends for their personal support and encouragement. Special thanks go to my immediate family: Pavao, Ranka, Bogdan, and Kata Miscevic. Their involvement was fundamental in completion of this research. 
Dedicated to my late grandfather,

Bogdan Miscevic. 


\section{Table of Contents}

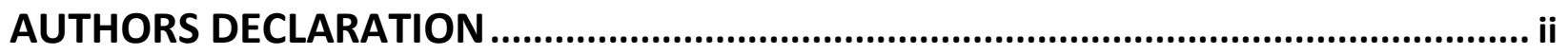

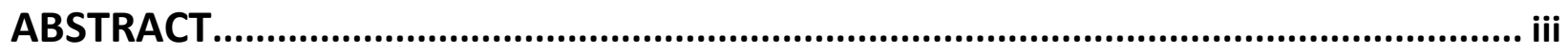

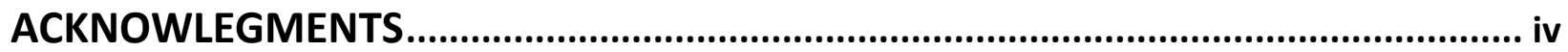

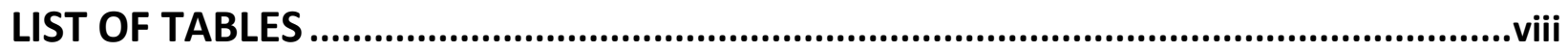

LIST OF FIGURES

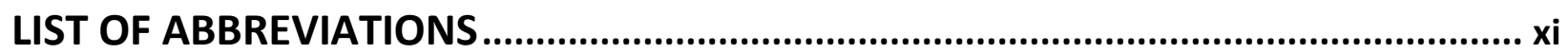

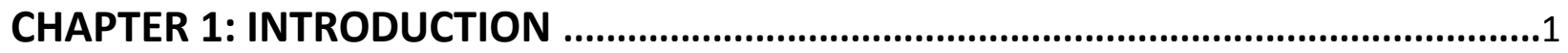

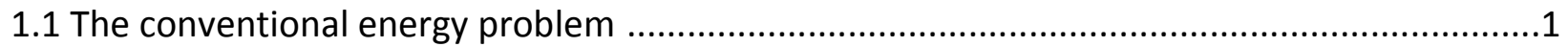

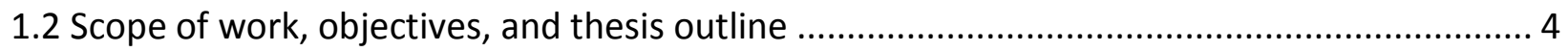

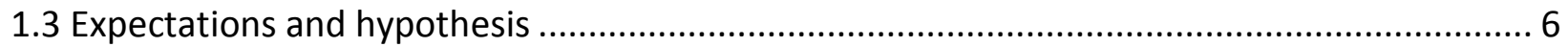

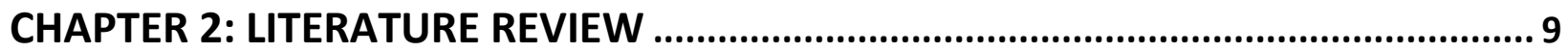

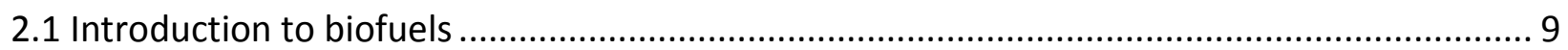

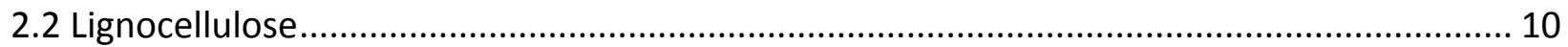

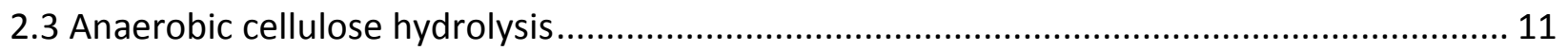

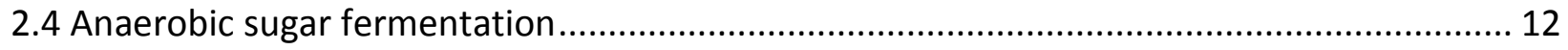

2.5 Early ethanol production methods and challenges ........................................................... 13

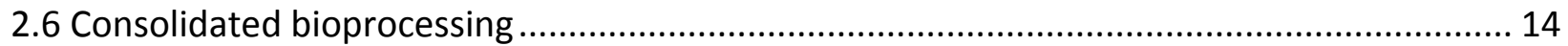

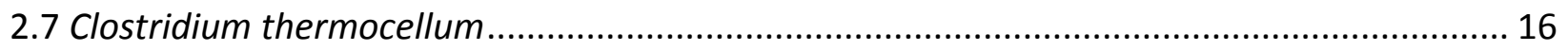

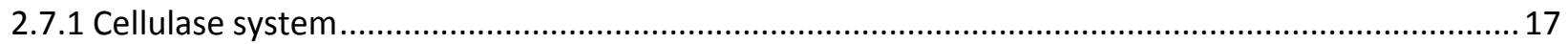

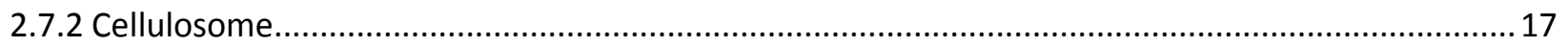

2.7.3 Cellulose-binding domain and cellulose degradation...............................................................

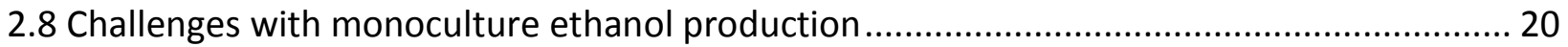

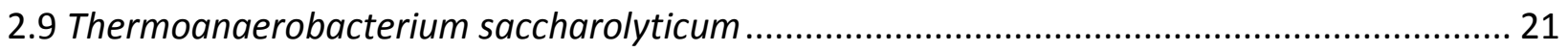

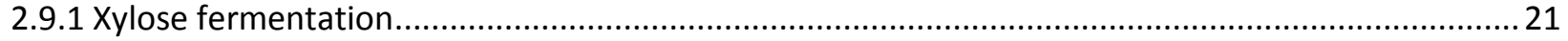

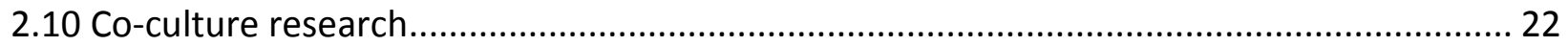

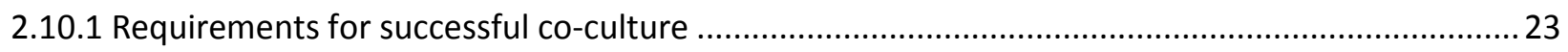

2.10.2 Clostridium thermocellum and Thermoanaerobacterium saccharolyticum ....................................2 24

2.11 Carbon catabolite repression and co-culture sugar utilization .......................................... 25 


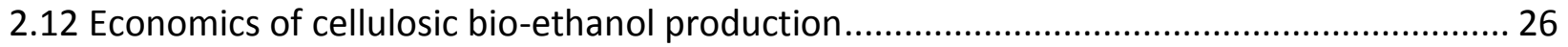

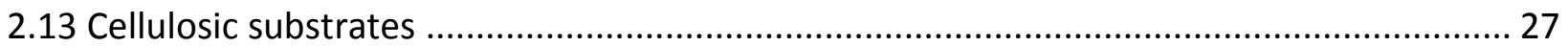

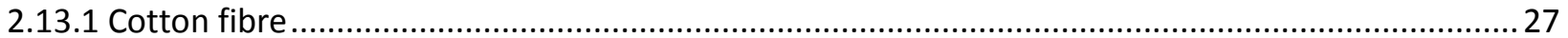

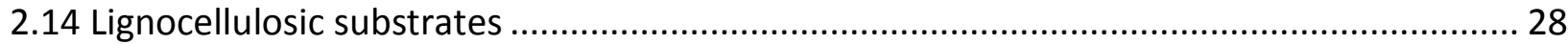

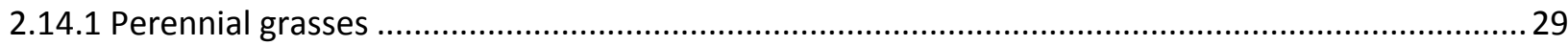

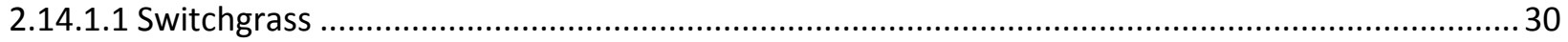

CHAPTER 3: EXPERIMENTAL ..............................................................32

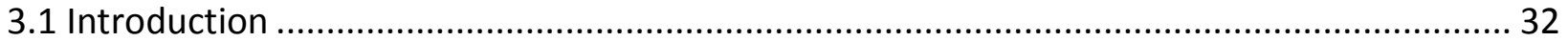

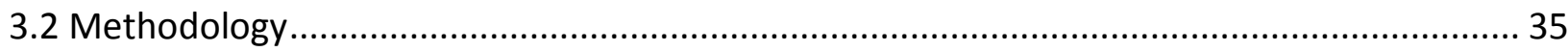

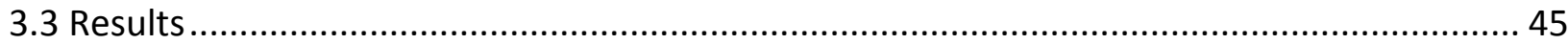

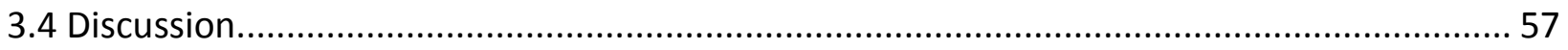

CHAPTER 4: OVERALL CONCLUSIONS AND FUTURE WORKS ...........................72

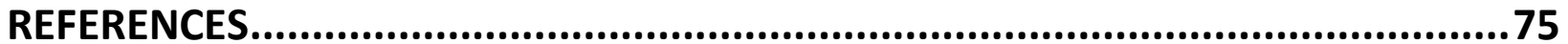




\section{LIST OF TABLES}

Table 3.1: Culture media preparation for each continuous-flow experiment with respect to HCS and LCS composition .37

Table 3.2: Sequences of designed forward primers, reverse primers, and probes used for amplification of $C$. thermocellum and T. saccharolyticum used in real-time PCR analysis .42

Table 3.3: Summary of the quantitative results for qPCR, HPLC, and solid carbon remaining at the end of the four individual continuous-flow experiments 56 Table 3.4: Peak concentrations of other end products produced from fermentation and hydrolysis

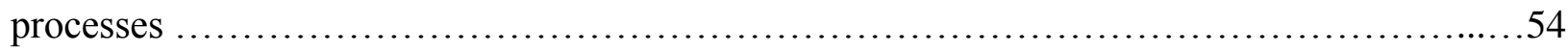




\section{LIST OF FIGURES}

Figure 2.1: Carbon metabolism in C. thermocellum ATCC 27405............................13

Figure 2.2: Consolidated bioprocessing with respect to SHF, SSF, and SSCF processes ........15

Figure 2.3: Simplistic model of a typical cellulosomal structure ...........................18

Figure 2.4: Xylose metabolism indicating key enzymes and identified co-factors in the central

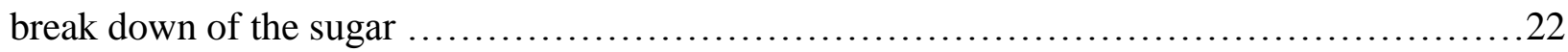

Figure 2.5: Simplified process using C. thermocellum and T. saccharolyticum in a co-culture for

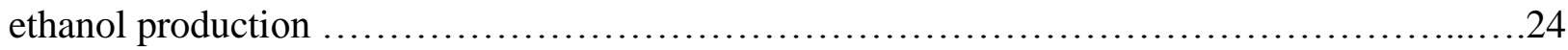

Figure 2.6: Live cell image of C. thermocellum ATCC 27405 monoculture grown in the flow

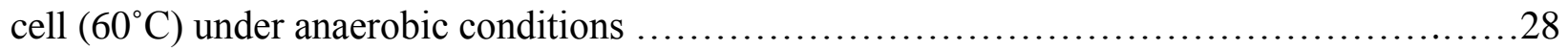

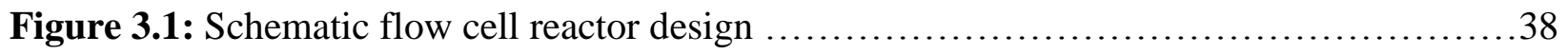

Figure 3.2: Schematic illustration of the continuous-flow cell system design for the four substrate attachment experiments .......................................................40

Figure 3.3: An overall continuous-flow system used for the four concentration dynamics measurements and HPLC experiments .................................................. 40

Figure 3.4: Epifluorescence morphology comparison images ............................45

Figure 3.5: Carbon material attachment efficiency of $T$. saccharolyticum DSM 706 ...........46

Figure 3.6: Comparing sugar utilization and ethanol production between $C$. thermocellum ATCC 27405 and T. saccharolyticum DSM 7060 monocultures and in co-culture samples in batch systems

Figure 3.7: qPCR analysis of $C$. thermocellum ATCC 27405 monoculture flow cell abundance on cotton fibre 49 
Figure 3.8: qPCR analysis of $C$. thermocellum ATCC 27405 monoculture flow cell abundance on switchgrass .50

Figure 3.9: qPCR analysis of $C$. thermocellum ATCC 27405 and T. saccharolyticum DSM 7060 co-culture flow cell abundance on cotton fibre .51

Figure 3.10: qPCR analysis of $C$. thermocellum ATCC 27405 and T. saccharolyticum DSM 7060 co-culture flow cell abundance on switchgrass .52

Figure 3.11: HPLC results displaying ethanol production of four continuous-flow experiments with respect to HCS and LCS 54 


\section{LIST OF ABBREVIATIONS}

ATCC American Type Culture Collection

CBD Cellulose binding domain

CBP Consolidated bioprocessing

CEM Cellulose-enzyme-microbe complex

DSM Deutsche Sammlung von Mikroorganismen

DSMZ Deutsche Sammlung von Mikroorganismen und Zellkulturen

DNA Deoxyribonucleic acid

HCS High carbon supplement

HPLC High performance liquid chromatography

LCS Low carbon supplement

qPCR Quantitative polymerase chain reaction

SHF Separate hydrolysis and fermentation

SSCF Simultaneous saccharification and co-fermentation 


\section{CHAPTER 1: INTRODUCTION}

\subsection{The conventional energy problem}

Currently with an equivalent global consumption of over 11 billion tonnes of oil in fossil fuels per year and crude oil vanishing at a rate of 4 billion tonnes per year, it is estimated, considering the world population increase as a major source of influence, that our known oil deposits could be completely depleted by the end of this century (Shafiee and Topal, 2009). The International Energy Agency (IEA) has predicted that the world's crude oil supply will peak in 2014, followed by a steadily decline in the upcoming years (Evans, 1999). Other estimates state that 64 of the 98 oil-producing countries have already reached their peak oil production in the last few years (Scragg, 2009). The world depends on a regular supply of energy, meaning that whatever the statistics are for the finite fossil fuel reserves, alternative sources of energy need to be introduced.

Aside from the shrinking fossil fuel supply, the conventional method used to extract fossil fuels has a tremendous negative effect on the environment. Carbon dioxide $\left(\mathrm{CO}_{2}\right)$ that is emitted causes the pollution of air and contributes to $55 \%$ of global warming (Scragg, 2009). According to the IEA, the annual carbon dioxide discharge from the use of coal, gas, and oil were above $23 \mathrm{Gt}$ in the year 2000 having risen to $15.7 \mathrm{Gt}$ in 1973 from $0 \mathrm{Gt}$ in pre-industrial period (IEA, 2002). Nitrogen oxides $\left(\mathrm{NO}_{\mathrm{x}}\right)$ produced during burning of fossil fuels can contribute to ozone depletion and on a molecule-to-molecule basis it absorbs infrared radiation 200 times more than carbon dioxide (Hameed and Dignon, 1992; Khalil and Rasmussen, 1989).

Release of sulphur dioxide $\left(\mathrm{SO}_{2}\right)$ during combustion of fossil fuels can generate acid precipitation which has a wide range of negative effects on waters, flora, and fauna (Scragg, 2009; Van Breeman et al., 1982). Finally, discharge of radioactive substances such as uranium 
and thorium into the atmosphere can increase the risk of lung cancer (Hameed and Dignon, 1992; Van Breeman et al., 1982). Thus, it is essential to search for more sustainable and environmentally friendly techniques for energy production.

To date, there are various renewable energy sources that are considered to be alternatives to fossil fuels. These alternatives include (but are not limited to) wind or solar power, hydroelectricity, geothermal power, and biomass (Kallos and Apostolopoulou, 2007). Out of many renewable energy sources present globally, biofuels generated from biomass are generally more sustained, have the ability to be stored for transportation, and contain zero carbon footprint (Kallos and Apostolopoulou, 2007).

First generation biofuels are type of biofuels that extract energy from crops such as sugarcane, sugarbeet, maize, wheat, soybean, and soyflower (Scragg, 2009). However, the main issue with this type of biofuel is that it requires large areas of land to completely replace fossil fuels gas, petrol and diesel (Scragg, 2009). Therefore, there is not an adequate amount of land to successfully grow sufficient energy crops without competing with food crops for land which causes increase in food prices as a result. For these specific reasons, second generation biofuels are under development. The second generation biofuels are produced from lignocellulosic biomass and wastes which tend to provide better yields per hectare and thus do not compete with food crops (Sims and Taylor, 2008; Damartzis and Zabaniotou, 2011). In addition to food competitions, they also require less fertilizer and pesticide usage, contain a more satisfying energy balance, and reduce the amount of greenhouse gas emission than first generation biofuels (Sims and Taylor, 2008). According to Kallos and Apostolopoulou, cellulosic bioethanol has 1.25 times more megajoule (MJ) of energy output than sugar ethanol and 10 times MJ of energy output than corn ethanol (Kallos and Apostolopoulou, 2007). Furthermore, cellulosic ethanol 
produces only 1.36 kilograms of $\mathrm{CO}_{2}$ per $130 \mathrm{MJ}$ of energy delivered, whereas sugar ethanol produces 5.44 kilograms of $\mathrm{CO}_{2}$, and corn ethanol 9.53 kilograms of $\mathrm{CO}_{2}$ (Kallos and Apostolopoulou, 2007).

The term lignocellulose was first introduced by Edwards John Bevan (1856-1921) and Charles Fredrick Cross (1855-1935), who were leading British chemists in cellulose technology in the late $19^{\text {th }}$ century (Kamm et al., 2006). Lignocellulosic biomass is currently the most abundant feedstock on Earth for biofuel production (Lynd et al., 2008). Some examples of lignocellulosic substrates include wood chips, bagasse, agave, grasses, and paper sludge (Lynd et al., 2002). In 2005, it was estimated that the total combustible renewables and waste consumption was approximately 1,149 Mtoe, with $94 \%$ of this material being lignocellulosic biomass (Sims and Taylor, 2008). Although abundant and renewable, only limited amount of this particular feedstock can actually be utilized in practice. Lignocellulosic structure itself is very tough to break down due to the strong $\beta-1-4$ glycosidic bonds between the monomer sugars (Sims and Taylor, 2008). In addition, current technology is limited when it comes to fermenting both pentose and hexose sugars present in cellulose and hemicelluloses components. Therefore, it is essential to the future of second generation biofuels to develop a system that will be able to utilize all the available sugars present in the lignocellulosic structure, as well as optimizing bioethanol production by using renewable biocrops that are environmentally friendly. 


\subsection{Scope of work, objectives, and thesis outline}

Much attention has been given to the strictly anaerobic thermophile $C$. thermocellum, more specifically how its cellulolytic and ethanologenic abilities can be used in converting biomass into an applicable energy source. However, the model bacterium $C$. thermocellum pure cultures are often limited to the amount of available sugars that they can ferment from the lignocellulosic substrate. In other words, being capable of fermenting only hexose sugars, $C$. thermocellum's chances of reaching a sufficient abundance of ethanol end-product are slim (Lynd et al., 2002). The addition of anaerobic thermophilic bacterium, T. saccharolyticum, and its ability to ferment pentose sugars found in hemicellulose, can increase the potential of valuable end products (Maki et al., 2009). By applying this co-culture to a promising biocrop, such as switchgrass, this study intended to fill in an important gap in the lignocellulosic biomass research.

The scope of the research was focused on studying the relationship between $C$.

thermocellum and T. saccharolyticum and how their interaction can be utilized to develop ethanol production from cellulosic and lignocellulosic substrates. This was based on three main objectives of the research: (i) comparing morphology and analyzing the interaction between the two thermophilic anaerobes in their attachment capabilities to various carbon sources, (ii) examining the competitive vs. co-operative behaviour based on physiology tests and relative numbers on different substrates, and (iii) investigating the extent of solid substrate solubilisation and end product formation.

This thesis is divided into four specific chapters. Chapter 1 lays down the framework of the project as far as the reasoning and motivation behind this particular work is concerned. This chapter also describes the goals and general expectations of the work. Chapter 2 offers 
background information on some of the key elements and terms of the research through literature review. The experimental approach, results, and discussion of the present study are presented in chapter 3. Finally, chapter 4 deals with general conclusions and recommendations for future research in this particular field. 


\subsection{Expectations and hypothesis}

Due to the fact that hardly any detailed microscopy and physiology testing has been performed on T. saccharolyticum DSM 7060, it would be of great interest to compare morphological differences and metabolic production to its cellulolytic counterpart. Morphological differences would reveal easier differentiation between $C$. thermocellum and $T$. saccharolyticum with future co-culture imaging. Furthermore, microbe attachment to different biomass substrates has been extensively researched in the past. C. thermocellum's ability to bind to cellulosic and lignocellulosic materials has been covered by Lamed and Bayer (1988), Raman et al. (2011), and Dumitrache et al. (2013); the results show that this anaerobic microbe can adhere to various cellulosic sources at different rates. In addition, $C$. thermocellum is well known to occupy carbon material such as cellulose and cellobiose, with a growth rates of $0.23 \mathrm{~h}^{-1}$ and $0.35 \mathrm{~h}^{-1}$, respectively (Dror et al., 2003). Attachment capabilities of $T$. saccharolyticum are still largely unknown, and there is no record in literature which points to Thermoanaerobacterium strains binding to cellulosic or lignocellulosic sources. This part of the study also aimed to determine whether or not there is any physical competition between $C$. thermocellum and $T$. saccharolyticum when it comes to substrate colonization. Consequently, due to $T$. saccharolyticum's lack of cellulose-binding domains (CBDs) it is expected that this strain has limited attachment to carbon material.

The competitive vs. cooperative aspect of the research has shed light on the interaction dynamics between $C$. thermocellum and $T$. saccharolyticum. To measure this interaction, the carbon supply in the medium had to be effectively controlled. First, yeast extract is considered to be unfeasible and uneconomical for cultivation of cellulolytic bacteria; therefore, minimal amount of this carbon source was used for this experimentation. Second, using lower yeast 
extract and sugar supplements have provided a more accurate carbon sharing between the two thermophiles in continuous-flow preparations. This experimentation was organized by preparing a continuous-flow system and using high carbon supplement medium for obtaining successful initial growth of both thermophiles then switching the medium to minimal carbon supplement to then compare the respective numbers of each bacterium. A quantitative analysis by the use of a real-time PCR has provided prosperity measurement of each bacterium during the nutritional change. Competitive interaction between the two thermophiles would be indicated by one bacterium outcompeting the other nutritionally (digesting more carbon available over the other). On the other hand, a cooperative interaction would be demonstrated by a lack of significant change or a stable recovery in numbers of each thermophile after the high-to-low carbon supplement medium switch. Previous research by Liu and colleagues (1996) has shown that $T$. saccharolyticum is known to utilize pentose and hexose type sugars. This parallel sugar metabolism hints towards a lowered competition between $C$. thermocellum and $T$. saccharolyticum since $C$. thermocellum can only metabolize hexose sugars. Therefore, the expectations for this part of the research are that $C$. thermocellum will efficiently hydrolyze the carbon substrates and the pentose metabolites released will be fermented by $T$. saccharolyticum, thus alluding to a more cooperative interaction in consortium.

The extent of carbon solubilization and ethanol production, the final two parts of the study, are to reveal the true value of cellulosic utilization and end product formation from this particular co-culture. Research on measurement of solid carbon degradation with both cellulolytic and hemicellulolytic thermophiles in co-culture is limited; however, previous experimentation suggested cooperative relationship between the two anaerobes will result in 
higher ethanol yield than in $C$. thermocellum monoculture due to the additional fermentation of pentose sugars by T. saccharolyticum (Suib, 2013).

It was hypothesized that $T$. saccharolyticum will exhibit little substrate attachment and will also utilize sugars produced by $C$. thermocellum hydrolysis of cellulosic and lignocellulosic material and as a result, increase ethanol production in both cases. 


\section{CHAPTER 2: LITERATURE REVIEW}

\subsection{Introduction to biofuels}

Biofuel, in general terms, is fuel that is generated from dead organic material by living organisms via carbon fixation (Lal, 2005; Barber, 2008). Biofuels are produced through biochemical reactions, which can be carried out in industrial or laboratory setting that use decomposed organic matter (known as biomass). Today, approximately $2 \%$ of the world's transportation fuel is either derived from ethanol fermentation or processing of plant oils to generate biodiesel (Koonin, 2006). Furthermore, biofuels can be characterized into three specific groups: i) first generation biofuels - fuel derived from sugar, starch, or vegetable oil, ii) second generation biofuels - fuel derived from lignocellulosic biomass (woody crops), grasses, or agricultural waste, and (iii) third generation biofuels - fuel derived from algae (Antizar-Ladislao and Turrion-Gomez, 2008; Naik et al., 2010). It is important to note that the structure of the fuel does not change between generations, but rather the source from which the fuel is derived. These types of biofuels have the capability to generate a wide variety of fuel, such as bio-alcohols (ethanol, propanol, and butanol), biodiesel, bio-ethers, and biogas (Naik et al., 2010). Analyses of various biofuels showed that cellulosic ethanol (second generation biofuel) delivers more energy per 1 mega joule (MJ) than fossil fuel energy (a ten-fold increase in energy output) (Kallos and Apostolopoulou, 2007). Finally, second generation biofuels are projected to account for over $90 \%$ of total biofuel production by the year 2050 due to its higher efficiency, feedstock availability, and not being in competition with the food industries (Bardle and Abadi, 2010; IEA, 2010). 


\subsection{Lignocellulose}

Lignocellulose is the most abundant renewable natural resource and inexpensive substrate available for conversion to fuels (Demain, 2005). This substrate is composed of cellulose, hemicellulose, and lignin that constitute an essential part of woody cell walls of plants. Cellulose $\left(\mathrm{C}_{6} \mathrm{H}_{10} \mathrm{O}_{5}\right)_{\mathrm{n}}$ is an organic polymer (polysaccharide) that is composed of thousands of repeating Dglucose molecules which are linked by $\beta-1-4$ glycosidic bonds (Dauenhauer et al., 2007). This particular straight chain polymer can be predominately found in nature as a structural component in the cell wall of plants and many forms of algae (Baldan et al., 2001). Cellulose can make up 35-50\% of plant dry weight and is the most abundant component of plant biomass (Lynd et al., 2002). Hemicellulose is a heteropolymer that is made up of simple sugars, for example, xylose, galactose, mannose, and arabinose (Ronan, 2011). Hemicellulose accounts for 20-35\% total dry weight of lignocellulose (Zavrel et al., 2009). Last, lignin can comprise up to 5\% to $30 \%$ of plant dry weight and is considered to be more resistant organic polymer within which cellulose fibres are entangled (Lynd et al., 2002). One particular measure of lignin composition is a ratio of its guaiacyl (G) and syringyl (S) moieties (Davison et al., 2006). Guaiacyl units can covalently crosslink with three other units and syringyl can link with only two units (Davison et al., 2006). The S/G ratio has a large effect on processability and delignification of lignocellulosic material (Ohra-aho et al., 2013). Thus, lignocellulosic substrates with an increased S/G ratio are more easily delignfied and more ideal for biofuel use (Lima et al., 2008).

Cellulolytic microorganisms contain specific enzymes that enable them to efficiently degrade cellulose substrates. These endoglucanase and exoglucanase enzymes are called cellulases and are known to break or cleave the $\beta-1-4$ glycosidic bonds within a cellulose polymer (see section 2.7.1) (Demain et al., 2005). Interestingly, the ability of microorganisms to 
degrade cellulose is widely distributed in different environmental conditions such as $\mathrm{pH}$, oxygen content, temperature, and salinity (among others). Due to various environmental conditions, cellulolytic microorganisms (both fungi and bacteria) can fall under both aerobe and anaerobe groups.

\subsection{Anaerobic cellulose hydrolysis}

Some anaerobic bacteria contain a protein complex called cellulosome (see section 2.7.2) that is used for the degradation of cellulose. This protein complex is located on the outside of the cell wall and is composed of up to 11 subunits consisting of enzymatic cellulase and nonenzymatic regions (Shwartz, 2001). Cellulosomes are capable of breaking the $\beta-1-4$ glycosidic bonds in the cellulose fibre and this cleavage releases independent glucose molecules from the chain in a process called hydrolysis (Kim, 1995). Anaerobic cellulolytic bacteria have evolved to use cellulosomes due to their advantages over cell-free enzymes. The cellulosome allows the cell to directly regulate and control the ratio of expression of enzymatic subunits, which directly affects the rate of hydrolysis (Norsker et al., 1999). In addition, the physical distance between the cell and the cellulose substrate is subsequently reduced (Lynd et al., 2002). Currently, the specific anaerobes that are known to contain a cellulosome complex are: Acetivibrio cellulolyticus, Bacteroides cellulosolvens, Clostridium acetobutylicum, Clostridium cellulolyticum, Clostridium cellulovorans, Clostridium josui, Clostridium papyrosolvens, Clostridium thermocellum, and Ruminococcus flavefaciens (Shoseyov et al., 1992; Kakiuchi et al., 1998; Ding et al., 1999; Pages et al., 1999; Nolling et al., 2001). 


\subsection{Anaerobic sugar fermentation}

Anaerobic fermentation is the biological conversion of sugar molecules into alcoholic derivatives such as ethanol (Bai et al., 2008). It is important to state that from all cellulosedegrading microorganism identified, Clostridium thermocellum has the highest hydrolyzing rate (see section 2.7) (Lu et al., 2006; Sparling et al., 2006). First, the liberated cellulose and cellobiose products from the hydrolysis step are used by specific types of microorganisms and, in the absence of oxygen, are fermented into desired end products via the Embden-Meyerhof pathway (Figure 2.1). In other words, the degraded cellulose products, such as glucose and cellodextrins (two or more glucose monomers), are transported into the bacterial cell for metabolism. Glycolysis generates pyruvate molecules from sugars and these pyruvate molecules are then fermented to produce ethanol (producing acetaldehyde intermediate in the process) (Ronan, 2011). C. thermocellum is known to produce two major end-products: ethanol and acetate. On a cellulose source such as a cotton fibre, the two products contain a final ratio of 2:1 (ethanol to acetate) (Dumitrache et al., 2013). 


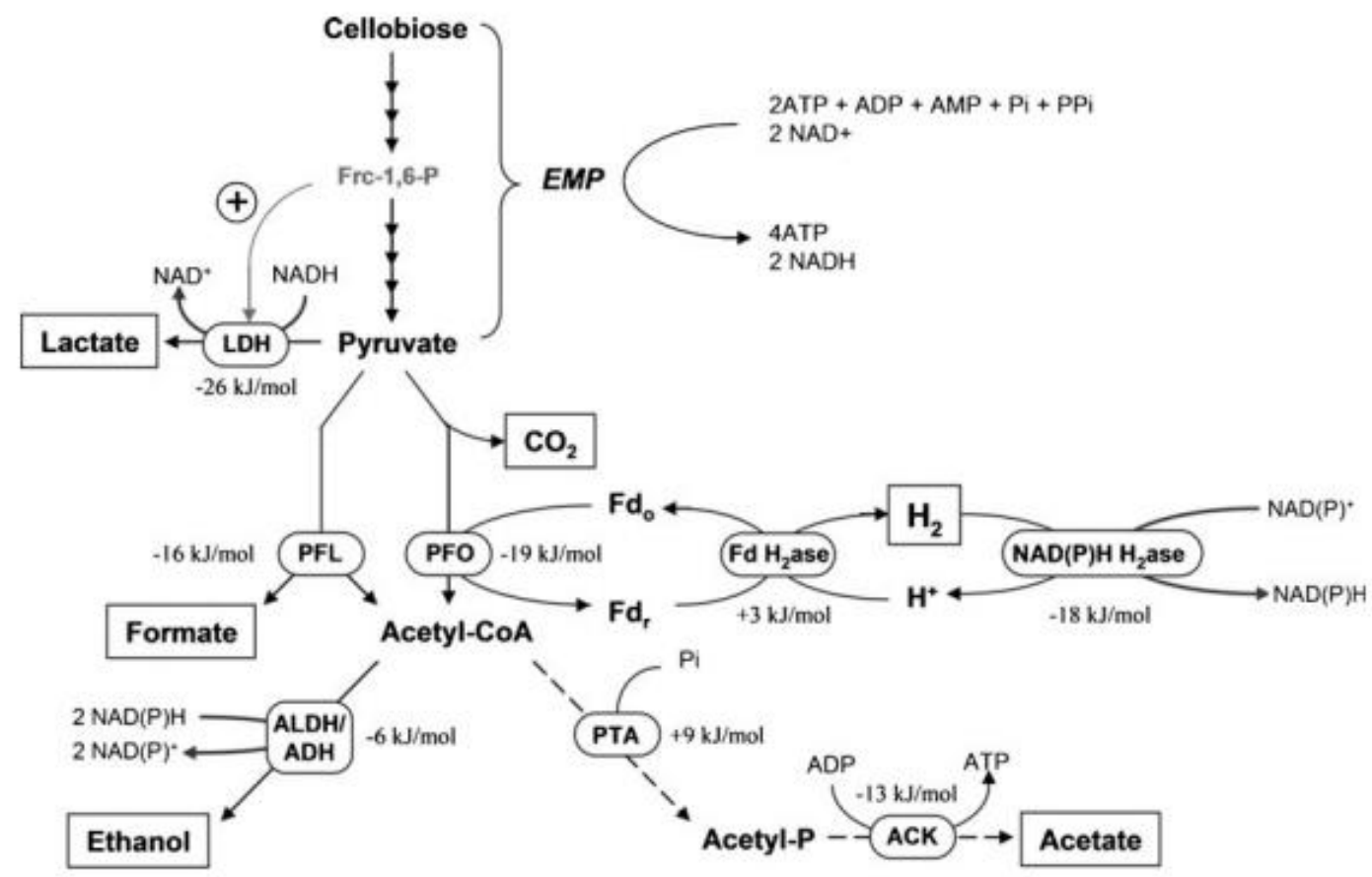

Figure 2.1: Carbon metabolism in C. thermocellum ATCC 27405. Solid lines indicate verified enzyme pathway activity; dashed lines are genetically deduced pathway not verified by enzyme activity. Abbreviations : LDH, lactate dehydrogenase (fructose-1,6-bisphosphate activated); PFL, pyruvate:formate lyase; PFO,pyruvate:fd oxidoreductase; ALDH/ADH, acetaldehyde dehydrogenase/alcohol dehydrogenase; PTA, phosphotransacetylase; ACK, acetatekinase; Fd-H2ase, ferredoxin hydrogenase; NAD(P)H H2ase, NAD(P)Hhydrogenase (Adopted from Rydzak et al., 2011).

\subsection{Early ethanol production methods and challenges}

For successful biological conversion of cellulosic biomass into fuels, four biologically mediated events must occur: (i) cellulase enzyme production, (ii) hydrolysis of cellulose and other polysaccharides (if present), (iii) fermentation of soluble cellulose sugar products, and (iv) fermentation of soluble hemicelluloses sugar products (Lynd et al., 2002). Prior to the 1980s, ethanol yield was achieved by performing each of the four events individually by a process known as separate hydrolysis and fermentation (SHF) (Figure 2.2) (Lynd et al., 2002). Microorganisms used in steps i and ii were generally fungal microbes such as Trichoderma reseei and Trichoderma viride, due to their most efficient cellulase production at the time 
(Taherzageh and Karimi, 2007). In 1988, Wright and colleagues developed a method to combine hydrolysis and fermentation into one step using mixed yeast cultures, known as simultaneous saccharification and fermentation (SSF) (Wright et al., 1988). However, cellulase production and hemicelluloses sugar fermentation occurred in two additional and individually separate steps (Lynd et al., 2002). In the early 1990s, cellulase production was successfully joined to SSF to develop a new process called simultaneous saccharification and cofermentation (SSCF) (Wyman and Goodman, 1993). Finally, in 1996 Dr. Lee Lynd and colleagues from Dartmouth College were able to develop a one-step biological conversion of biomass into ethanol in a process called direct microbial conversion (DMC), which was later termed consolidated bioprocessing (CBP) (Lynd et al., 2002). No single microbe is capable of successfully performing CBP; however there are few microorganisms that have been considered as potential candidates (see section 2.6).

Two of the early major challenges facing ethanol production were the plant resistance to hydrolysis and land use concerns (Lynd et al., 2005). As plants evolve they develop stronger structures and become more resistant to degradation as a result. Due to this phenomenon, increased costs for heat and cellulase enzymes are required. Furthermore, the land use concerns relate to food vs. fuel debate since many acres of land are necessary to cultivate and harvest crops for bioethanol production.

\subsection{Consolidated bioprocessing}

Consolidated bioprocessing (CBP) is a biological conversion of lignocellulose into desired products that combines cellulase production, lignocellulose hydrolysis, and hexose and pentose fermentation into a single step (Lynd et al., 2005). One potential CBP candidate is

Clostridium thermocellum, due to its cellulolytic and fermentation capabilities (see section 2.7). 
This microorganism contains a more effective cellulosome complex that is capable of hydrolyzing cellulose at a faster rate than other cellulosome-containing microbes and at the same time fermenting glucose or six-carbon (hexose) sugars into ethanol (Sparling et al., 2006). It is worth mentioning that to date no other natural occurring microbes have been isolated that can compete with C. thermocellum's efficiency to carry out CBP (Sizova et al., 2011; Mazzoli, 2012). Figure 2.2 illustrates the effectiveness of CBP in comparison to other ethanol production methods.

\begin{tabular}{c}
\hline $\begin{array}{c}\text { Biologically } \\
\text { mediated event }\end{array}$ \\
\hline $\begin{array}{c}\text { Cellulase } \\
\text { production }\end{array}$ \\
$\begin{array}{c}\text { Cellulose } \\
\text { hydrolysis } \\
\text { fermentation } \\
\text { Pentose } \\
\text { fermentation }\end{array}$
\end{tabular}

Figure 2.2: Consolidated bioprocessing with respect to SHF, SSF, and SSCF processes (Adopted from Lynd et al., 2002)

In addition to the time saving advantage of $\mathrm{CBP}$, this process also offers the potential for lowering cost and increasing overall efficiency (He et al., 2011). Unnecessary expenses can be avoided when using CBP due to the fact that this process requires less spending on cellulase enzymes and other raw material that are used in ethanol production. Total cost for biological processing of hydrolysis and fermentation individually (which includes the cost for yield lost, utilities, raw materials, and capital and related spending) is about US $\$ 0.19$ per gallon (US $\$ 0.05 / \mathrm{L}$ ), which is more than fourfold larger than US $\$ 0.04$ per gallon(US $\$ 0.01 / \mathrm{L}$ ) projected for CBP (Lynd et al., 2005). 


\subsection{Clostridium thermocellum}

A model organism for cellulose degradation is the C. thermocellum ATCC 27405 strain (Dumitrache et al., 2013, Pers. Comm.). Along with being an anaerobe, this strain is amenable to genetic engineering and can thrives in high temperature environments (thermophilic) at around $60^{\circ} \mathrm{C}$ and an optimum pH range between 6.5 and 7.2 (Argyros et al., 2011; Dumitrache et al., 2013, Pers. Comm.). In addition, C. thermocellum is a Gram-positive, spore forming bacterium that is capable of hydrolyzing cellulose; fermenting hexose sugar oligomers to ethanol and other products such as organic acids, carbon dioxide $\left(\mathrm{CO}_{2}\right)$, and hydrogen gas $\left(\mathrm{H}_{2}\right)($ Dumitrache et al., 2013, Pers. Comm.).

The interest of $C$. thermocellum in the biotechnological application in biofuel research is due to several of factors. First, this particular microbe is currently the number one high utility candidate for use in consolidated bioprocessing applications (Akinosho et al., 2014). Second, $C$. thermocellum is an anaerobic microorganism. This specific characteristic provides great advantage to the technology since of most expensive steps in industrial fermentations is that of providing adequate oxygen transmission (Demain et al., 2005). Third, aside from being anaerobic, this bacterium is also thermophilic. Having an optimal temperature around $60^{\circ} \mathrm{C}$, the possibility for contamination is greatly reduced (Demain et al., 2005). Fourth, growth at high temperatures promotes the recovery of ethanol. Fifth, more of the cellulose substrate can be converted to ethanol due to anaerobic ability to possess low cell yield (Demain et al., 2005). Last, the release of carbon dioxide into the atmosphere during fermentation is recycled by growth of plants. Hence ethanol-based fuel does not contribute to the mobilization of carbon from the deep geosphere into the biosphere and possible global warming as in the case of fossil fuels. 


\subsubsection{Cellulase system}

The cellulase system is composed of series of enzymes that are produced by cellulolytic organisms in order to metabolize cellulose (Demain et al., 2005). Specifically, the $C$. thermocellum cellulase complex displays a high activity on crystalline cellulose, which refers to its ability to completely solubilize crystalline forms of cellulose such as cotton or avicel (Demain et al., 2005). This unique complex of enzymes is comprised of: (i) endo- $\beta$-glucanases, responsible for random breakdown of cellulose fibre; (ii) exoglucanases that generate cellobiose; (iii) cellobiose phosphorylase which breaks down cellobiose into glucose and glucose-1-phosphate; (iv) cellodextrin phosphorylase, whose function is to phosphorylyze $\beta$-1,4-oligoglucans; and (v) two $\beta$-glucosidases that hydrolyze cellobiose to glucose (Demain et al., 2005).

\subsubsection{Cellulosome}

The cell bound, multi-enzyme complex called the cellulosome is a typical structural property found in many anaerobic cellulolytic strains such as those belonging to Closridium spp. and Ruminococcus spp., and is considered to be the most efficient biochemical system for cellulose degradation (Mazzoli, 2012). This particular protein complex is attached to the outside of the cell wall and contains both enzymatic (cellulase) and non-enzymatic regions of up to 11 subunits long (Schwarz, 2001). Early studies in Massachusetts Institute of Technology speculated that the true activity of cellulase system belongs to a larger aggregate with a molecular weight of more than $1.5 \mathrm{x}$ $10^{6} \mathrm{~g} / \mathrm{mol}$ (Johnson, 1983). This allowed researchers to further investigate this aggregate and to eventually purify a cellulosome complex for the first time in 1983 from a $C$. thermocellum strain (Bayer et al., 1994). 
Today, the majority of cellulosome components has been identified and genetically mapped (Figure 2.3). The cellulosome multi-subunit complex contains various domains that have their specific function, and as a whole contribute to the biological degradation of cellulose. These domains include a three repeat S-layer homology (SLH) domain that is directly attached to the cell wall of the cellulolytic microorganism. Next, an anchoring protein physically connects the SLH repeats to the 1,850 amino acid long scaffoldin protein, also known as cellulosome-integrating protein (CipA) (Lamed et al., 1987). This attachment is made possible through the binding of the Type II cohesion domain on the anchoring protein and Type II dockerin domain on the CipA, which requires calcium $\left(\mathrm{Ca}^{+}\right)($Demain $e t$ al., 2005). Furthermore, according to researchers at the Weizmann Institute of Science in Israel, the interaction between cohesins and dockerins is one of the strongest found in nature (disassociation constants $<10^{-9} \mathrm{M}$ ) (Mechaly et al., 2001).

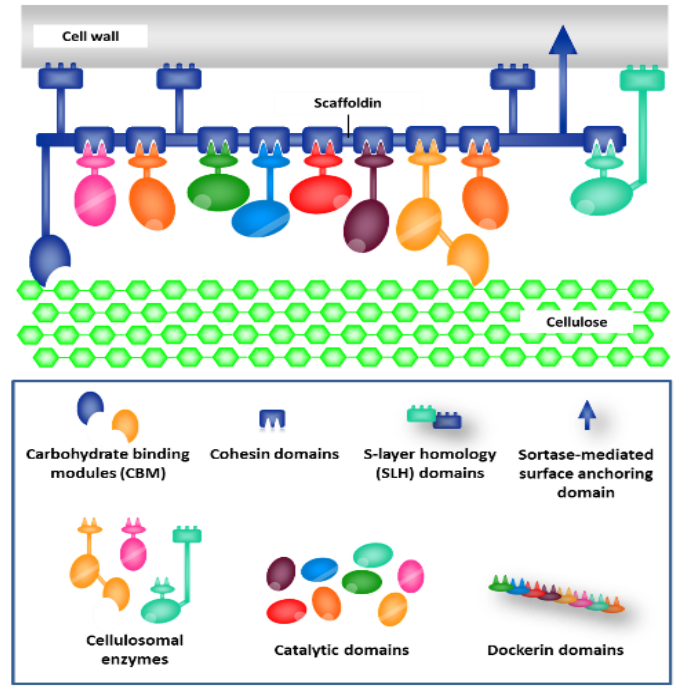

Figure 2.3: Simplistic model of a typical cellulosomal structure (Adapted from Mazzoli, 2012).

Recent studies have suggested that linker regions between cohesins and scaffoldin proteins play an essential role when it comes to cellulosome plasticity and catalytic efficiency (Garcia-Alvarez et al., 2011; Molinier et al., 2011). Moving on, along the length of the CipA protein are multiple cohesion domains as well as cellulose-binding modules or cellulose-binding domains (CBDs). The multiple 
cohesion domains are called Type I cohesion domains and they are bound to a Type I dockerins of various enzymatic components of the cellulosome (Carere et al., 2008), which includes cellobiohydrolase (Shwarz, 2001). In addition, the CBDs mediate the attachment of the bacterial cell to the cellulose fibre. However, it is important to state that the underlying mechanism of how cellulosomes actually attach to cellulose substrates is still unknown (Liu et al., 2008).

During active growth, the cellulosome structure is attached with strong affinity to the surface of the cell as well as the solid substrate. This complex interaction is known as the cell-cellulosomecellulose interaction (Waller et al., 2012). In late-stationary phase, C. thermocellum is known to release its cellulosome altogether (Demain et al., 2005). This cellulosome release during fermentation is believed to be necessary since it would allow for the development of new cellulosomes with modified contents. Another theory relating to this phenomenon is that controlled release of cellulosomes during growth may serve as a process to release $C$. thermocellum from its substrate, leaving liberated cellulosome to further proceed in hydrolyzing cellulose (Bayer and Lamed, 1986).

Finally, not all cellulolytic microorganisms such as $C$. thermocellum actually produce cellulosomes. Research is still weak in explaining why this may be the case, and very little is currently known regarding the mechanisms by which non-cellulosome forming microbes attach to and metabolize cellulose fibres (Wang et al., 2011).

\subsubsection{Cellulose-binding domain and cellulose degradation}

Cellulose-binding domains are crucial components of the cellulosome structure that promote cellulase stable binding to cellulose. However, it is important to note that different CBDs appear to target different sites on crystalline cellulose (Carrard et al., 2000). The CipA CBD from cellulolytic $C$. thermocellum binds many more sites of the cellulose substrate than CBDs from other cellulolytic 
bacteria such as Cellulomonas fimi and Trichoderma reseei (Carrard et al., 2000). The $C$.

thermocellum CipA CBD belongs to the family IIIa (out of 10 families identified) and binds to crystalline cellulose with a $\mathrm{K}_{\mathrm{d}}$ of $0.4 \mu \mathrm{M}$ and a maximum binding capacity of $10 \mathrm{mg}$ of CBD per 1 gram of microcrystalline cellulose (Morag et al., 1995). In addition, the maximum binding capacity for amorphous cellulose is 20 -fold higher. Furthermore, even though the precise mechanism of CBD attachment to cellulose substrate is a mystery, it is believed that cellulose binding likely involves interaction between planar amino acids and two adjacent glucose chains of cellulose (Shimon et al., 2000). The binding itself appears to be extremely stable, although the cellulose degrading enzymes may undergo lateral diffusion on the substrate surface (Bayer et al., 1998). Recent studies have shown that CBDs could also be able to induce conformational changes in the quaternary structure of cellulosomes via direct interaction with linker segments of cohesion domains (Yaniv et al., 2012).

\subsection{Challenges with monoculture ethanol production}

Despite a wide range of positive attributes, $C$. thermocellum does contain a drawback in its ability to ferment to high ethanol yields. Even though this strain has been regarded as the highest ethanol producer from all the cellulolytic microorganisms, it still generates relatively low levels of ethanol ranging from 0.08 to $0.29 \mathrm{~g}$ ethanol per gram of glucose equivalents (Linger and Darzins, 2013). Other studies have reported highest concentration of ethanol produced by $C$. thermocellum at levels below $30 \mathrm{~g} / \mathrm{L}$ (Rani et al., 1996). One of the main reasons for the latter issue is related to its native ability to ferment specific groups of carbohydrates. Clostridium thermocellum is known to ferment only hexose sugars, that is, six carbon sugars such as glucose (Lynd et al., 2002). Five carbon sugars (pentose) such as xylose (found in hemicellulose) are not fermented by this microbe. Xylan (a xylose polysaccharide) makes up the majority of hemicellulose found in lignocellulose material (see 
section 2.2). Hence, a xylose-fermenting process must also occur in order to improve ethanol production as a whole (Shaw et al., 2008).

\subsection{Thermoanaerobacterium saccharolyticum}

The second microorganism of focus, Thermoanaerobacterium saccharolyticum, shows much similarity to $C$. thermocellum. It is also an anaerobic, Gram-positive non-sporulating bacterium that thrives in high temperature environments (between 45 and $66^{\circ} \mathrm{C}$ ) and a $\mathrm{pH}$ range of 4.0 and 6.5 (Shaw et al., 2006). However, unlike C. thermocellum, it is capable of fermenting almost all types of sugar derivatives found in lignocellulosic biomass, including xylose sugars. Several xylan-degrading enzymes have been isolated from this microorganism including an acetyl xylan esterase, a $\beta$-xylosidase, $\alpha$-glucuronidase, and a cell associated xylanase (Liu et al., 1996). In addition, numerous studies were performed on T. saccharolyticum resulting in its classification as a microbe with an ability to ferment high ethanol yields. This production has a maximum titer of $37 \mathrm{~g} / \mathrm{L}$, which for a thermophilic anaerobe is the highest reported (Shaw et al., 2008). Nonetheless, cellular morphology and substrate attachment capabilities of $T$. saccharolyticum strains are still widely unknown.

\subsubsection{Xylose fermentation}

A xylose sugar monomer is considered to be the main building block of hemicellulose heteropolymer found in certain types of plants (Hilz et al., 2007). In addition, two xylose sugar subunits (connected by $\beta-1-4$ bonds) form a disaccharide known as xylobiose (Hilz et al., 2007).

Like $C$. thermocelum, all $T$. saccharolyticum are described to have a mixed fermentation pathway, producing mainly ethanol, organic acids, hydrogen, and carbon dioxide (Lacis et al., 
1991; Altarcas et al., 2001). Xylose fermentation seen in Figure 2.4 shows the typical metabolic pathway in non-cellulolytic utilization of this five-carbon sugar.

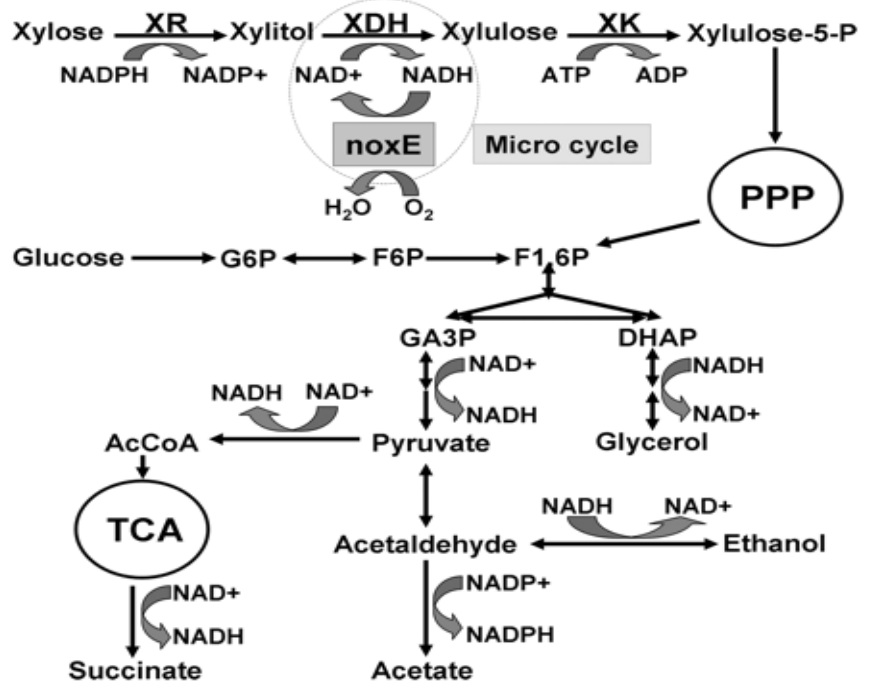

Figure 2.4: Xylose metabolism showing key enzymes and identified cofactors in central break down of this sugar. Abbreviations: XR, xylose reductase; XDH, xylitol dehydrogenase; XK, xylulokinase; G6P, glucose-6-phosphate; F6P, fructose-6-phosphate; F1,6P, fructose-1,6-bisphosphate; PPP, pentose phosphate pathway; GA3P, glyceraldehyde-3-phosphate; DHAP, dihydroxyacetone phosphate; AcCoA, acetylcoenzyme A; TCA, tricarboxylic acid cycle (Adopted from Zhang et al., 2011).

\subsection{Co-culture research}

One of the earliest co-culture studies with Clostridium thermocellum dates back to 1977 when Weimer and Zeikus from University of Wisconsin examined fermentation of cellulose by using Clostridium thermocellum in the presence of Methanobacterium thermoautotrophicum. In this study it was discovered that cellulase activity in $C$. thermocellum appeared earlier in coculture and that more biohydrogen was produced than in mono-culture (Weimer and Zeikus, 1977). A few years later, C. thermocellum was tested with Zymomonas mobilis; however, only about $27 \%$ of the cellulose substrate was converted to ethanol (Saddler et al., 1981). The $Z$. mobilis was capable of fermenting only glucose, fructose, and sucrose but not other forms of 
sugars (Tojo, 2013). A similar research with C. thermocellum and Clostridium

thermohydrosulfuricum co-culture on Solka Floc cellulose generated ethanol/acetate ratio of

greater than 7 (Ng et al., 1981). However, C. thermohydrosulfurican was unable to utilize xylan.

Therefore, xylose and the majority of hemicellulose were left un-fermented by these previous microorganisms.

Once a genetically engineered strain of $C$. thermocellum was developed, co-culture research focused on improving cellulose degradation. When inoculating $C$. thermocellum and non-cellulolytic Clostrodium thermopalmarium on cellulose (filter paper), results displayed an increase in hydrolysis by 7-fold (from $1.23 \mathrm{~g} / \mathrm{L}$ to $8.59 \mathrm{~g} / \mathrm{L}$ utilized cellulose) (Geng et al., 2009). This left the question of how co-cultures involving cellulolytic and non-cellulolytic microorganisms influence hydrolysis and ethanol production on applicable lignocellulosic material and not just laboratory cellulose sources.

Geng and colleagues from Xi'an Jiaotong University in PR China stated that, "The mechanism of cooperation and competition between two strains [in co-culture analysis] should be studied further by comparing monoculture versus co-cultures” (Geng et al., 2009). Understanding the way the two microorganisms interact with one another has the potential to fill in the gap in co-culture research and improve bio-ethanol production as a whole (Burrel et al., 2004; Salimi and Mahadevan, 2013).

\subsubsection{Requirements for successful co-culture}

A potential CBP organism or effective co-culture must be able to meet three main requirements: (i) able to hydrolyze cellulose and hemicelluloses; (ii) able to ferment both hexose and pentose sugars; and (iii) able to produce ethanol at high yield (Shaw, 2008). Since $C$. 
thermocellum is capable of utilizing only the six carbon sugars (hexoses) and not the five carbon sugars (pentoses), which are derived from cellulose and hemicellulose (Figure 2.5) the use of coculture or mixed culture systems is of significant interest. Previous research showed that $C$.

thermocellum and Thermoanaerobacter spp. strains are capable of working together by fermenting more sugar molecules and as a result significantly increase the production of ethanol end-product (Svetlitchnyi et al., 2013; Jiang et al., 2013). Figure 2.5 illustrates how the interaction would be carried out:

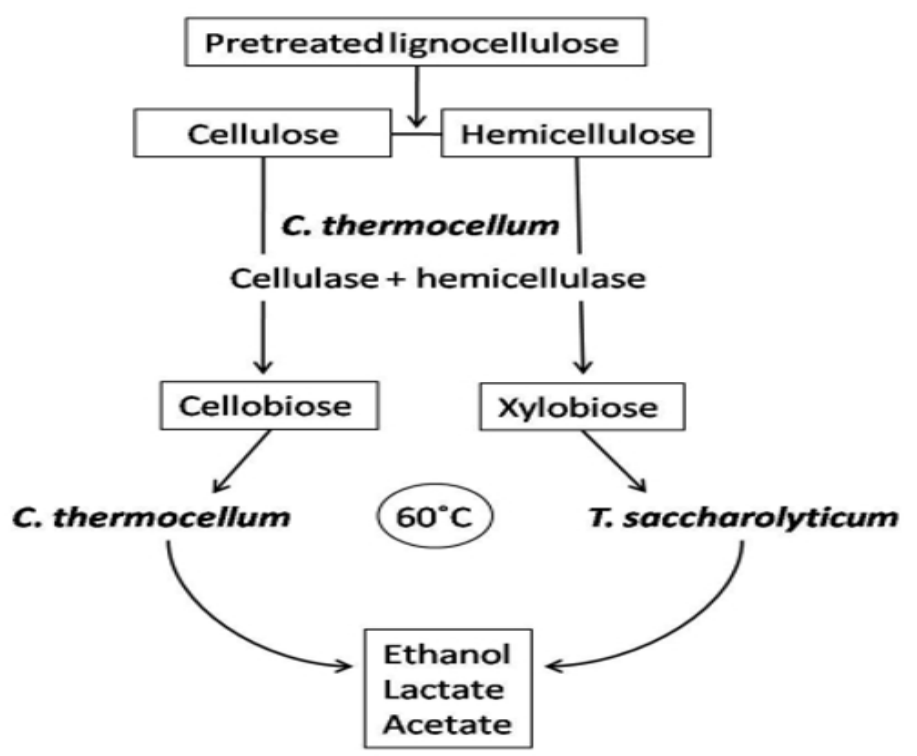

Figure 2.5: Simplified process using C. thermocellum and T. saccharolyticum in co-culture for ethanol production (Adopted from Maki et al., 2009).

\subsubsection{Clostridium thermocellum and Thermoanaerobacterium saccharolyticum}

As can be seen in Figure 2.5, a cellulolytic $C$. thermocellum produces two disaccharide molecules: cellobiose (two glucose molecules) and xylobiose (two xylose molecules). The noncellulolytic $T$. saccharolyticum strain helps during the fermentation stage by converting the fivecarbon sugar xylose into desired end products. A study performed by Bungay (1982) showed that Clostridium thermosaccharolyticum (now classified as T. saccharolyticum) has the potential to 
utilize cellobiose faster than Clostridium spp. thus having the ability to prevent any build-up that may be caused by the inhibitory or repressive actions of this disaccharide. Therefore, this particular bacterial combination may lead to a closely associated, syntrophic, and quite stable dual culture (Wiegel, 1980).

\subsection{Carbon catabolite repression and co-culture sugar utilization}

Carbon catabolite repression (CCR) is a general mechanism that dictates the order in which types of sugars are utilized by a microorganism (Tsakraklides et al., 2012). Carbon catabolite repression in some bacteria allows for quick adaption to a readily metabolisable carbohydrate energy source first. This adaptation is achieved via inhibition of synthesizing enzymes involved in catabolism of sugars that are not mainly preferred (Slonczewski, 2014). In other words, the cell's CCR system is responsible for making sure that the energy expenditure on sugar import and eventual metabolism will be guided to the source of carbon that is most readily available and allows for most rapid growth (Brückner and Titgemeyer, 2002; Gorke and Stulke, 2008). CCR can become a barrier for lignocelluloses-derived sugar mixtures in consortia due to the fact that different microorganisms will compete for the same type of sugar source and thus create unwanted competition (Vinuselvi et al., 2012). In addition, the accumulation of unused substrates may complicate extraction of desired end-products downstream (Vinuselvi et al., 2012).

Studies on species belonging to the Clostridia class (which includes both C. thermocellum and $T$. saccharolyticum) show that these microorganisms utilize glucose substrates via Histidinecontaining Protein (HPr) and cell membrane transporter called Phosphotransferase System (PTS) (Tsakraklides et al., 2012). Fortunately, carbon catabolite repression in T. saccharolyticum 
shows that this microorganism uses an alternative cell membrane transporter called ATP-Binding Cassette (ABC) when utilizing xylose (Tsakraklides et al., 2012). Therefore, glucose and xylose utilization or transport in T. saccharolyticum can occur in parallel due to the presence of two separate sugar transporters located within its cell membrane. As a result, this tends to lower the competition with $C$. thermocellum for glucose and generates a more efficient co-culture partnership.

\subsection{Economics of cellulosic bio-ethanol production}

Typical lignocellulosic biomass found on the North American continent contains roughly 45\% glucan (one straight chain of D-glucose molecules) (Lavoie et al., 2012). This amount of stored glucose can lead to a production of about 313 litres (L) of ethanol per ton of raw biomass (Lee and Lavoie, 2013). Since the market value is US\$0.68/L, with a production price approximately US\$0.30/L, the cellulosic bio-ethanol production value is US\$212/ton (\$192/metric tonne) of biomass (Lee and Lavoie, 2013). According to Patzek and colleagues from University of California, bio-ethanol fuel has a gasoline gallon equivalency (GGE) value of 1.5 US gallons (5.7 L) (Patzek et al., 2005). In other words, it takes 1.5 gallons (5.7 L) of bioethanol to produce the energy equivalent of 1 gallon $(3.8 \mathrm{~L})$ of gasoline. Hence, one crucial way to optimize bio-ethanol production and in turn make it more economically competitive with fossil fuel production is to utilize all sugars present in lignocellulosic material, not just glucose sugars.

Currently, regular engines on vehicles can use up to $25 \%$ anhydrous ethanol (E25) blend with regular gasoline and no engine modification is required (Costa and Sodre, 2010). However, engines that use $85 \%$ (E85) blend and 100\% (E100) ethanol require structural changes. The 
average cost to produce a modified flex fuel engine for a new vehicle is approximately US $\$ 100$ (Anderson and Sallee, 2011). This value can range up to US\$500 depending on the type of the engine (Anderson and Sallee, 2011).

\subsection{Cellulose Substrates}

One of the most important features of cellulose is its crystalline structure (Lynd et al., 2002). Roughly 30 different separate cellulose molecules are put together into larger protofibrils, which are assembled into larger units called microfibrils, and these are in turn are the components of cellulose fibres (Lynd et al., 2002). Avicel and Sigmacell are commonly used sources of cellulose in laboratories for batch processing. Avicel, for example, is a microcrystalline cellulose powder and outside research settings it can be used in food preparations (Wolf et al., 1984). Microcrystalline celluloses are nearly pure cellulose in composition, possess a straight, nonbending structure and have the ability to get completely utilized or hydrolyzed.

\subsubsection{Cotton fibre}

Over the past few year cotton has started to gain more attention as a valuable carbon source candidate for continuous-flow experimentation and imaging. Cellulose component of cotton can range anywhere from $85 \%$ to $100 \%$; however, once bleached most commercially available cotton balls will yield up to $99 \%$ pure cellulose (Tripp and Rollins, 1952). The majority of cellulose that is found in cotton fiber is assembled in the secondary wall and for this reason is considered to be both physically and economically the most important portion of the fiber (Tripp and Rollins, 1952). The diameter of one cotton fiber is from $10 \mu \mathrm{m}$ to $20 \mu \mathrm{m}$, making it an excellent size for microscope imaging with cellulolytic microorganisms (Figure 2.6). 


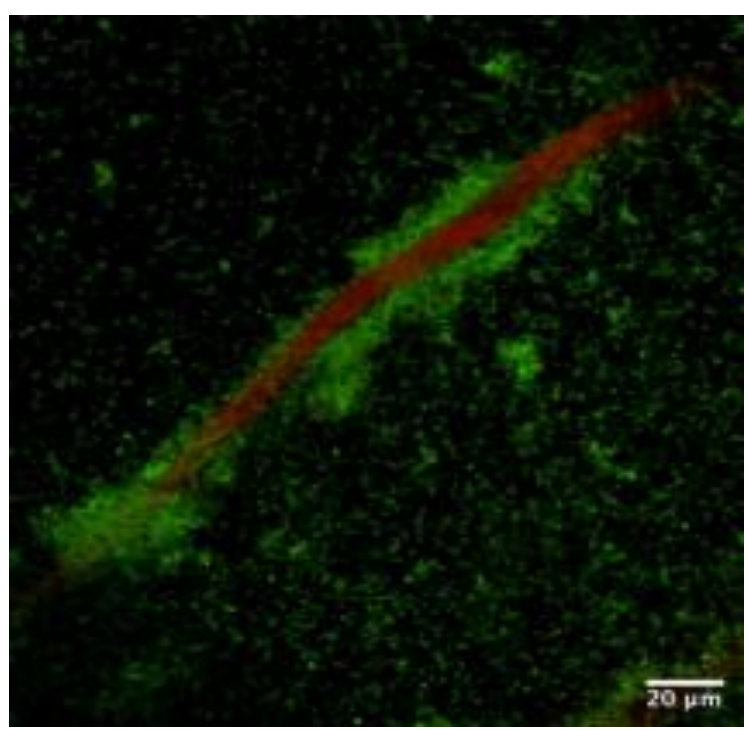

Figure 2.6: Live cell image of $C$. thermocellum ATCC 27405 monoculture grown in the flow cell $\left(60^{\circ} \mathrm{C}\right)$ under anaerobic conditions. Cotton fiber can be seen in brown and colonization of cells (green) around the fiber. Cell were stained with $\mathrm{SP}_{-} \mathrm{DilC}_{18}(3)$ (Adopted from Wang et al., 2013).

\subsection{Lignocellulosic substrates}

Lignocellulosic biomass is biological material that is composed of cellulose, hemicelluloses, and lignin polymers (see section 2.2). This type of material is organic in nature and may be used as a source of energy and/or chemicals (Scragg, 2009). Biomass in the form of wood, specific crops, crop residues and organic wastes meet both sustainable and renewable criteria due to their ability to become replanted (Scragg, 2009). Theoretically, biofuel from biomass can be regarded as carbon dioxide neutral since any carbon dioxide discharged during their combustion had to be fixed first from the atmosphere during photosynthesis stage. However, in the cultivation, harvesting, preparation, and transportation of biomass, the use of fossil fuels may be required and thus making them more accurately $85-93 \%$ carbon neutral (Parikka, 2004; Venturi and Venturi, 2003). There are five general categories of solid biofuels or second generation biofuels: i) agricultural residues (corn stover, crop straws, and bagasse); ii) herbaceous crops (perennial grasses); iii) short rotation woody crops; iv) forestry residues; and v) 
waste paper and other wastes (municipal and industrial) (Limayem and Ricke, 2012). From the latter categories, perennial grasses are regarded as the best option as a source for energy since they are readily available energy feedstock, relatively easy to grow and harvest, can grow on marginal lands, and the yield per acre is greater than for wood (Igboanugo et al., 2013).

\subsubsection{Perennial grasses}

Perennial grasses are plants that are able to live for more than two years (Kephart et al., 1992). They have been used in the past as fodder crops but have recently been gaining more attention as a valuable energy crop source due to a high cellulose and hemicelluloses contents (Scragg, 2009). In 2003, a study performed by Lewandowski and colleagues isolated various perennial grass sources as optimum substrates for energy production. In this study, trials with sixteen perennial grasses were performed for energy use in both USA and Europe. The criteria used in the selection as an energy crop were: i) suitable for the climate in the region; ii) easily propagated; iii) a consistent and high yield per hectare; iv) positive balance of energy; v) the crop can be cultivated in a suitable manner; vi) resistance to pests and diseases; vii) broad genetic diversity; viii) harvesting possible with existing technology; ix) perennial; and x) competitive on cost with food crops (Lewandowski et al., 2003). Results have shown that from the sixteen different perennial grasses, four have been chosen as the suitable energy crops and they are miscanthus (S/G ratio of 0.70 ), switchgrass (S/G ratio of 0.68 ), reed canary grass (unknown S/G ratio), and giant reed ( $\mathrm{S} / \mathrm{G}$ ratio of 1.13 ). They have been chosen based on their yield, establishment time, photosynthetic pathway, fertilizer use, water supply, pesticide use, establishment cost, pest/disease content, day/length of growth, plantation longevity, energy content, and energy output (Lewandowski et al., 2003). 
Furthermore, one of the most important characteristics of perennial grasses is the type of metabolism used. The two types of metabolism are $\mathrm{C} 4$ and $\mathrm{C} 3$ and they refer to the pathways used to incorporate carbon dioxide during photosynthesis process (Scragg, 2009). The C4 metabolism, rather than $\mathrm{C} 3$ metabolism, is preferred since $\mathrm{C} 4$ plants are more efficient at higher light exposure and temperature (Scragg, 2009). C4 plants also have a lower moisture content, need less fertilizer input and as far as water requirement, are twice as efficient (Scragg, 2009). According to Alan Scragg (2009) "(Switchgrass) is perhaps the best choice as it is a perennial C4 grass, drought-tolerant, gives high yields, and can be harvested once a year".

\subsubsection{Switchgrass}

Panicum virgatum, or better known as switchgrass, is a perennial bunchgrass that can be commonly found in temperate to subtropics regions of North America (south of $55^{\text {th }}$ parallel) (Price and Casler, 2014). Researchers have first considered switchgrass as a good source for biofuel production in the early 1990s due to its wide adaptability in temperate climates and ability to produce moderate to high yields on marginal farmlands (Robertson et al., 2011). The more research is performed on this crop, the more attention it is given when it comes to being utilized for ethanol and butanol production. Switchgrass can produce almost 1200 gallons of ethanol per acre ( $11,000 \mathrm{~L} /$ hectare $)$ whereas conventional corn or maize can produce about 400 gallons per acre ( 3,700 L/hectare) (Kent, 2012). In addition, switchgrass also uses much less water for irrigation purposes than maize crops. It can use anywhere from 1.9 to 9.0 gallons of water per gallon of ethanol and maize requires anywhere from 10 to 324 gallons of water per one gallon of ethanol produced (Wu et al., 2008). According to Schmer and colleagues at the University of Nebraska, switchgrass crops in Minnesota could provide feedstock to produce 
$540 \%$ more energy than energy consumed in its production and cut down greenhouse gas (GHG) emissions by $94 \%$ when compared to gasoline (Schmer et al., 2007). Therefore, switchgrass has a great potential to overcome the challenge of land use concerns and simultaneously create more sustainable and environmentally friendly energy.

Last, previous research has shown that using the SSCF method with a genetically modified yeast (S. cerevisiae 424A - LNH ST) inoculum, switchgrass has presented ethanol yields of $32.1 \mathrm{~g} / \mathrm{L}$ and sugar conversions of glucan and xylan of $80.3 \%$ and $84.3 \%$, respectively (Monti, 2012). Thus, it would be interesting to see how switchgrass digestion using bacterial coculture and CBP method would compare to ethanol yield values in the literature. 


\section{CHAPTER 3: EXPERIMENTAL}

\subsection{Introduction}

For the past century, the global economics, geopolitical statuses, social class, and almost all human life on the planet continue to rely primarily on a single natural resource called fossil fuels. Unfortunately, fossil fuels are a non-renewable energy source and due to an exponential increase in global population, energy consumption has dramatically increased as a result. According to some prominent studies, it is predicted that complete depletion of fossil fuel reserves may be reached within next few decades (Radolfi et al., 2009). Consequently, there is an unavoidable need for a more renewable and in turn sustainable alternative energy source.

The growing interest in bioethanol originates from a combination of different elements which include security of supply, climate change, and accelerated increase in oil prices (RosilloCalle and Johnson, 2010). This particular interest is continually supported by evidence that, if adequate management practises are applied, the social, economic, and environmental benefits of bioethanool production can overcome its potential negative environmental impacts (RosilloCalle and Johnson, 2010). The current mode of bioethanol production is achieved mainly from cellulosic food sources such as corn and sugar cane. Growing these edible biocrops is considered to be a strain on agricultural lands and a direct cause of food price inflation (Inderwildi and King, 2009). However, fuels that are derived from lignocellulosic biomass - the fibrous and generally inedible part of the plant structure - present a substitute to conventional energy sources (Burkheisser, 2010). Cellulose and hemicellulose portions of the lignocellulosic structure are found in plant cell walls and are polysaccharides composed of energy-rich sugars that can be converted into ethanol through bio-processing. In addition, lignocellulosic biomass is an 
attractive bioenergy feedstock due to supplies being domestically and globally sufficient (Burkheisser, 2010).

One promising bioenergy crop that has been receiving attention in the recent years is a perennial herbaceous plant called Panicum virgatum or commonly referred to as switchgrass. In general, switchgrass is a $\mathrm{C} 4$ plant that has a potential for being a biofuel feedstock due to its ability to grow in a diverse range of climates, less water requirement for irrigation, high yield rates, and low fertilizer demand compared to other common biocrops (Fike et al., 2005). Other management advantages of switchgrass include low nitrogen, phosphorus, and potassium requirements, as well as, acid soil tolerance and low harvest costs (Smith and Greenfield, 1979; Morris et al., 1982; Jung et al., 1990; Wright, 1990).

Plants have evolved an efficient system for resisting biodegradation of their structural support by microbial species (Himmel et al., 2007). Thus, current methods used to break down lignocellulosic biomass into simple sugars are considered to be ineffective and therefore establish the main barrier to producing bioethanol at quantities and prices that are competitive with petroleum (Burkheisser, 2010). Chemical pre-treatment and enzyme addition used for hydrolyzing this resistant plant wall barrier are costly and time consuming process. One solution to this particular problem was solved by the invention of consolidated bioprocessing (CBP). This process involves the use of a genetically modified Clostridium thermocellum, a thermophilic anaerobe that is able to hydrolyze cellulosic biomass - with already present cellulose degrading enzyme complex - into useful sugar products and can simultaneously ferment these sugars into ethanol (Yee et al., 2014). Hence, CBP remains a fair alternative due to the potential of lowered 
costs related to reducing unit operations and enzyme additives (Lynd et al., 2002; Olson et al., 2012).

Despite C. thermocellum's positive CBP attributes, major hurdles still remain with this microbe's inability to produce sufficient levels of ethanol and lack of metabolic capability to ferment pentose sugars found in lignocellulosic material (Linger and Darzins, 2013). Recent studies have shown that the anaerobic thermophilic, hemicellulosic bacterium Thermoanaerobacterium saccharolyticum contains valuable properties that make it a potential member for a CBP consortium because $T$. saccharolyticum can ferment pentose and other biomass-derived sugars and has a highly effective metabolic activity allowing it to produce ethanol with a maximum titer (Shaw et al., 2008). Thus, studying the nature of $C$. thermocellum and T. saccharolyticum co-culture interaction and their combined ability to produce higher ethanol yield is an important step in improving CBP and lignocellulosic bioethanol production as a whole.

The objectives of this study were: (i) to compare the respective morphologies and examine the interaction between $C$. thermocellum and $T$. saccharolyticum in their abilities to bind to different carbon substrates, (ii) to investigate competitive vs. co-operative behaviour physiologically and numerically on various carbon sources between the two thermophiles, and (iii) to determine the extent of substrate solubilisation and high-value product formation using HPLC analysis. 


\subsection{Methodology}

\section{Bacterial strains and chemicals used}

Clostridium thermocellum ATCC 27405 was donated by Dr. Paul Weimer (University of Wisconsin) and was maintained in the laboratory for three generations in RM medium (Ozkan et al., 2001) with added Avicel PH-101 cellulose substrate. Thermoanaerobacterium saccharolyticum DSM 7060 was purchased from Deutsche Sammlung von Mikroorganismen und Zellkulturen (DSMZ) (Braunschweig, Germany). All the reagent chemicals used were purchased from Sigma-Aldrich Corporation (St. Louis, MO, USA) and VWR International (Radnor, PA, USA). Fluorescent stains have been purchased from Life Technologies Inc. (Burlington, ON, CA) while compressed gas was acquired from Linde Canada Ltd. (Concord, ON, CA). Last, ultra-pure water used in preparation of assays and medium was produced with a Milli-Q Gradient system purchased from EMD Millipore (Billerica, MA, USA).

\section{Culture media}

\section{$\underline{\text { Batch systems }}$}

Batch culture medium for all tests were prepared in $30 \mathrm{~mL}$ glass crimp-sealed vials (VWR, ON, CA) capped with rubber stoppers (Bellco Glass Inc., NJ, USA) with buffer modified DSMZ Medium 122 containing (per litre of sterile water): $0.5 \mathrm{~g}$ urea, $1.43 \mathrm{~g} \mathrm{KH}_{2} \mathrm{PO}_{4}, 2.5 \mathrm{~g}$ $\mathrm{K}_{2} \mathrm{HPO}_{4}, 2$ g yeast extract, $4 \mathrm{~g} \mathrm{Na}$ - $\beta$-glycerophosphate $\bullet 4 \mathrm{H}_{2} \mathrm{O}$, and 0.002 g oxygen indicator resazurin. The media were autoclave-sterilized $\left(121^{\circ} \mathrm{C}, 2\right.$ hours $)$ and vacuum sparged with pure nitrogen gas for 10 minutes (40 second vacuum, 20 second nitrogen sparging intervals). Sterile mixtures of $0.9 \mathrm{~mL}$ salt and minerals $\left(1.3 \mathrm{~g} \mathrm{MgCl}_{2} \bullet 6 \mathrm{H}_{2} \mathrm{O}, 0.13 \mathrm{~g} \mathrm{CaCl}_{2} \bullet 2 \mathrm{H}_{2} \mathrm{O}, 0.02 \mathrm{~g} \mathrm{FeSO}_{4} \bullet\right.$ 
$7 \mathrm{H}_{2} \mathrm{O}$ ), $0.1 \mathrm{~mL}$ vitamin solution ( $0.01 \mathrm{~g}$ pyridoxamine dihydrochloride, $0.002 \mathrm{~g}$ P-aminobenzoic acid, $0.001 \mathrm{~g}$ biotin, $0.001 \mathrm{~g}$ vitamin B12, $0.002108 \mathrm{~g}$ thiamine, $0.0025 \mathrm{~g}$ nicotinic acid, 0.00025 $\mathrm{g} \alpha$-lipoic acid) and $0.1 \mathrm{~mL}$ trace elements $\left(0.001256109 \mathrm{~g} \mathrm{MnCl}_{2} \bullet 4 \mathrm{H} 2 \mathrm{O}, 0.0005 \mathrm{~g} \mathrm{ZnCl}_{2}\right.$, $0.000125 \mathrm{~g} \mathrm{CoCl}_{2} \bullet 6 \mathrm{H}_{2} \mathrm{O}, 0.000125 \mathrm{~g} \mathrm{NiCl}_{2} \bullet 6 \mathrm{H}_{2} \mathrm{O}, 0.000125 \mathrm{~g} \mathrm{CuSO}_{4} \bullet 5 \mathrm{H}_{2} \mathrm{O}, 0.000125 \mathrm{~g}$ $\mathrm{H}_{3} \mathrm{BO}_{3}, 0.000125 \mathrm{~g} \mathrm{Na}_{2} \mathrm{MoO}_{4} \cdot 2 \mathrm{H}_{2} \mathrm{O}$ ), with sterile $1 \mathrm{~g} \mathrm{~L}$-cysteine $\mathrm{HCl}$ (reducing agent).

Morphology tests The medium for C. thermocellum ( $3 \mathrm{~mL}$ inoculum) was supplemented with 10 $\mathrm{g} / \mathrm{L}$ cellobiose and the medium for $T$. saccharolyticum ( $3 \mathrm{~mL}$ inoculum) was prepared with 10 g/L xylose supplement.

Physiology tests The respective media contained supplements of these sugars at $5 \mathrm{~g} / \mathrm{L}$. The $\mathrm{pH}$ was $\sim 6.5$ before $3 \mathrm{~mL}$ inoculation of C. thermocellum ATCC 27405 and T. saccharolyticum DSM 7060 in monoculture and both volumes combined in co-culture batch medium.

$\underline{\text { Continuous-flow systems }}$

Continuous-flow testing were separated into four separate experiments and each experiment medium was conducted in $1800 \mathrm{~mL}$ sterile glass water bottles where the concentrations of urea, $\mathrm{KH}_{2} \mathrm{PO}_{4}, \mathrm{~K}_{2} \mathrm{HPO}_{4}, \mathrm{Na}_{2}-\beta$-glycerophosphate $\bullet 4 \mathrm{H}_{2} \mathrm{O}$, and resazurin was added and sealed with rubber caps. After autoclave sterilization $\left(121^{\circ} \mathrm{C}, 2\right.$ hours $)$, the medium vessel was cooled down under sparging with pure nitrogen for a period of six hours. Using 10 $\mathrm{mL}$ syringe (containing $0.2 \mu \mathrm{L}$ syringe filters), sterile mixtures of trace elements, vitamins, salt and minerals, and L-cycteine $\mathrm{HCl}$ (reducing agent) were added to the medium afterwards (at the same final concentrations as in batch systems mentioned previously). 
Substrate attachment capabilities Continuous-flow medium was prepared for four types of analyses: i) T. saccharolyticum DSM 7060 on cotton; ii) T. saccharolyticum DSM 7060 on switchgrass; iii) co-culture on cotton; and v) co-culture on switchgrass as mentioned above with an additional $0.3 \mathrm{~g} / \mathrm{L}$ cellobiose and $10 \mathrm{~g} / \mathrm{L}$ xylose additives. A detailed analysis of attachment by $C$. thermocellum has been described by Dumitrache et al. (2013).

Competition vs. cooperation test and end product analysis Continuous-flow media for a further series of experiments had different yeast extract and sugar supplements, depending on the experiment performed and as detailed in Table 3.1. Yeast extract was added before autoclave sterilization and sugar supplementation was added after autoclave sterilization to prevent charring.

Table 3.1: Culture media preparation for each continuous-flow experiment with respect to HCS and LCS composition

\begin{tabular}{|c|c|c|c|c|c|c|}
\hline \multirow[t]{2}{*}{ Experiment } & \multicolumn{3}{|c|}{$\begin{array}{c}\text { High Carbon Supplement } \\
\text { (HCS) }\end{array}$} & \multicolumn{3}{|c|}{$\begin{array}{c}\text { Low Carbon Supplement } \\
\text { (LCS) }\end{array}$} \\
\hline & $\begin{array}{c}\text { Yeast } \\
\text { Extract } \\
(\mathrm{g} / \mathrm{L})\end{array}$ & $\begin{array}{c}\text { Cellobiose } \\
\text { (g/L) }\end{array}$ & $\begin{array}{c}\text { Xylose } \\
(\mathrm{g} / \mathrm{L})\end{array}$ & $\begin{array}{c}\text { Yeast } \\
\text { Extract } \\
(\mathrm{g} / \mathrm{L})\end{array}$ & $\begin{array}{c}\text { Cellobiose } \\
(\mathrm{g} / \mathrm{L})\end{array}$ & $\begin{array}{c}\text { Xylose } \\
(\mathrm{g} / \mathrm{L})\end{array}$ \\
\hline $\begin{array}{l}\text { 1. C. thermocellum } \\
\text { ATCC } 27405 \text { on cotton fibre }\end{array}$ & 2.0 & 0.3 & N/A & 0.3 & 0.0 & N/A \\
\hline $\begin{array}{l}\text { 2. C. thermocellum } \\
\text { ATCC } 27405 \text { on switchgrass }\end{array}$ & 2.0 & 0.3 & N/A & 0.3 & 0.0 & N/A \\
\hline 3. Co-culture* on cotton fibre & 2.0 & 0.3 & 10 & 0.3 & 0.0 & 0.0 \\
\hline 4. Co-culture ${ }^{*}$ on switchgrass & 2.0 & 0.3 & 10 & 0.3 & 0.0 & 0.0 \\
\hline
\end{tabular}

* Co-culture containing C. thermocellum ATCC 27405 and T. saccharolyticum DSM 7060 together

\section{Continuous-flow design}

\section{Flowcell reactor}

Continuous-flow (Figure 3.1) experiments with lignocellulosic substrate were prepared with a flowcell reactor that contained $0.51 \mathrm{~g}$ midseason untreated switchgrass processed with 6 
mm screen (kindly provided by Dr. Julie Paye from Dartmouth College, USA) and those with cellulosic substrates were prepared with $0.13 \mathrm{~g}$ of commercially available cotton (substrate attachment capability experiment - T. saccharolyticum DSM 7060 on cellulose trial and competition vs. cooperation tests $-C$. thermocellum on cotton and co-culture on cotton)

A

TOP VIEW

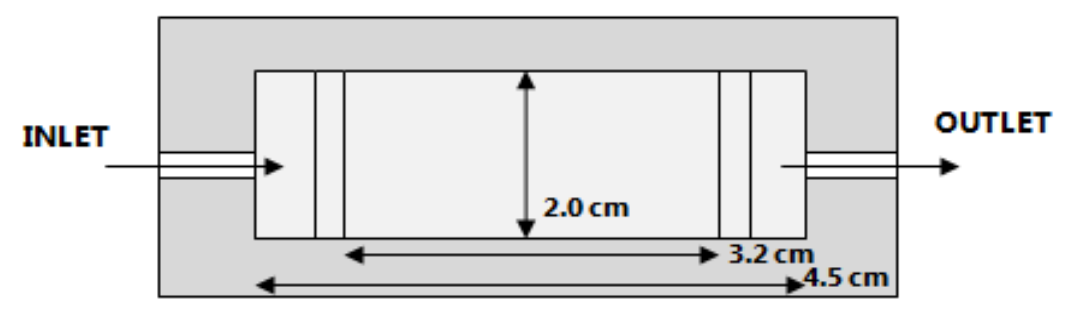

B

\section{LATERAL VIEW}

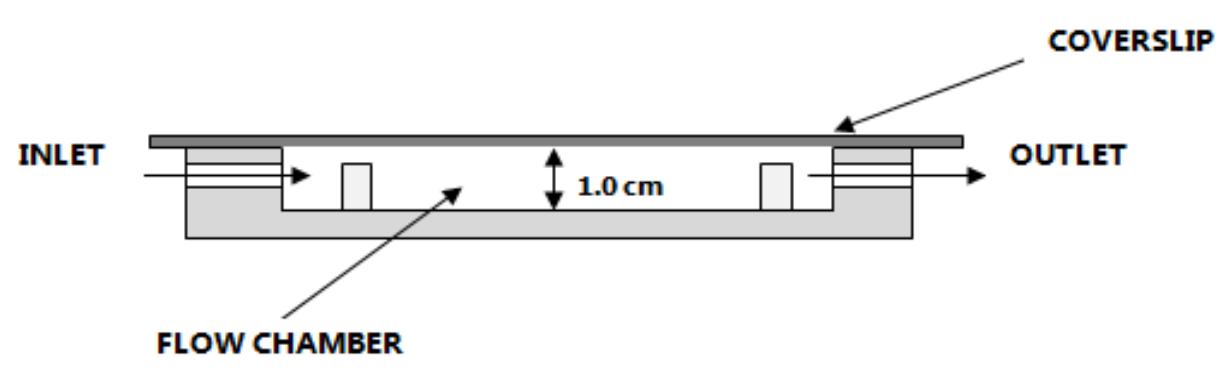

Figure 3.1: Schematic of flow cell reactor design displaying top view (A) and lateral view (B).

\section{Continuous-flow system}

The general arrangement of the components in all of the continuous-flow experiments (such as medium, flow cell reactor, and effluent sample) in the anaerobic cabinet (Type B vinyl anaerobic chamber; Coy Laboratory Products, MI, USA) can be seen in Figure 3.2 and Figure 
3.3. Unidirectional flow was from the medium to the effluent flask ( 2 litre), and was maintained by a peristaltic pump (model 205S, Watson Marlow, Cornwall, England). Silicon tubing ( $0.188 \mathrm{x}$ 0.313 x 0.063 in., I.D x O.D x Wall, VWR, ON, CA) along with polycarbonate adapters were used to link all the components in the anaerobic chamber. Prior to using the culture media, all the tubing and the flowcell reactor were sterilized with a mixture of $10 \%$ sodium hypochlorite and 90\% distilled water for 1 hour (118 mL/hour) and washed with sterile water for 12 hours (33 $\mathrm{mL}$ /hour) with continuous-flow. C. thermocellum ATCC 27405 and T. saccharolyticum DSM 7060 was inoculated from the respective batch sources via sterile syringe and needles (BD size 25G, Fisher Scientific, ON, CA). The flow of the medium was stopped for a period of 1 hour to allow for substrate colonization $\left(60^{\circ} \mathrm{C}\right.$ incubation). Regular flow was then resumed (10 $\mathrm{mL} / \mathrm{hour})$.

Substrate attachment capabilities Each of the four continuous-flow experiments was performed as described above. Experiment $1-T$. saccharolyticum on cotton, experiment 2 -co-culture on cotton, experiment $3-T$. saccharolyticum on switchgrass, and experiment 4 -co-culture on switchgrass had incubation growth for 3 days before confocal microscopy imaging. 


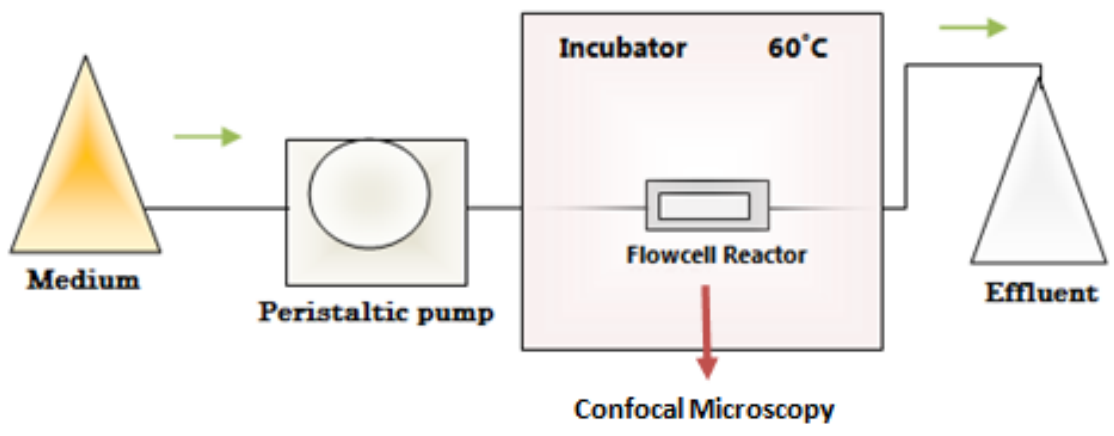

Figure 3.2: Schematic illustration of the flow cell system design for the four substrate attachment experiments. The system was used under normal atmosphere in an anaerobic chamber where a $\sim 60^{\circ} \mathrm{C}$ incubator was used for the growth of anaerobic, thermophiles C. thermocellum ATCC 27405 and T. saccharolyticum DSM 7060 (flow rate of $10 \mathrm{~mL} / \mathrm{h}$ ). Confocal microscopy was used for imaging of the strains and substrates.

Concentration dynamics The four separate continuous flow experiments: Experiment $1-C$. thermocellum on cotton, experiment $2-C$. thermocellum on switchgrass, experiment 3 - coculture on cotton, and experiment 4 - co-culture on switchgrass were each tracked over a six day period at two day intervals. General schematic can be seen in Figure 3.3:

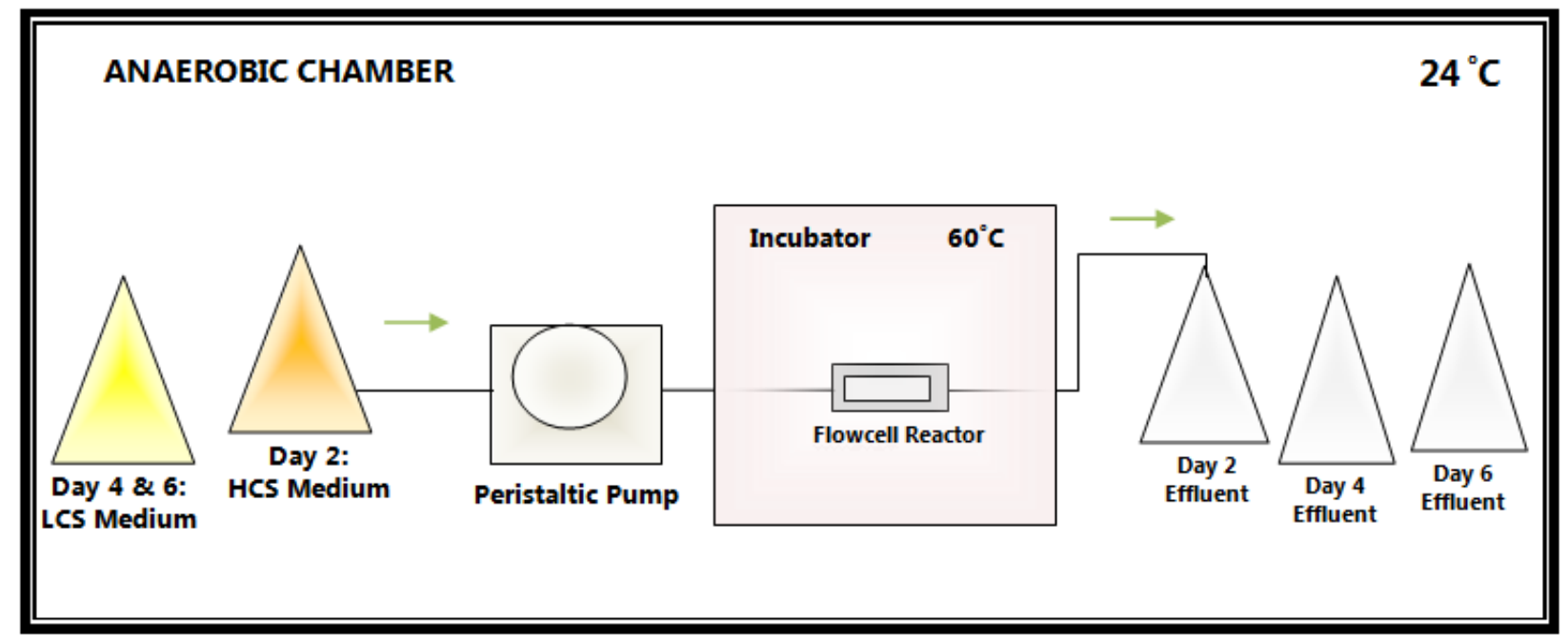

Figure 3.3: An overall continuous flow cell system used for the four concentration dynamics and HPLC experiments. A high carbon supplement (HCS) medium was used for the first two days for culture growth $\left(60^{\circ} \mathrm{C}, 10\right.$ $\mathrm{mL} /$ hour flow rate). After 2 days of incubation, sample effluent was collected for analysis and HCS medium was switched to low carbon supplement (LCS) medium for the next four days (two day effluent sample collecting intervals). Temperature of anaerobic chamber was around room temperature. See Table 3.1 for HCS and LCS medium contents for each experimental trial. 
For these series of continuous-flow experiments, DSMZ-Medium 122 along with high carbon supplement (contents seen in Table 3.1) was used as a source of nutrients for the first two days of culture medium flow in order to grow $C$. thermocellum and $T$. saccharolyticum successfully in $60^{\circ} \mathrm{C}$ incubation. Effluent samples were collected for real-time PCR and HPLC analysis, as described under the respective headings below. The culture medium was then switched to DSMZ-Medium 122 with low carbon supplement (LCS) and further day 4 and day 6 samples were collected for similar analysis.

\section{Imaging}

\section{Epifluorescent Microscopy}

Morphology comparison This comparison experiment was stained and imaged by a protocol described by Kepner and Pratt (1994). A $1 \mathrm{~mL}$ bacterial sample from both $C$. thermocellum and T. saccharolyticum batch systems was extracted and the cells were targeted with $0.5 \mu \mathrm{L}$ SYBR ${ }^{\circledR}$ Gold Nucleic Acid Stain (Life Technologies, CA, USA) and diluted to 1 in 100 with ultrapure water. The dilution sample was then left in dark for 15 minutes before vacuum filtration on a prewetted polycarbonate membrane filter with 0.2 micron pore size and $25 \mathrm{~mm}$ diameter (Fisher Scientific, ON, Canada). Images were immediately obtained with a Nikon Eclipse 80i fluorescent microscope (Nikon Instruments Inc., ON, CA) using X60 oil immersion objective. Confocal Laser Scanning Microscopy (CLSM)

Substrate attachment Imaging of cell attachment to different substrates were acquired in-situ with a Nikon Eclipse 80i-C1 confocal laser scanning microscope following the same procedure as described by Dumitrache et al. (2013). Syto 9 (2 $\mu \mathrm{L})$ stain was used to target cells while cellulose fibres (in case of cotton experiments) and lignocelluloses (for switchgrass experiments) were targeted by a $15 \mu \mathrm{L}$ carbohydrate binding lectin wheat germ agglutinin (WGA) conjugated 
with a far-red fluorescent Alexa Fluor® 633 (AF633) dye. Syto 9 and WGA-AF33 were prepared as a mixture with ultrapure water and the stain was then applied with a syringe and needle into the flowcell tubing (inlet end) (Figure 3.1). Fifteen minutes were allowed for stain binding to cells and substrate (in the dark), with the medium flow turned off. The flow was then resumed (peristaltic pump turned on) for 20 minutes to remove excess dye and the flowcell reactor was sealed at both inlet and outlet ends, removed from anaerobic cabinet, and placed onto the microscope stage for imaging.

\section{DNA extraction and real-time PCR quantification}

Competition vs. cooperation experiments The genomic DNA of both $C$. thermocellum and $T$. saccharolyticum was extracted using InstaGene ${ }^{\mathrm{TM}}$ Matrix with specifically formulated $6 \% \mathrm{w} / \mathrm{v}$ Chelex resin (Bio-Rad Laboratories Inc., ON, Canada) as stated by the manufacturer's protocol. Extracted genomic DNA was stored in a $-20^{\circ} \mathrm{C}$ freezer until further use. Quantitative PCR (qPCR) was performed on both $C$. thermocellum's and T. saccharolyticum's extracted DNA using specifically designed forward and reverse primers (Life Technologies Inc., CA, USA) and probes (Biosearch Technologies, CA, USA). See Table 3.2 for sequence information.

Table 3.2: Individual sequence of the designed forward primer, reverse primer, and probe used for amplification of $C$. thermocellum and $T$. saccharolyticum used in real-time PCR analysis

\begin{tabular}{|c|c|c|c|}
\hline $\begin{array}{l}\text { Bacterial } \\
\text { Sample }\end{array}$ & Forward Primer & Reverse Primer & Probe \\
\hline $\begin{array}{c}C \text { C. } \\
\text { thermocellum } \\
\text { ATCC } 27405^{*}\end{array}$ & $\begin{array}{l}5^{\prime}- \\
\text { GTTATCACTGTTGAAGAAGC } \\
-3,\end{array}$ & $\begin{array}{l}5^{\prime}- \\
\text { TTCTTGTCTGTAATGAGGAT } \\
-3,\end{array}$ & $\begin{array}{l}5^{\prime} \text { d HEX- } \\
\text { AATGGGCACAAACCTCGAAA } \\
\text {-BHQ-13 }\end{array}$ \\
\hline $\begin{array}{c}T . \\
\text { saccharolyticum } \\
\text { DSM } 7060^{* *}\end{array}$ & $\begin{array}{l}5^{\prime}- \\
\text { AGATCGAAGAGACTACATCA } \\
-3,\end{array}$ & $\begin{array}{l}5^{\prime}- \\
\text { AGAGCATCTTCTATTCTGTG } \\
-3,\end{array}$ & $\begin{array}{l}5^{\prime} \text { d FAM - } \\
\text { TTACTGCAACACCGCCAGAA } \\
\text {-BHQ-13 }\end{array}$ \\
\hline
\end{tabular}

* Sequenced from Nucleotide UT Sequence

** Sequenced from cpn60 gene 
Each $15.5 \mu \mathrm{L}$ qPCR reaction contained $2 \mu \mathrm{L}$ of template DNA and $13.5 \mu \mathrm{L}$ of master mix which was composed of $C$. thermocellum's forward primer, reverse primer, and probe ( $20 \mu \mathrm{L}, 20$ $\mu \mathrm{L}, 13.8 \mu \mathrm{L}$ respectively); $T$. saccharolyticum's forward primer, reverse primer, and probe (20 $\mu \mathrm{L}, 20 \mu \mathrm{L}$, and 13.8 $\mu \mathrm{L}$ respectively); $\mathrm{iQ}^{\mathrm{TM}}$ Multiplex Powermix (Bio-Rad Laboratories Inc., ON, Canada) (345 $\mu \mathrm{L})$ which contains dNTPs, $11 \mathrm{mM} \mathrm{MgCl} 2$, iTaq DNA Polymerase, and additional stabilizers; and sterilized water $(142.6 \mu \mathrm{L})$. Standard curves for $C$. thermocellum $\left(\mathrm{R}^{2}\right.$ of 0.94) and T. saccharolyticum ( $\mathrm{R}^{2}$ of 0.99$)$ were generated for the standard dilutions of 1:2, 1:200, 1:20,000, and 1:2,000,000. Once the standard curves were developed, effluent samples from experimentations outlined in Figure 3.3 were collected for qPCR analysis. Each sample reaction was prepared in the same way as mentioned above.

All qPCR samples were analyzed with a LightCycler® 2.0 Instrument (Hoffmann-La Roche Limited, ON, Canada). The samples first went through an initialization step at $95^{\circ} \mathrm{C}$ for 3 minutes followed by 10 seconds of denaturation at $95^{\circ} \mathrm{C}$. Primer annealing was programmed for another 10 seconds at $55^{\circ} \mathrm{C}$, followed by elongation time of 30 seconds at $72^{\circ} \mathrm{C}$. The annealing temperature was set at $57^{\circ} \mathrm{C}$ for a period of 50 seconds. The whole qPCR reaction was programmed for a total of 39 cycles.

\section{High performance liquid chromatography analysis}

Samples that were collected for physiology test and effluent samples from continuousflow experiments for end-product analysis were transferred into $1.5 \mathrm{~mL}$ cryovials (SigmaAldrich, MO, USA) and acidified to $\mathrm{pH} 2$ by adding $1.5 \mathrm{mmol} \mathrm{HCl}$. The sample was further centrifuged for 5 minutes at $10,000 \mathrm{rpm}$. Around $800 \mu \mathrm{L}$ of supernatant was removed and pipetted into $1 \mathrm{~mL}$ HPLC vials (Cole-Parmer, QC, CA). End products of interest were xylose, cellobiose and ethanol for T. saccharolytium's physiology test in batch and ethanol, acetate, 
lactate, formate, xylose, and cellobiose for continuous-flow (pure and co-culture) end product analysis. These specific products were analyzed by high performance liquid chromatography (HPLC) on Perkin Elmer Series 200 HPLC System (Woodbridge, ON, CA) and a carbohydrate analysis Aminex ${ }^{\circledR} \mathrm{HPX}-87 \mathrm{H}$ column (Bio Rad Laboratories Inc., ON, CA) with $9 \mu \mathrm{m}$ particle size and $300 \times 7.8 \mathrm{~mm}$ dimension. The solution used for the mobile phase was $5 \mathrm{mM} \mathrm{H}_{2} \mathrm{SO}_{4}$ and was introduced into the column at a flow rate of $0.5 \mathrm{~mL} / \mathrm{min}$ with a column temperature of $60^{\circ} \mathrm{C}$ (Yee et al., 2012). In addition, to allow for the detection of all soluble constituents present, each sample was run for the period of 28 minutes. The data were analyzed and final concentrations were calculated by the use of TotalChrom software program. A standard curve was generated for the mixtures of different standard concentrations of 50,20,10,5,2,1, and $0.5 \mathrm{mM}$. The standards were also run separately at a concentration of $20 \mathrm{mM}$ to determine their retention time values.

\section{Solid substrate utilization}

The initial substrate mass $\left(\mathrm{S}_{\mathrm{i}}\right)$ of both cotton and switchgrass (for all four continuousflow experiments) was determined by dry weight measurements after incubating substrates for three hours in an oven at $120^{\circ} \mathrm{C}$. The final mass of both substrates remaining in the flow cell reactor at day 6 was also determined by dry weight measurements. In addition, day 2, day 4, and day 6 effluent samples were treated with $\mathrm{NaOH}\left(0.2 \mathrm{~N}\right.$ final concentration) for one hour at $50^{\circ} \mathrm{C}$ to digest cellular biomass (but not cellulose itself) (Dumitrache et al., 2013). Once treated, the samples were then filtered on 934-AH Borisilicate glass fiber filters (Sterilitech Corporation, WA, USA) to remove undigested residual substrate particles and baked to determine dry weight of substrate lost to the effluent $\left(\mathrm{S}_{\mathrm{f}}\right)$. Total solid substrate $\left(\mathrm{S}_{\mathrm{t}}\right)$ utilization was calculated as follows: $S_{t}=S_{i}-S_{f}$. 


\subsection{Results}

\section{Cell morphology}

C. thermocellum ATCC 27405 and T. saccharolyticum DSM 7060, grown separately in batch system in a similar medium composition, were imaged using epifluorescence microscopy. The morphology comparison can be seen in Figure 3.4.

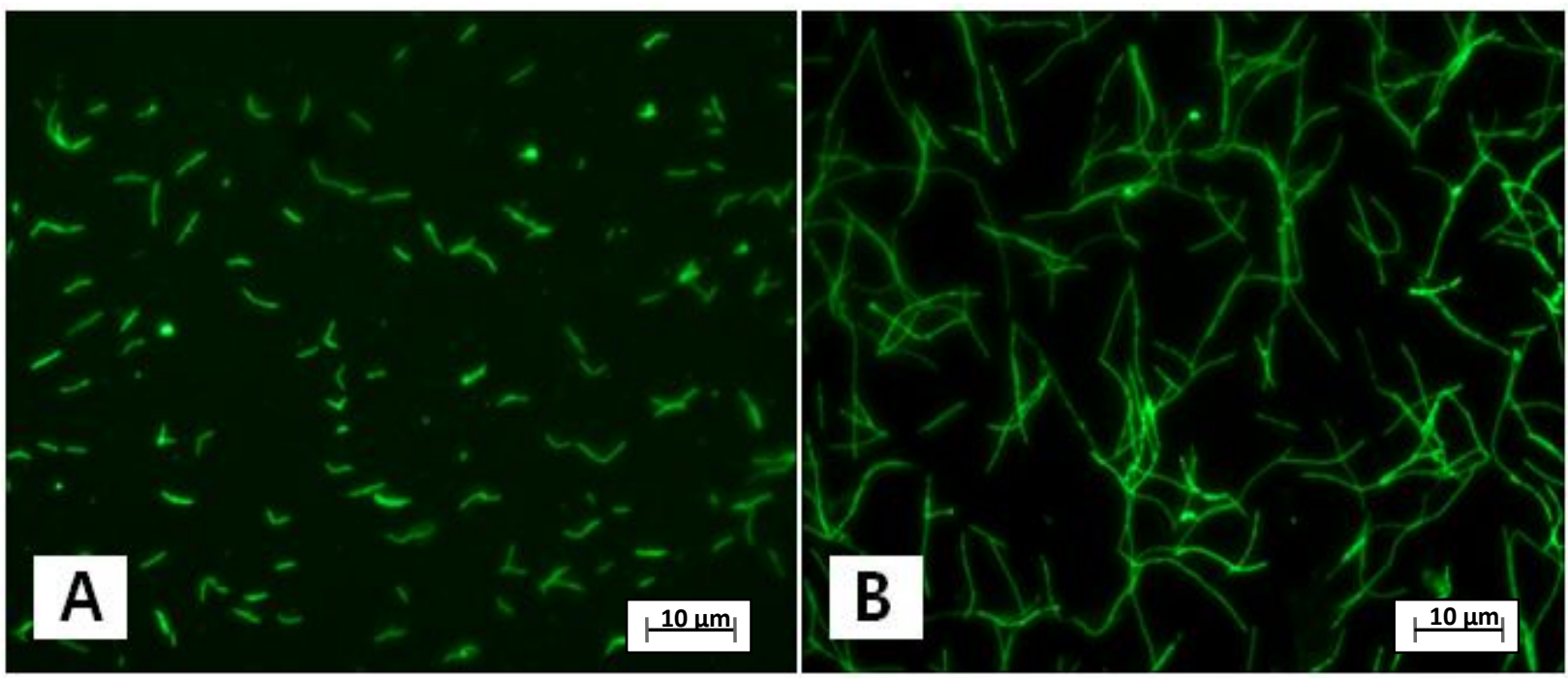

Figure 3.4: Epifluorescence microscopy showing A) C. thermocellum ATCC 27405 cells gown in batch $(2 \mathrm{~g} / \mathrm{L}$ yeast extract with $10 \mathrm{~g} / \mathrm{L}$ cellobiose supplement) and B) T. saccharolyticum DSM 7060 (2 g/L yeast extract with 10 $\mathrm{g} / \mathrm{L}$ xylose supplement), showing that the latter had a more elongated cell morphology that flocked together. Cells (1:100 dilution) were stained with SYTO9 green stain and observed under 60x objective lens.

It can be seen that $T$. saccharolyticum $(8-15 \mu \mathrm{m}$ cell size) has elongated cells, while those of C. thermocellum (3-5 $\mu \mathrm{m})$ were smaller and rod shaped. T. saccharolyticum cells tend to undergo higher amount of intertwining or linking together than the individually separate $C$. thermocellum cells. It also appears that T. saccharolyticum DSM 7060 does not show any sporulation. 
Substrate attachment capabilities of $T$. saccharolyticum

Four separate continuous-flow experiments have been carried out to test the binding efficiency of T. saccharolyticum to cellulosic and lignocellulosic materials. Figure 3.5 illustrates the images gathered with CLSM of T. saccharolyticum attachment on cotton (cellulose),

switchgrass (lignocellulose), as well as its relative spatial distribution when present together with C. thermocellum in co-culture.

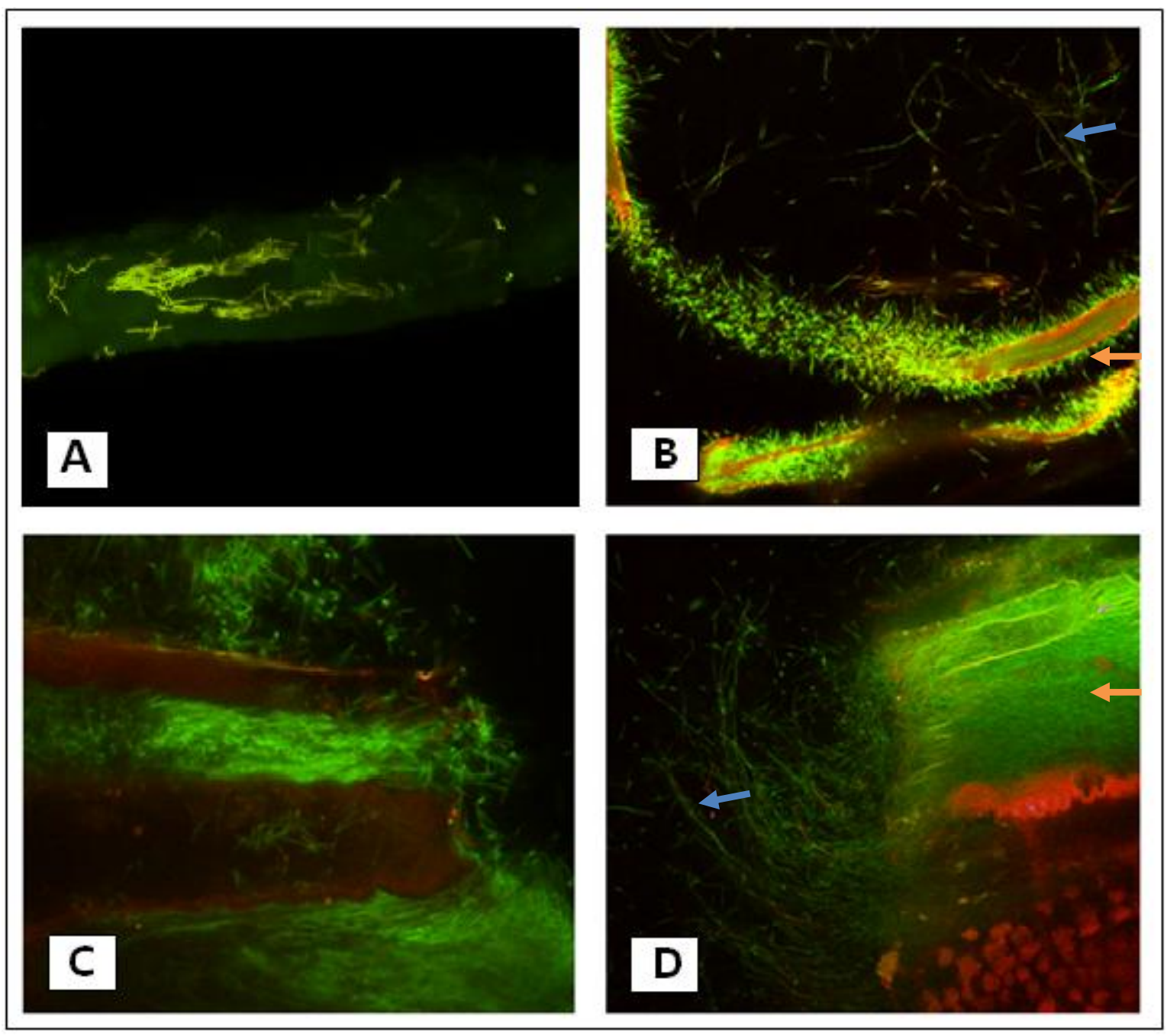

Figure 3.5: Attachment of T. saccharolyticum DSM 7060 on cellulosic (cotton) substrate in A) pure culture and B) in co-culture with $C$. thermocellum ATCC 27405, and on lignocellulosic (switchgrass) substrate in C) pure culture and D) in co-culture with C. thermocellum ATCC 27405. Blue arrow: T. saccharolyticum DSM 7060. Orange arrow: C. thermocellum ATCC 27405. 
Figure 3.5A and Figure 3.5C show that T. saccharolyticum monoculture can in fact bind to both carbon substrates, and this attachment appears to be non-specific for both substrates. However, both images shown here reveal partial binding. Comparison with co-culture in Figure 3.5B and Figure 3.5D show that $C$. thermocellum cells occupy more substrate surface area and $T$. saccharolyticum tend to be more free floating and in close proximity to C. thermocellum. The blue arrows on Figure 3.5B and Figure 3.5D indicate where T. saccharolyticum is most likely located compared to $C$. thermocellum, shown by orange arrows.

\section{T. saccharolyticum DSM 7060 physiology test}

An HPLC analysis was performed to show yet undetermined physiology of $T$. saccharolyticum DSM 7060 strain in monoculture and in comparison with $C$. thermocellum in co-culture (Figure 3.6). The results revealed that T. saccharolyticum DSM 7060 is capable of utilizing both cellobiose $(2.88 \mathrm{mM}$ remaining at the end of 3 day incubation period) and xylose (4.44 $\mathrm{mM}$ remaining) sugars in parallel without the interference of carbon catabolite repression. In other words, both pentose and hexose sugars are fermented simultaneously without significant preference for one type of sugar over the other. When in co-culture, T. saccharolyticum could utilize xylose more efficiently, with $0.4 \mathrm{mM}$ remaining at the end of the incubation period. On the other hand, $C$. thermocellum's ability to utilize cellobiose decreased in co-culture when comparing to monoculture, $6.59 \mathrm{mM}$ to $1.16 \mathrm{mM}$ respectively. Ethanol production increased in co-culture $(4.89 \mathrm{mM})$ by $23 \%$ when comparing to overall ethanol production in $C$. thermocellum monoculture $(3.97 \mathrm{mM})$. Last, it should be noted that all three batch samples experienced a drop in $\mathrm{pH}$ after inoculation and 3 day incubation period (C. thermocellum monoculture - decrease of $\sim 0.08$; T. saccharolyticum monoculture - decrease of $\sim 0.61$; and co-culture - decrease of $\sim 0.37$ ). 


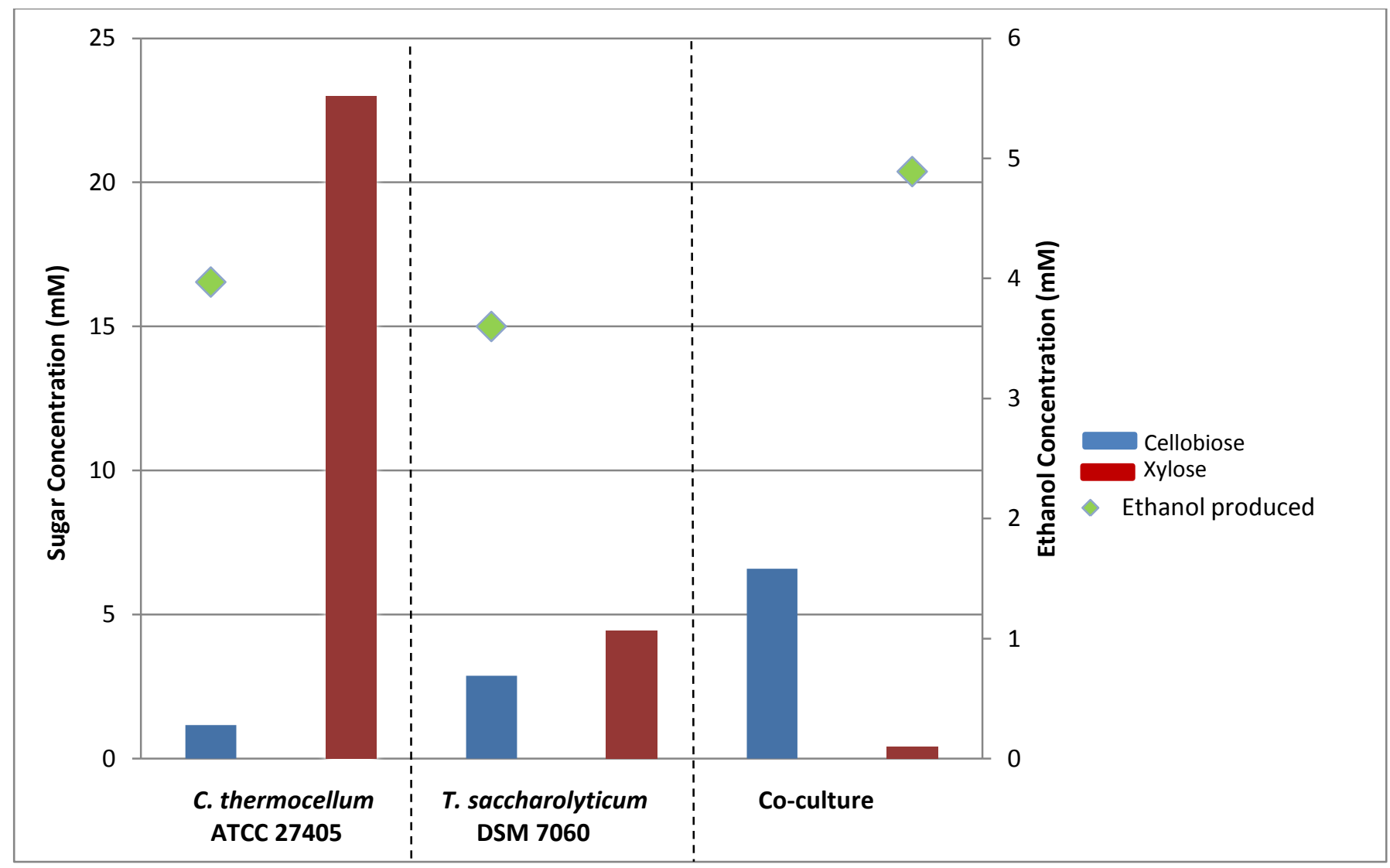

Figure 3.6: Comparing sugar utilization and ethanol production between C. thermocellum ATCC 27405 and $T$. saccharolyticum DSM 7060 monoculture and co-culture samples in batch system with $5 \mathrm{~g} / \mathrm{L}$ cellobiose and $5 \mathrm{~g} / \mathrm{L}$ xylose as sugar supplements in medium. $\mathrm{pH}$ before inoculation: $\sim 6.5$. The $\mathrm{pH}$ after inoculation and 3 days incubation period: $C$. thermocellum ATCC 27405 - 6.42; T. saccharolyticum DSM 7060 - 5.89; Co-culture - 6.13.

\section{Concentration dynamics: Competition vs. cooperation analysis}

Experiment 1 - C. thermocellum on cotton

Quantitative PCR analysis (Figure 3.7) shows that the DNA concentration (see Table 3.3 at the end of the results section) of $C$. thermocellum for the first two days of continuous-flow on cotton with high carbon supplement (HCS) (2 g/L yeast extract with $0.3 \mathrm{~g} / \mathrm{L}$ cellobiose) was 408 $\mathrm{ng} / \mu \mathrm{L}\left(\mathrm{C}_{\mathrm{p}}=26.93\right)$. Once low carbon supplement (LCS) $(0.3 \mathrm{~g} / \mathrm{L}$ yeast extract with no cellobiose) was introduced that concentration number changed to $355 \mathrm{ng} / \mu \mathrm{L}\left(\mathrm{C}_{\mathrm{p}}=27.27\right)$ for day 4, a decrease of nearly $13 \%$. However, at day 6 under the same LCS medium, the concentration has steadily increased to $378 \mathrm{ng} / \mu \mathrm{L}\left(\mathrm{C}_{\mathrm{p}}=27.01\right)$. Concentration $(\mathrm{ng} / \mu \mathrm{L})$ values were determined 
by creating a standard curve that measured known dilution concentrations and their corresponding crossing point $\left(\mathrm{C}_{\mathrm{p}}\right)$.

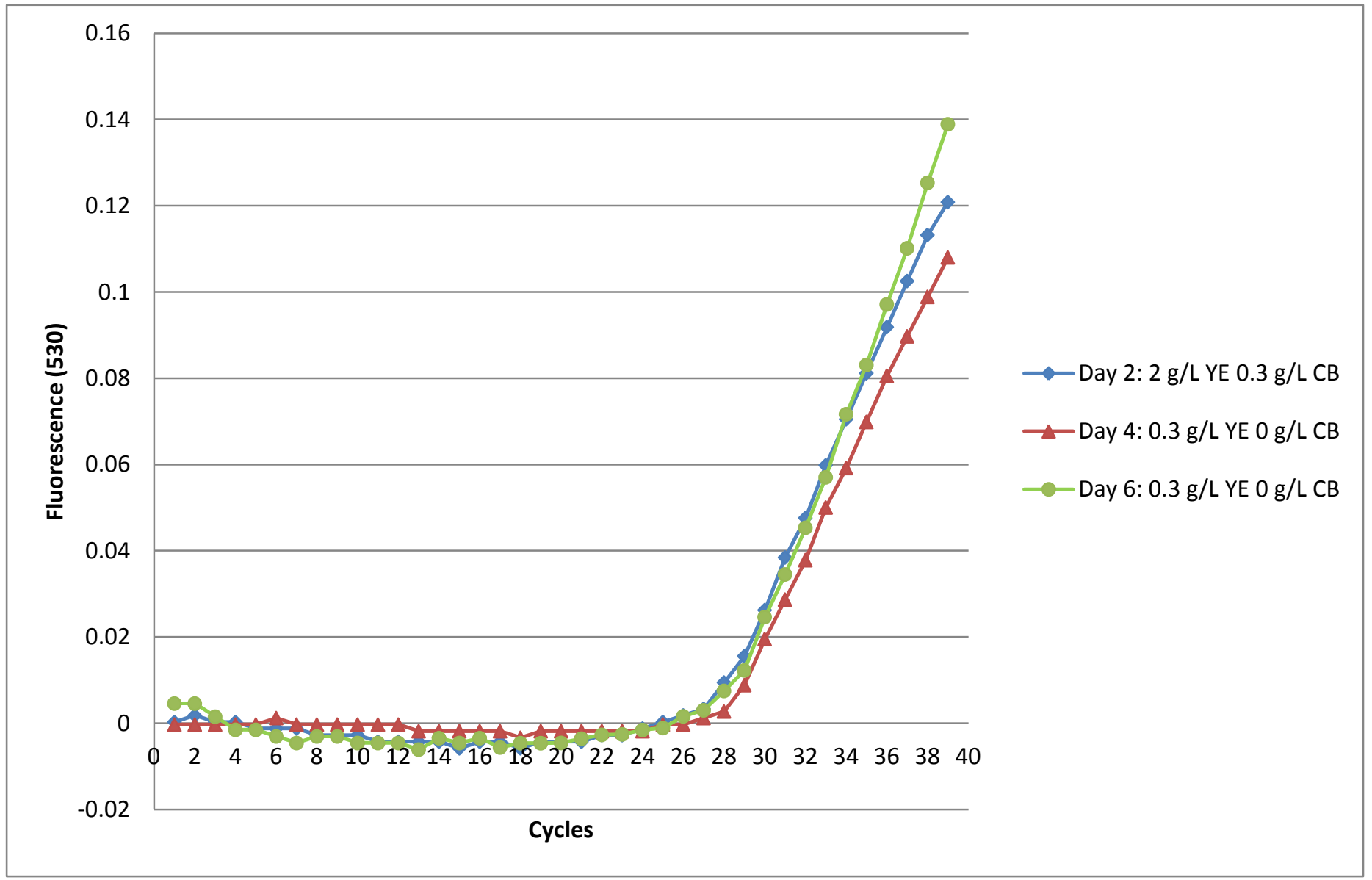

Figure 3.7: qPCR analysis of $C$. thermocellum ATCC 27405 monoculture flowcell abundance on cotton with respect to HCS ( $2 \mathrm{~g} / \mathrm{L}$ yeast extract and $0.3 \mathrm{~g} / \mathrm{L}$ cellobiose) and LCS $(0.3 \mathrm{~g} / \mathrm{L}$ yeast extract without cellobiose) over the course of 6 days

Experiment $2-$ C. thermocellum on switchgrass

Within the first two days, $C$. thermocellum DNA concentration with HCS medium reached $639 \mathrm{ng} / \mu \mathrm{L}\left(\mathrm{C}_{\mathrm{p}}=20.48\right)$. Next $\mathrm{qPCR}$ analysis at day 4 , with medium switched to LCS, has dropped the latter concentration value to $509.1 \mathrm{ng} / \mu \mathrm{L}\left(\mathrm{C}_{\mathrm{p}}=24.77\right)$. This is a decrease of $20.3 \%$ in DNA concentration value. At day 6, much like in day 6 in cotton experiment, the DNA 
concentration of this bacterium gradually increased to $528.3 \mathrm{ng} / \mu \mathrm{L}\left(\mathrm{C}_{\mathrm{p}}=24.19\right)$, which represents an increase of $3.8 \%$.

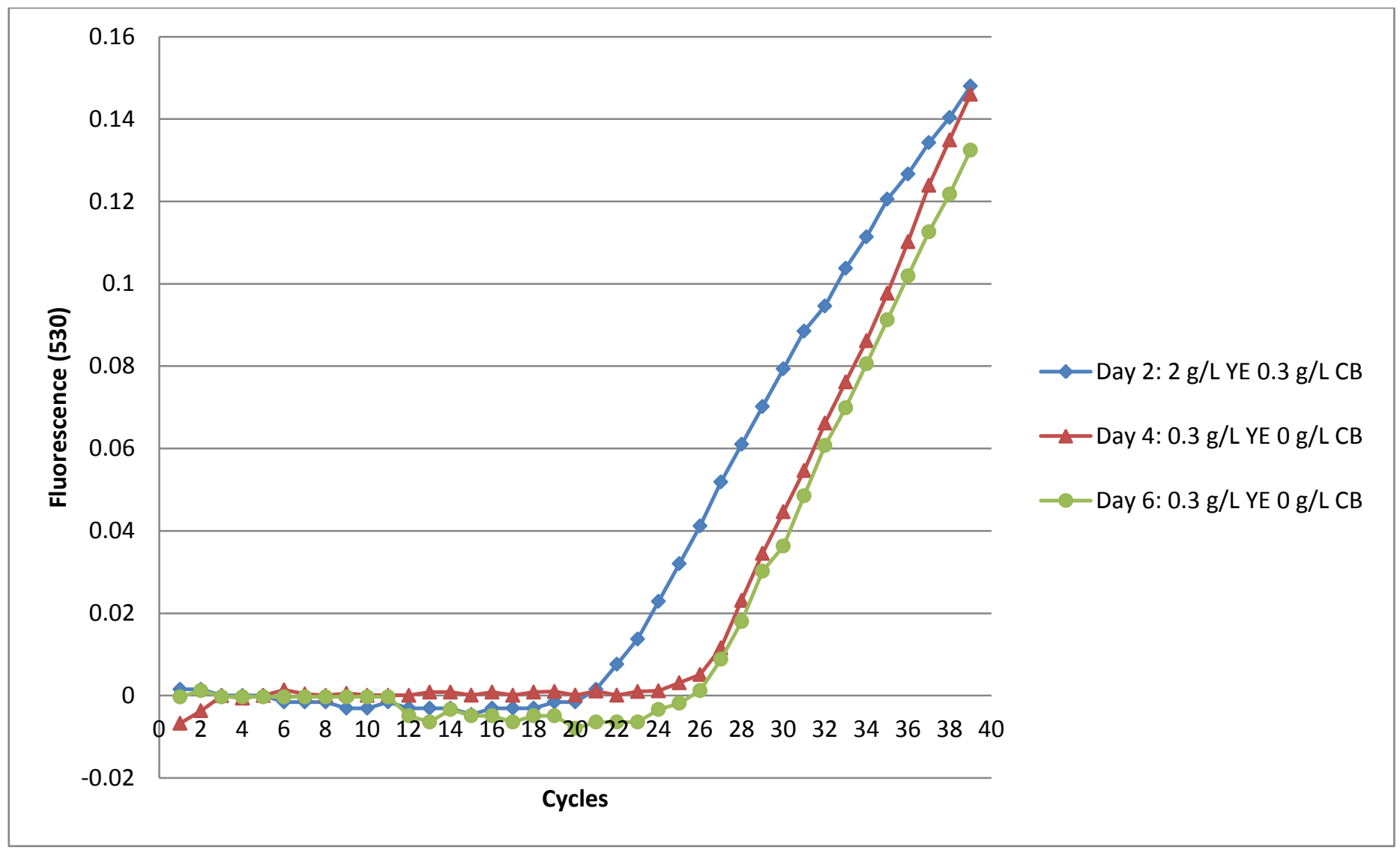

Figure 3.8: qPCR analysis of $C$. thermocellum ATCC 27405 monoculture flowcell DNA abundance on switchgrass with respect to HCS ( $2 \mathrm{~g} / \mathrm{L}$ yeast extract and $0.3 \mathrm{~g} / \mathrm{L}$ cellobiose) and LCS $(0.3 \mathrm{~g} / \mathrm{L}$ yeast extract with no cellobiose) over the course of 6 days

Experiment 3 - Co-culture on cotton

Figure 3.9 presents the results of the co-culture investigations over a period of six days.

Both C. thermocellum and T.saccharolyticum exhibit greatest abundance at day $2(591.8 \mathrm{ng} / \mu \mathrm{L}-$ $\mathrm{C}_{\mathrm{p}} 21.21$ and $578.6 \mathrm{ng} / \mu \mathrm{L} \mathrm{C}_{\mathrm{p}} 21.36$ respectively) with $\mathrm{HCS}$ as the medium source. These values drop to $463 \mathrm{ng} / \mu \mathrm{L}\left(\mathrm{C}_{\mathrm{p}}=25.26\right)$ in day 4 for $C$. thermocellum and to $122 \mathrm{ng} / \mu \mathrm{L}\left(\mathrm{C}_{\mathrm{p}}=31.27\right)$ for T. saccharolyticum. Finally at day 6, C. thermocellum DNA concentration dropped further to $441.5 \mathrm{ng} / \mu \mathrm{L}\left(\mathrm{C}_{\mathrm{p}}=25.65\right)$ and $T$. saccharolyticum increased slightly to $133.4 \mathrm{ng} / \mu \mathrm{L}\left(\mathrm{C}_{\mathrm{p}}=31.12\right)$. 


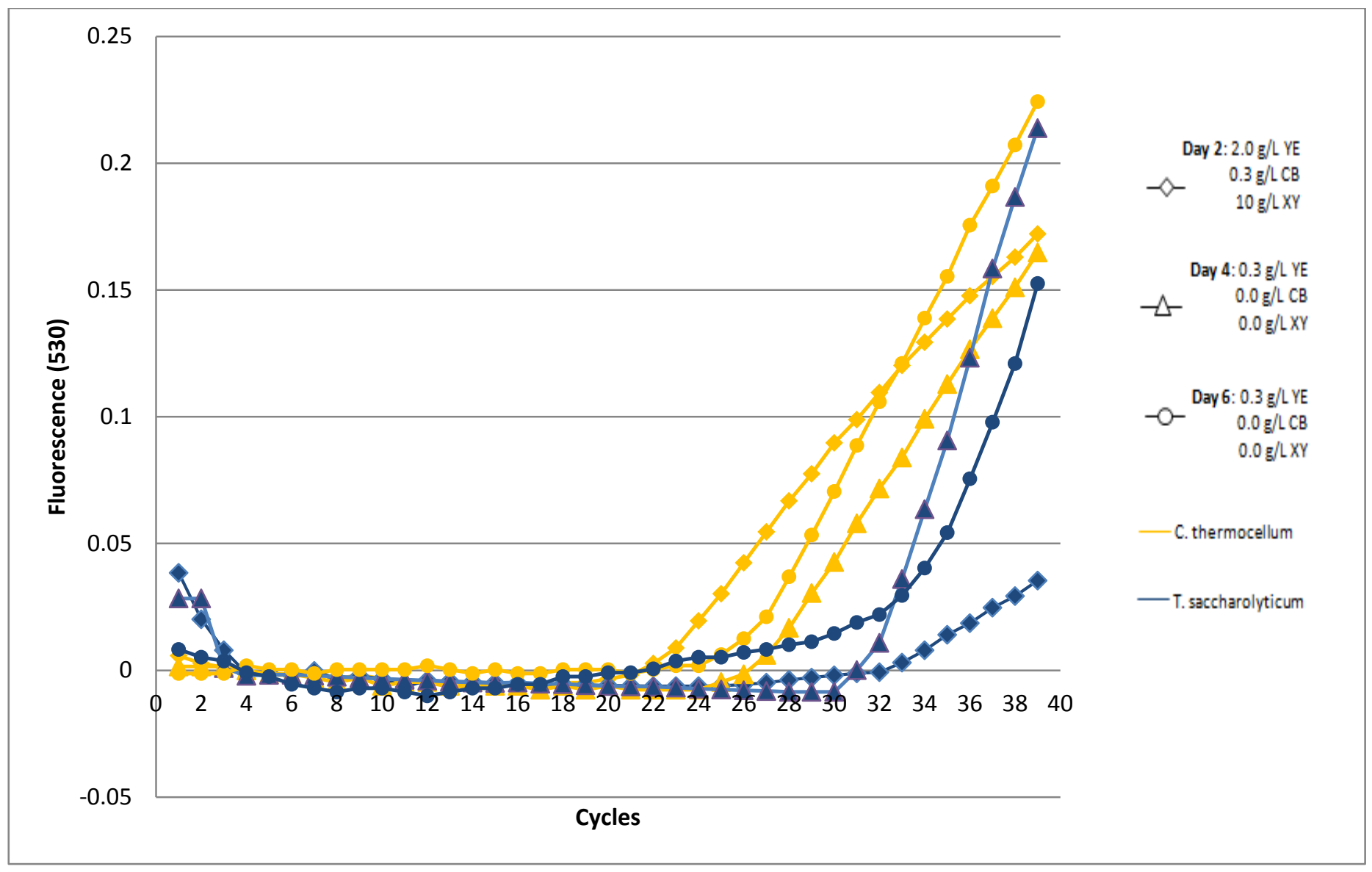

Figure 3.9: qPCR analysis of $C$. thermocellum ATCC 27405 and $T$. saccharolyticum DSM 7060 flowcell co-culture DNA abundance on cotton with respect to HCS $(2.0 \mathrm{~g} / \mathrm{L}$ yeast extract, $0.3 \mathrm{~g} / \mathrm{L}$ cellobiose, and $10 \mathrm{~g} / \mathrm{L}$ xylose $)$ and LCS $(0.3 \mathrm{~g} / \mathrm{L}$ yeast extract with no sugar supplement) over the course of 6 days. See Table 3.2 for numerical analysis

Experiment 4 - Co-culture on switchgrass

Figure 3.10 shows that the concentrations of $C$. thermocellum $\left(641 \mathrm{ng} / \mu \mathrm{L}-\mathrm{C}_{\mathrm{p}} 20.46\right)$ and T. saccharolyticum $\left(315 \mathrm{ng} / \mu \mathrm{L}-\mathrm{C}_{\mathrm{p}} 30.40\right)$ with $\mathrm{HCS}$ at day 2 decreased to $543 \mathrm{ng} / \mu \mathrm{L}(15.3 \%$ drop) and $73.5 \mathrm{ng} / \mu \mathrm{L}$ (76.7 \% drop), respectively by day 4 when the medium has been switched to LCS. These values tend to mimic cotton substrate concentration pattern at day 6 since values of $C$. thermocellum dropped slightly to $524 \mathrm{ng} / \mu \mathrm{L}\left(\mathrm{C}_{\mathrm{p}}=23.63\right)$ and $T$. saccharolyticum recovered to $112 \mathrm{ng} / \mu \mathrm{L}\left(\mathrm{C}_{\mathrm{p}}=33.49\right)$. Data for crossing points $\left(\mathrm{C}_{\mathrm{p}}\right)$, DNA concentrations, and solid carbon remaining at the end of the experimentation can be found in Table 3.3. 


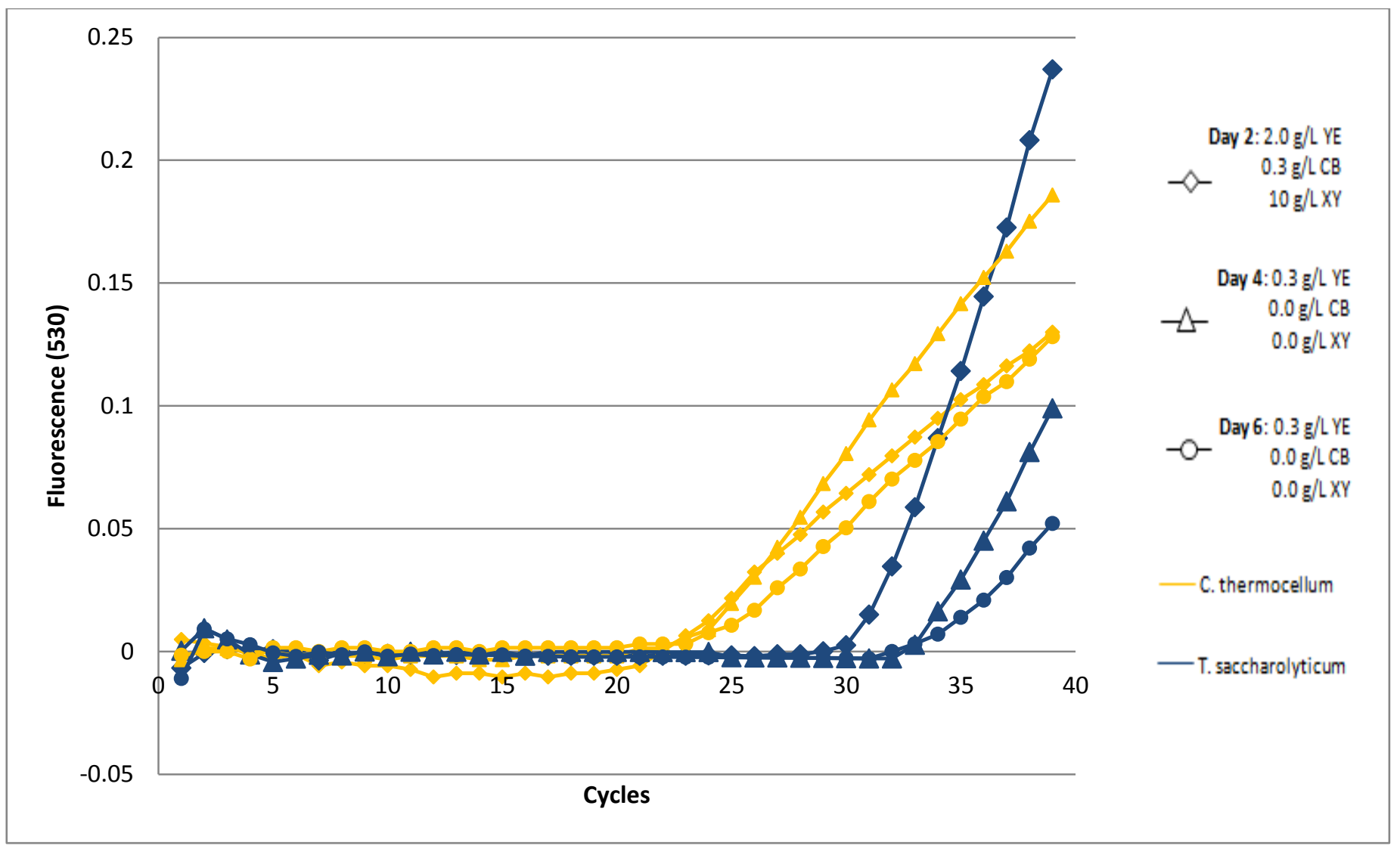

Figure 3.10: qPCR analysis of $C$. thermocellum ATCC 27405 and $T$. saccharolyticum DSM 7060 flowcell coculture DNA abundance on switchgrass with respect to HCS (2.0 g/L yeast extract, $0.3 \mathrm{~g} / \mathrm{L}$ cellobiose, and $10 \mathrm{~g} / \mathrm{L}$ xylose) and LCS (0.3 g/L yeast extract with no sugar supplement) over the course of 6 days 


\section{End product analysis}

The end product analysis, as determined with high performance liquid chromatography (HPLC) can be seen in Figure 3.11, showing that $C$. thermocellum growing on cotton exhibited least amount of ethanol production variation, fermenting $4.06 \mathrm{mM}$ ethanol at day $2 \mathrm{HCS}$ medium, $3.64 \mathrm{mM}$ at day $4 \mathrm{LCS}$ medium, and $3.59 \mathrm{mM}$ at day $6 \mathrm{LCS}$ medium. These results differed from $C$. thermocellum on switchgrass since more ethanol was produced at day 2, day 4, and day 6 (7.77 mM, $6.31 \mathrm{mM}$, and $6.27 \mathrm{mM}$ respectively). Co-culture end product investigation have shown that for day 2 ethanol production was $4.86 \mathrm{mM}$, dropping to $3.72 \mathrm{mM}$ at day 2 , and spiking up to $5.09 \mathrm{mM}$ at day 6. Lastly, co-culture on switchgrass results displayed highest amount of ethanol yield of $8.95 \mathrm{mM}$ at day 2, after plummeting to $3.8 \mathrm{mM}$ ethanol for day 6 the system started to recover at day 6 with ethanol production at $4.53 \mathrm{mM}$. Table 3.4 displays other by-products of fermentation and hydrolysis that were generated from the four continuous-flow experiments. 


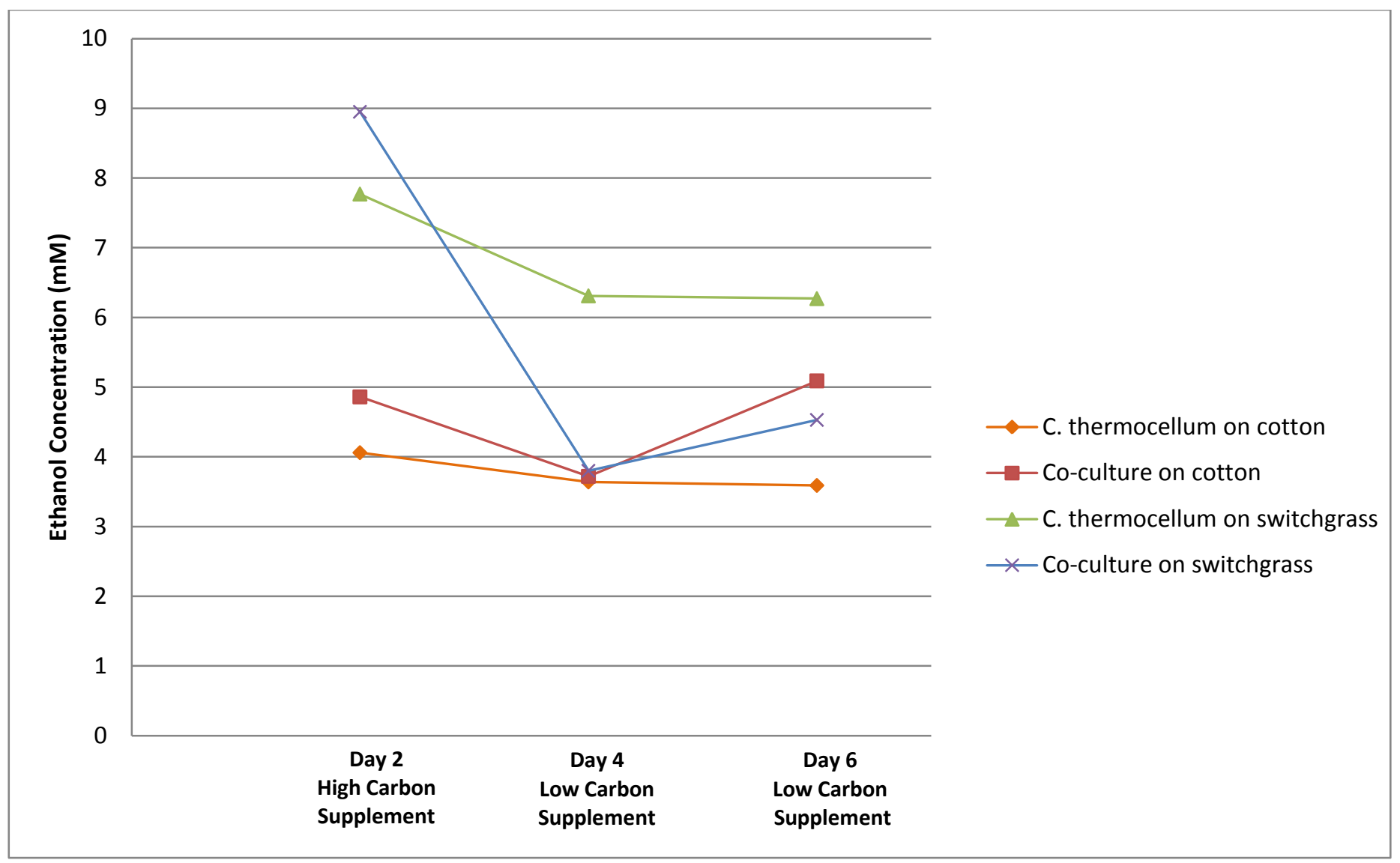

Figure 3.11: HPLC results displaying ethanol production for $C$. thermocellum ATCC 27405 monoculture on cotton and switchgrass with HCS ( $2 \mathrm{~g} / \mathrm{L}$ yeast extract and $0.3 \mathrm{~g} / \mathrm{L}$ cellobiose) for first two days and LCS $(0.3 \mathrm{~g} / \mathrm{L}$ yeast extract with no sugar additive) for the next four days, and the same time periods and carbon sources with $T$. saccharolyticum DSM 7060 in co-culture with HCS ( $2 \mathrm{~g} / \mathrm{L}$ yeast extract, $0.3 \mathrm{~g} / \mathrm{L}$ cellobiose, and $10 \mathrm{~g} / \mathrm{L}$ xylose) and LCS $(2 \mathrm{~g} / \mathrm{L}$ yeast extract with no sugar additives) in flowcell systems 
Table 3.4: Peak concentrations of other end products generated from fermentation and hydrolysis processes

\begin{tabular}{|c|c|c|c|c|c|}
\hline & $\begin{array}{l}\text { Acetate } \\
(\mathbf{m M})\end{array}$ & $\begin{array}{l}\text { Lactate } \\
(\mathbf{m M})\end{array}$ & $\begin{array}{c}\text { Formate } \\
(\mathbf{m M})\end{array}$ & $\begin{array}{l}\text { Cellobiose } \\
(\mathbf{m M})\end{array}$ & $\begin{array}{c}\text { Xylose } \\
(\mathbf{m M})\end{array}$ \\
\hline \multicolumn{6}{|c|}{$\begin{array}{c}\text { C. thermocellum on } \\
\text { cotton }\end{array}$} \\
\hline Day 2 & 0.93 & 0.04 & 6.78 & 2.91 & N/A \\
\hline Day 4 & ND & ND & 3.31 & 3.50 & N/A \\
\hline Day 6 & 1.12 & 0.41 & ND & 3.26 & N/A \\
\hline \multicolumn{6}{|c|}{$\begin{array}{c}\text { C. thermocellum on } \\
\text { switchgrass }\end{array}$} \\
\hline Day 2 & 3.37 & 0.01 & 5.33 & 1.79 & 4.44 \\
\hline Day 4 & 2.81 & ND & 2.01 & 2.73 & ND \\
\hline Day 6 & 2.60 & ND & 2.69 & ND & ND \\
\hline \multicolumn{6}{|c|}{ Co-culture on cotton } \\
\hline Day 2 & 0.53 & 0.03 & 7.80 & 1.58 & N/A \\
\hline Day 4 & 1.28 & 0.02 & 2.33 & ND & N/A \\
\hline Day 6 & 5.65 & ND & ND & ND & N/A \\
\hline \multicolumn{6}{|c|}{$\begin{array}{l}\text { Co-culture on } \\
\text { switchgrass }\end{array}$} \\
\hline Day 2 & 4.83 & ND & 6.66 & 1.26 & 0.77 \\
\hline Day 4 & ND & ND & 2.17 & ND & 3.90 \\
\hline Day 6 & ND & ND & 2.09 & 1.01 & 3.79 \\
\hline
\end{tabular}

\section{Total solid substrate hydrolysis}

The initial mass of dry cotton was $0.13 \mathrm{~g}$ and the initial mass of switchgrass was $0.51 \mathrm{~g}$.

The total amount of substrate remaining after experimentation for two control monoculture trials was $0.05 \mathrm{~g}(\sim 62 \%$ hydrolyzed) and $0.25 \mathrm{~g}(\sim 51 \%$ hydrolyzed $)$ for cotton and switchgrass respectively (Table 3.3). Co-culture experiments with $T$. saccharolyticum resulted in solid substrate residue of $0.03 \mathrm{~g}(\sim 75 \%$ hydrolyzed) and $0.21 \mathrm{~g}(\sim 59 \%$ hydrolyzed $)$ (Table 3.3). Coculture on cotton resulted in increased degradation by $13 \%$ and on switchgrass by $8 \%$. Therefore, co-culture trials have suggested partial increase in both cellulosic and lignocellulosic degradation when compared to $C$. thermocellum in monoculture. 
Table 3.3: Summary of the quantitative results for qPCR, HPLC, and solid carbon remaining at the end of the four individual continuous-flow experiments

\begin{tabular}{|c|c|c|c|c|c|c|c|c|c|c|c|c|c|c|c|c|c|c|}
\hline & \multicolumn{18}{|c|}{ Continuous-flow experiment } \\
\hline & \multicolumn{3}{|c|}{$\begin{array}{l}\text { C. thermocellum } \\
\text { on cotton } \\
\text { (0.13 g dry mass) }\end{array}$} & \multicolumn{3}{|c|}{$\begin{array}{l}\text { C. thermocellum } \\
\text { on switchgrass } \\
\text { (0.51 g dry mass) }\end{array}$} & \multicolumn{6}{|c|}{$\begin{array}{l}\text { Co-culture on cotton } \\
(0.13 \text { g dry mass })\end{array}$} & \multicolumn{6}{|c|}{$\begin{array}{l}\text { Co-culture on switchgrass } \\
\text { (0.51 g dry mass })\end{array}$} \\
\hline & $\begin{array}{c}\text { Day } \\
2\end{array}$ & $\begin{array}{c}\text { Day } \\
4\end{array}$ & $\begin{array}{c}\text { Day } \\
6\end{array}$ & $\begin{array}{l}\text { Day } \\
2\end{array}$ & $\begin{array}{c}\text { Day } \\
4\end{array}$ & $\begin{array}{c}\text { Day } \\
6\end{array}$ & \multicolumn{2}{|c|}{ Day 2} & \multicolumn{2}{|c|}{ Day 4} & \multicolumn{2}{|c|}{ Day 6} & \multicolumn{2}{|c|}{ Day 2} & \multicolumn{2}{|c|}{ Day 4} & \multicolumn{2}{|c|}{ Day 6} \\
\hline & \multicolumn{3}{|c|}{$\begin{array}{l}\text { C. thermocellum } \\
\text { ATCC } 27405\end{array}$} & \multicolumn{3}{|c|}{$\begin{array}{l}\text { C. thermocellum } \\
\text { ATCC } 27405\end{array}$} & C.t ${ }^{*}$ & T.s ${ }^{* *}$ & C.t ${ }^{*}$ & T.s & C.t ${ }^{*}$ & T.s ${ }^{* *}$ & C.t ${ }^{*}$ & T.s. & C.t ${ }^{*}$ & T.s ${ }^{* *}$ & C.t ${ }^{*}$ & T.s ${ }^{* *}$ \\
\hline $\begin{array}{l}\text { Crossing point } \\
\left(\mathbf{C}_{\mathbf{p}}\right)\end{array}$ & 26.93 & 27.27 & 27.01 & 20.48 & 24.77 & 24.19 & 21.21 & 21.36 & 25.26 & 31.27 & 25.65 & 31.12 & 20.46 & 30.40 & 22.88 & 34.00 & 23.63 & 33.49 \\
\hline $\begin{array}{c}\text { DNA } \\
\text { concentration } \\
(\mu \mathrm{g} / \mu \mathrm{L})\end{array}$ & 408 & 355 & 378 & 639 & 509.1 & 528.3 & 591.8 & 578.6 & 463 & 122 & 441.5 & 133.4 & 641 & 315 & 543 & 73.5 & 524.4 & 112 \\
\hline $\begin{array}{l}\text { Ethanol } \\
\text { Produced } \\
(\mathrm{mM})\end{array}$ & 4.06 & 3.64 & 3.59 & 7.77 & 6.31 & 6.27 & 4. & 86 & 3. & 72 & & 09 & 8.9 & & 3. & 80 & & 53 \\
\hline $\begin{array}{l}\text { Total solid } \\
\text { substrate } \\
\text { remaining }(\mathrm{g})\end{array}$ & \multicolumn{3}{|c|}{$\begin{array}{c}0.05 \\
(\sim 62 \% \text { hydrolyzed })\end{array}$} & \multicolumn{3}{|c|}{$\begin{array}{c}0.25 \\
(\sim 51 \% \text { hydrolyzed })\end{array}$} & \multicolumn{6}{|c|}{$\begin{array}{c}0.03 \\
(\sim 75 \% \text { hydrolyzed })\end{array}$} & \multicolumn{6}{|c|}{$\begin{array}{c}0.21 \\
(\sim 59 \% \text { hydrolyzed })\end{array}$} \\
\hline
\end{tabular}

* C. thermocellum ATCC 27405

** T. saccharolyticum DSM 7060 


\subsection{Discussion}

\section{Cell morphology}

The first experiment that was performed was epifluorescent staining $(0.5 \mu \mathrm{L}$ SYBR $®$ Gold Nucleic Acid Stain) to observe the general morphological characteristics of $C$. thermocellum ATCC 27405 and T. saccharolyticum DSM 7060 in batch culture (DSMZ Medium 122 with $2 \mathrm{~g} / \mathrm{L}$ yeast extract, $5 \mathrm{~g} / \mathrm{L}$ cellobiose and $5 \mathrm{~g} / \mathrm{L}$ xylose) (Figure 3.4). Cellobiose was used as the main carbon source for the growth of $C$. thermocellum due to its high preference and maximum growth rates exhibited on this particular sugar ( $\mathrm{Ng}$ and Zeikus, 1982; Zhang and Lynd, 2005). This morphology test was of great importance since it would lay down a general platform for identification and classification of $T$. saccharolyticum as cellular structure, which was yet to be described in literature. Figure 3.4 shows that $T$. saccharolyticum does not contain the typical Clostridia family rod shape, but it is roughly 3 times larger when compared to $C$. thermocellum. The morphological characteristics of T. saccharolyticum are more elongated and tend to interlink with other cells in batch system more than $C$. thermocellum.

In addition, a previous study performed by Lee et al. (1993) on various unknown strains of Thermoanaerobacterium spp. has revealed that one strain $\mathrm{B} 6 \mathrm{~A}-\mathrm{RI}^{\mathrm{T}}$ contains much longer rod shaped cells and once nutrients become limiting or once they reach their stationary phase, become more elongated and are more prone to aggregation. These morphological characteristics are viewed as a mechanism of survival under competitive or limiting nutrient conditions. Typical DSM Medium 122 (ingredients described in the methodology section) with limited yeast extract of $2 \mathrm{~g} / \mathrm{L}$ in batch system does generate nutritionally unfavourable conditions for $T$. 
saccharolyticum that mimic those same morphological indicators of $\mathrm{B} 6 \mathrm{~A}-\mathrm{RI}^{\mathrm{T}}$ mentioned in the past. However, these conditions do provide an easier identification from $C$. thermocellum which was of great value in the subsequent substrate attachment analysis.

\section{Substrate attachment capabilities of $T$. saccharolyticum}

The ability of $C$. thermocellum to bind to carbon material has been extensively researched and examined (Bayer et al., 1983; Lynd et al., 2002; Wang et al., 2013; Dumitrache et al., 2013). It is hypothesized that one reason for efficient $C$. thermocellum attachment to cellulosic substrates is due to it enzymatic and cell-bound complex called the cellulosome (Lynd et al., 2002). However, since $T$. saccharolyticum does not contain this enzymatic complex, its attachment to carbon material was questionable. Furthermore, understanding the degree of binding for this hemicellulosic bacterium in co-culture with $C$. thermocellum can provide more insight in the colonization competition and overall spatial distribution of these two thermophiles.

Figure 3.5 shows confocal microscopy results that were obtained from four separate continuous-flow experiments where $T$. saccharolyticum's binding ability to cellulosic and lignocellulosic (both substrates stained with Syto9 with WGA-AF633) materials were tested in monoculture and in consortium. Figure 3.5A and Figure 3.5C present T. saccharolyticum images on cotton and switchgrass, respectively. To note, cotton fibre was used as a cellulosic substrate for all continious-flow experiments due to its high cellulose content and its ability to pack well into a flowcell reactor. Moving on, in both examples (cotton and switchgrass) it can be noticed that this thermophile only partially binds to the carbon substrates. Figure $3.5 \mathrm{C}$ indicates the bacterium's accumulation in the regions between switchgrass fibres. There are few cells visible on the lignocellulosic material, however in much smaller numbers than C. thermocellum. Similar 
results can be seen in Figure 3.5A on cotton material where the fibres are only partially colonized by $T$. saccharolyticum cells when compared to full colonization in the case of the cellulosic C. thermocellum (Dumitrache et al., 2013). These results show that in consortium $T$. saccharolyticum should not be of significant competition for substrate colonization and thus should not interfere with $C$. thermocellum's ability to hydrolyze carbon sources.

C. thermocellum and T. saccharolyticum in co-culture on cellulosic material and lignocelluosic material can be viewed in Figure 3.5B and 3.5D, respectively. Research in the past has demonstrated that $C$. thermocellum is capable of fully colonizing cellulosic (Dumitrache $e t$ al., 2013) material; however, similar research with lignocellulosic substrate is very limited in literature so far. The two confocal images show that $C$. thermocellum has likely colonized both cotton fibre and switchgrass (indicated by the orange arrow) and T. saccharolyticum can be seen in the background (indicated by the blue arrow). The $T$. saccharolyticum strain can be identified by its elongated shape and interlinking appearance in the empty regions of the objective field (as described in previos morphology experiment as well). These results provide significant information to the spatial distribution between the two thermophiles. Knowing that $T$. saccharolyticum does not significantly interfere with the actions of hydrolyzing $C$. thermocellum, it can be proposed that $T$. saccharolyticum will likely utilize the metabolites produced by $C$. thermocellum for subsequent fermentation.

These results support the suggested role of cellulose-binding modules within the cellulosome complex in $C$. thermocellum and its role in forming cellulose-enzyme-microbe (CEM) complex. The cellulosome complex is indeed vital for the adherence of this thermophile to cellulosic and lignocellulosic material. Further research on cellular signalling and CEM 
interaction with cellulose itself needs to be performed in order to completely understand microbe attachment to carbon substrates.

\section{T. saccharolyticum DSM 7060 physiology test}

Due to the lack of published research on DSM 7060 strain, it was an objective to perform experiments to assess the extent of carbon metabolism and sugar utilization preferences for this hemicellulolytic thermophile. Figure 3.6 shows the results of three separate batch system experiments on $5 \mathrm{~g} / \mathrm{L}$ xylose and $5 \mathrm{~g} / \mathrm{L}$ cellobiose (with $2 \mathrm{~g} / \mathrm{L}$ yeast extract) as the main carbon sources, in both monoculture and co-culture with $C$. thermocellum. These findings provided a further look into variability of Thermoanaerobacterium spp. ethanol yield on different sugar substrates. In monoculture DSM 7060 strain produced $3.6 \mathrm{mM}$ of ethanol, compared to literature where $0.46 \mathrm{mM}$ of ethanol was generated in mutant strain T. saccharolyticum JW/SL-YS485 ALKI on the same sugar supplement (Bardsley et al., 2008), $1.35 \mathrm{mM}$ of ethanol in $T$. saccharolyticum HKO7 ( $\Delta$ hfs $\Delta l d h$ ) on $10 \mathrm{~g} / \mathrm{L}$ glucose (Shaw et al., 2009), and $5.5 \mathrm{mM}$ of ethanol in Thermoanaerobacterium strain DSM 18780 inoculated with $10 \mathrm{~g} / \mathrm{L}$ cellobiose (Almarsdottir et al., 2011).

In addition to presenting the degree of ethanol yield in DSM 7060 strain, Figure 3.6 also shows whether or not carbon catabolite repression (see section 2.11) plays any significant role in co-culture with the hexose-only fermenting bacterium, C. thermocellum. As mentioned earlier, a microorganism preferring one type of sugar to the other can become an issue of competition in particular co-culture (Görke and Stülke, 2008). However, physiology test of DSM 7060 strain hint that carbon catabolite repression does not play a significant role in a medium with both hexose and pentose sugars since this strain is capable of fermenting both sugars simultaneously. 
In other words, it is able to co-utilize all sugars without serious competition with $C$.

thermocellum. Therefore, T. saccharolyticum DSM 7060 is a valuable co-culture partner for $C$. thermocellum in increasing ethanol yield. This increase can be seen in Figure 3.6 co-culture batch experiment with an overall ethanol production of $4.89 \mathrm{mM}$, an improvement in yield by approximately $23.2 \%$ compared to $C$. thermocellum monoculture (ethanol yield of $3.97 \mathrm{mM}$ ). Last, it should be noted that due to a $\mathrm{pH}$ drop from $\sim 6.5$ to 6.13 in co-culture (caused by the production of acid by-products), it is likely that $C$. thermocellum levels have dropped which might explain the high concentrations of cellobiose $(6.59 \mathrm{mM})$ in the batch system. The latter issue is not present with continuous-flow systems, due to constant culture media replenishment at a dilution rate of $\sim 10 \mathrm{~mL} / \mathrm{hour}$.

\section{Competition vs. cooperation interaction: Real-time PCR analysis}

Quantitative PCR results of continuous-flow experiments can be seen in Figure 3.7 ( $C$. thermocellum on cotton), Figure 3.8 (C. thermocellum on switchgrass), Figure 3.9 (Co-culture on cotton), and Figure 3.10 (Co-culture on switchgrass). This experimental analysis was performed to describe the degree of competition vs. cooperation between the cellulolytic and hemicellulolytic bacteria. Due to the use of minimal yeast extract at day 4 and day 6 , this experiment was to test whether or not $T$. saccharolyticum is truly capable of utilizing $C$. thermocellum metabolites, and as a result generate more ethanol.

Yeast extract is a complex nutrient source that includes carbon, vitamins, nitrogen, and various amino acids that are often used to cultivate different cellulolytic and ethanologenic microorganisms (Ronan, 2011). However, due to the high cost and extraneous steps used to produce yeast extract, its use in consolidated bioprocessing industry will be uneconomical 
(Maddipati et al., 2011). Thus, one of the goals to improving consolidated bioprocessing is to progress away from yeast supplemented culture media (Lynd et al., 2005).

Specific primer and probe construction of each strain used has enabled the development of PCR analysis in real-time to quantify DNA concentrations of one or both strains over a course of 6 days (sampled every two days). For all four experiments, the idea was to obtain a successful growth for the first two days with high carbon supplement (HCS) medium (high amount of yeast extract and sugar additives) and then switch the medium to low carbon supplement (LCS) medium (minimum yeast extract required for growth and no sugar additives) for the next four days. Minimum yeast extract of $0.3 \mathrm{~g} / \mathrm{L}$ was used for LCS medium since research in the past has demonstrated that is the minimal amount required for sufficient $C$. thermocellum growth.

The continuous-flow experiment where $C$. thermocellum monoculture was inoculated in a flowcell reactor filled with 0.13 grams of dry commercial cotton (Figure 3.7) shows that qPCR results for day 2, HCS medium, contains highest amount of $C$. thermocellum with a DNA concentration of $408 \mathrm{ng} / \mu \mathrm{L}$. Once the medium was switched to LCS, this DNA concentration value dropped to $355 \mathrm{ng} / \mu \mathrm{L}$ at day 4 , which is a decrease of $\sim 13.0 \%$. It is clear that high yeast extract and sugar supplement does play an important part in sustaining C. thermocellum numbers. The amount of high carbon supplement being introduced into the reactor was greater than the amount of sugar being hydrolyzed and metabolized by C. thermocellum. However, tracking DNA concentration for the next two days shows a steady increase in C. thermocellum numbers at day 6 with a value of $378 \mathrm{ng} / \mu \mathrm{L}$ and an increase of $\sim 6.5 \%$ from day 4 . This steady increase hints that gradual C. thermocellum recovery is occurring and that this cellulolytic strain is perfectly capable of surviving on cotton fibre solubilisation alone, with little yeast extract and 
no sugar supplement necessary. This means that after four days under LCS medium, $C$.

thermocellum eventually starts to utilize cotton fibres at a rate that helps it flourish in numbers.

The second continuous-flow experiment was designed to grow $C$. thermocellum on 0.51 grams of unpretreated midseason lignocellulosic switchgrass (Figure 3.8). The flow reactor exposed to the medium with HCS for the first two days generated $C$. thermocellum DNA concentrations of $639 \mathrm{ng} / \mu \mathrm{L}$. This is a significant increase to the $C$. thermocellum numbers for the first two days on cotton. This may be due to the higher amount of carbon material present in this experiment $\sim 0.19$ grams of digestible cellulose present since switchgrass is composed of $\sim 37 \%$ cellulosic material (Kumar et al., 2011). Also, past research has shown that switchgrass hydrolysis is known to generate 4 times less cellobiose than hydrolysis of pure cellulose (Basen et al., 2014).This particular disaccharide has been known to inhibit cellulase activity and thus slow down the rate of cellulose breakdown (Johnson et al., 1982; Gruno et al., 2004; Teugjas and Väljamäe, 2013). More specifically, it is the exoglucanase (Cel S) and endoglucanse cellulase activity that is constrained by the presence of cellobiose (Demain et al., 2005). According to the research performed by Zhao et al. (2014), it is suggested that steric hindrance is created between cellobiose and tryptophan residue that is located near the active site of cellobiohydrolase, which blocks cellulose fibre from binding to active site of cellulase. Thus, microbe abundance is known to increase under low cellobiose concentrations. Furthermore, much like in day 4 of the cotton results, after the medium has been switched to LCS, the DNA concentration of $C$. thermocellum dropped down by $\sim 20.3 \%$ to $509 \mathrm{ng} / \mu \mathrm{L}$. Although, unlike the results seen in experiment one, day 6 results showed a smaller increase in DNA concentration of $\sim 3.8 \%$ with $528.3 \mathrm{ng} / \mu \mathrm{L}$. One explanation for such outcome may be due to the more robust nature of lignocellulosic material (see chapter 2). Since lignin is considered harder to digest due to the strong polymer bonds that 
keep it in place, cellulosomes have a tougher time breaking them apart (Sanderson, 2011). In addition, due to a lowered carbon supplement, energy for the recovery in numbers is also diminished.

The third continuous-flow experiment included both $C$. thermocellum and $T$. saccharolyticum in co-culture on 0.13 grams of dry commercial cotton (Figure 3.9). The $C$. thermocellum DNA concentration after two days of HCS medium resulted in $591.8 \mathrm{ng} / \mu \mathrm{L}$ and $T$. saccharolyticum DNA concentration of $578.6 \mathrm{ng} / \mu \mathrm{L}$. There is an abundant increase in DNA concentration when comparing co-culture concentrations to $C$. thermocellum monoculture at day 2. The reason for this increase in numbers seems somewhat unclear; however, one possible explanation may be due to lowering of inhibitory effects caused by cellobiose produced via hydrolysis of cotton (Table 3.4). The cellobiose concentration in C. thermocellum monoculture on cotton was $2.91 \mathrm{mM}$ and in co-culture on cotton was $1.58 \mathrm{mM}$. Thus, the presence of $T$. saccharolyticum may have added to the fermentation of cellobiose and thus faster elimination from the system. Day 4 LCS medium results for experiment 3 co-culture on cotton, showed a drop in numbers for both C. thermocellum and T. saccharolyticum, with concentrations of 463 $\mathrm{ng} / \mu \mathrm{L}$ (decrease of $21.8 \%$ ) and $122 \mathrm{ng} / \mu \mathrm{L}$ (decrease of $78.9 \%$ ) respectively. A greater drop in $C$. thermocellum's DNA concentration in co-culture compared to monoculture on cotton after the medium switch may be due to less efficient attachment on cotton. Figure 3.5 shows $T$. saccharolyticum is capable of partially colonizing cellulosic material. This partial colonization may have interfered with $C$. thermocellum's ability to recover.

There are different potential explanations for the drastic drop in T. saccharolyticum numbers. First, T. saccharolyticum is dependent on C. thermocellum's metabolism in LCS 
medium and thus a drop in $C$. thermocellum numbers would result in a drop in $T$.

saccharolyticum's numbers as well. Second, the physiology test in Figure 3.6 has shown that $T$. saccharolyticum prefers xylose slightly over cellobiose and thus the switch from $10 \mathrm{~g} / \mathrm{L}$ xylose to $0 \mathrm{~g} / \mathrm{L}$ xylose may have caused a nutritional strain to this hemicellulolytic bacterium. Day 6 concentrations resulted in a slight dip in numbers of $C$. thermocellum with a DNA concentration of $441.5 \mathrm{ng} / \mu \mathrm{L}$ (decrease of $\sim 4.6 \%$ from day 4 ) and $T$. saccharolyticum increase in abundance to $133.4 \mathrm{ng} / \mu \mathrm{L}$ (increase of $\sim 9.3 \%$ from day 4 ).

The continual decrease in $C$. thermocellum numbers by day 6 might have been caused by a minor carbon competition during nutritional limitation. In low carbon environments, $C$. thermocellum is producing carbon source for both itself and its T. saccharolyticum partner; however, due to T. saccharolyticum's faster metabolic rate (maximum specific growth rate of $0.37 \mathrm{~h}^{-1}$ ), it will tend to ferment more sugars produced than C. thermocellum does (Shaw et al., 2008). However, $C$. thermocellum should eventually reach a stable growth rate and the numbers will start to increase in co-culture as well. The fact that $T$. saccharolyticum DNA concentration has increased by approximately $9.3 \%$ shows that this strain is capable of successfully utilizing $C$. thermocellum's metabolites as the only carbon source.

The last continuous-flow experiment was a co-culture on 0.51 grams of switchgrass as the carbon feedstock (Figure 3.10). Here it can be seen that DNA concentrations of $C$. thermocellum and T. saccharolyticum under HCS medium at day 2 is $641 \mathrm{ng} / \mu \mathrm{L}$ and $315 \mathrm{ng} / \mu \mathrm{L}$, respectively. The numbers of $C$. thermocellum are very similar to the ones in monoculture on switchgrass $(639 \mathrm{ng} / \mu \mathrm{L})$, hinting no significant change. The abundance of $T$. saccharolyticum was lower than in day 2 of experiment 3 on cotton $(578.6 \mathrm{ng} / \mu \mathrm{L})$, possibly due to longer time for 
C. thermocellum to break the lignin structure apart and expose hemicellulosic material and digestible cellulose. Furthermore, once LCS was introduced, DNA concentrations of both strains have decreased to $543 \mathrm{ng} / \mu \mathrm{L}$ (drop of $15.3 \%$ ) in C. thermocellum and $73.5 \mathrm{ng} / \mu \mathrm{L}$ (drop of $77 \%$ )

in $T$. saccharolyticum at day 4 . The latter concentrations mimic those seen in day 4 in experiment 3 co-culture on cotton.

Last, in day 6 LCS medium C. thermocellum results appeared similar to those in experiment 3. The abundance of $C$. thermocellum DNA dropped only slightly to $524.4 \mathrm{ng} / \mu \mathrm{L}$ (decrease of 3.4\% from day 4). On the other hand, T. saccharolyticum DNA concentrations increased by a surprisingly $52 \%$ from day 4 to $112 \mathrm{ng} / \mu \mathrm{L}$ at day 6 . These findings suggest very efficient co-culture cooperation due to the fact that $T$. saccharolyticum has drastically increased in numbers over sugars produced by cellulolytic metabolism of $C$. thermocellum. The rapid increase in concentration of $T$. saccharolyticum DNA on switchgrass can be explained by the fast growth of this bacterium and introduction of pentose sugars from degradation of lignocellulosic switchgrass. Once more pentose sugars are available, T. saccharolyticum will lower its competition with $C$. thermocellum for hexose sugars. In addition, DNA concentrations of $C$. thermocellum should eventually increase over time because of this factor as well.

\section{Solid substrate hydrolysis and end product analysis}

The final bioethanol yield and other by-products of fermentation and hydrolysis can be examined in Figure 3.11, Table 3.3, and Table 3.4. Samples that have been collected from the four previously mentioned continuous-flow experiments for $\mathrm{qPCR}$ analysis were also used for HPLC investigation. For experiment 1 - C. thermocellum on cotton, ethanol productions at day 2 (HCS), day 4 (LCS), and day 6 (LCS) resulted in: $4.06 \mathrm{mM}, 3.64 \mathrm{mM}$, and $3.59 \mathrm{mM}$, 
respectively. These findings have confirmed those of qPCR in Figure 3.7 since they follow the similar pattern with DNA concentration values. Due to high number of carbon supplement at day 2, metabolic activity of this cellulolytic thermophile is at its peak and has produced highest amount of ethanol. Trace amounts of acetate and lactate were also present at day 2 and day 6 . Day 2 has generated a surprising amount of formate $(6.78 \mathrm{mM})$, which was uncommon in literature for $C$. thermocellum to produce formate at such high concentration on cellulosic materials (Patni and Alexander, 1971; Biswas et al., 2014). According to Sparling et al. (2006), the presence of $p f l$, fnr, and adhE genes in C. thermocellum ATCC 27405 strongly suggests that this bacterium is capable of utilizing catabolic pathway which involves pyruvate to acetyl-CoA + formate (Figure 2.1) and thus fluctuate in its formate production depending on environmental conditions. Once the $\mathrm{pH}$ drops below 6.5, formate producing gene, $p f l$, gets activated in $C$. thermocellum ATCC 27405 (Sparling et al., 2006).

Cellobiose concentrations have also varied from day $2(2.91 \mathrm{mM})$, day $4(3.50 \mathrm{mM})$, and day $6(3.26 \mathrm{mM})$. These values indicate a slight drop in cellobiose fermentation after the HCSto-LCS medium switch, which gradually picks up at day 6. Last, when it comes to the extent of solid substrate hydrolysis, experiment 1 has demonstrated that $C$. thermocellum was capable of degrading roughly $62 \%$ of the original solid cellulosic material over the 6-day incubation.

Experiment $2-C$. thermocellum monoculture on switchgrass has generated similar end product results to experiment 1 with few differences. In general, ethanol yield was greater on switchgrass over the course of six days: day $2(7.77 \mathrm{mM})$, day $4(6.31 \mathrm{mM})$, and day $6(6.27$ $\mathrm{mM})$. These numbers do follow similar DNA concentration pattern over the course of the experiment. Ethanol concentrations remained relatively constant from day 4 to day 6 due to 
similar DNA concentrations at these days, indicating metabolic activity did not drastically change. Ethanol to acetate ratios remained constant at 1:2.3 on average for all 3 samples with minimum lactate production, which compares to research performed in the past on lignocellulosic biomass (Yee et al., 2014). Research performed by Yee et al. (2014) also confirmed lower formate production on transgenic unwashed switchgrass feedstock. Furthermore, xylose concentrations of $4.44 \mathrm{mM}$ were only detected at day 2. Solid substrate hydrolysis has shown that $C$. thermocellum was able to degrade approximately $51 \%$ of the original switchgrass mass. Other research with Clostridia class bacteria have shown similar degradation rates on various other lignocellulosic substrates such as unpretreated, unwashed cornstalk (56\% mass loss), corn cob (63\% mass loss), and wheat straw (59\% mass loss) (Cao et al., 2014).

Experiment 3 - Co-culture on cotton have produced many different end products compared to monoculture. The increased DNA concentration of $C$. thermocellum with the addition of T. saccharolyticum has generated more ethanol yield in all 3 samples than $C$. thermocellum alone: day $2(4.86 \mathrm{mM})$, day $4(3.72 \mathrm{mM})$, and day $6(5.09 \mathrm{mM})$. Cellobiose concentration at day $2(1.58 \mathrm{mM})$ was $\sim 54.3 \%$ lower than in monoculture $(2.91 \mathrm{mM})$, which demonstrates co-culture with $T$. saccharolyticum enhanced fermentation of this sugar. Day 4 DNA concentrations showed a significant decrease in numbers for both C. thermocellum $(21.8 \%$ decrease) and $T$. saccharolyticum (78.1\% decrease) which help explain why there is virtually no cellobiose present at day 4 LCS medium because whatever little sugar has been hydrolyzed by $C$. thermocellum was instantaneously utilized by both strains due to increased partial competition for this sugar. Ethanol concentration dropped as well by $\sim 23.5 \%$. However, due to the higher $T$. saccharolyticum numbers at day 6, ethanol concentrations spiked by $35 \%$ (5.09 mM) exceeding 
the original $4.86 \mathrm{mM}$ from day 2. The latter results show that the hemicellulolytic $T$.

saccharolyticum is capable of utilizing cellulolytic $C$. thermocellum's metabolites and as a result raise ethanol production levels. Since there is no evidence that the genome of $T$. saccharolyticum contains a gene encoding for formate dehydrogenase and thus inability to produce formate as described by Shaw et al. (2008a), the levels of this end product have remained fairly unchanged compared to monoculture. Finally, comparing solid substrate hydrolysis with monoculture in experiment 1, it was demonstrated that there was a $13 \%$ increase in degradation of cotton once $T$. saccharolyticum was added. These results can be explained, once again, due to the increased abundance of $C$. thermocellum throughout the whole 6 day experimentation period.

Experiment 4 - Co-culture on switchgrass ethanol production is: day 2 ( $8.95 \mathrm{mM})$, day 4 (3.80 mM), and day $6(4.53 \mathrm{mM})$. Compared to monoculture on switchgrass, ethanol yield followed a similar pattern with a drop following HCS-to-LCS medium switch; however, at day 6 there was a significant increase in ethanol (by 16.1\%) in co-culture. As seen in co-culture on cotton, there was a notable increase in T. saccharolyticum DNA concentration (increase by $53 \%$ ), which resulted in a more rapid fermentation and ethanol recovery overall. Lactate levels remained minimal and formate concentration showed similar fluctuations as seen in monoculture on switchgrass. However, due to the presence of xylose (generated from $C$. thermocellum's hydrolysis of lignocellulose) there was less competition for sugar between the two thermophiles and hence there was more cellobiose present in the day 6 sample. Moreover, hydrolysis of solid switchgrass by monoculture and co-culture mimic those on cotton in a sense that there is more degradation recorded with co-culture ( $8 \%$ increase). Relative DNA concentration of $C$. thermocellum was higher in co-culture than monoculture, which can be expected to lead to increased hydrolysis. 


\section{Concluding remarks}

Naturally occurring microbial ecosystems, changed and revised constantly through evolution, are almost exclusively composed of communities or (also known as) consortia (Bernstein and Carlson, 2012). These mixed communities can be found in a wide range of environmental conditions and can metabolize various complex organic substrates that, as a result, convert these substrates into useful forms of energy. A common consortial interaction strategy uses cooperative measures through division of labour (Crespi, 2001; Briones and Raskin, 2003). This division of labour permits lateral or sequential processing of substrates and can generally be considered as enhancing productivity and nutrient (carbon) recycling (Bernstein and Carlson, 2012). The carbon flow through the biosphere serves as an energy transfer between community members in a non-competitive manner that is established on metabolic functionality (Bernstein and Carlson, 2012). This template enables parallel processing of carbon substrates and can in turn be used to develop a consortium that is capable of simultaneously fermenting various types of sugars.

In principle, it is possible to take advantage of these microbial consortia and apply their metabolic capabilities to some of the problems relating to urban, agricultural, and industrial waste. Landfill space to manage this waste is become evermore limiting and expensive (Demain et al., 2005). Thus a potential solution to this problem is the microbial conversion of biomass into alternative energy source such as ethanol. This study has shown that using cellulolytic $C$. thermocellum in co-culture with hemicellulolytic $T$. saccharolyticum, with low carbon supplement, can increase the levels of carbon substrate hydrolysis and ethanol production as a result. Furthermore, the lack of $T$. saccharolyticum's substrate attachment and the lack of 
metabolic competition between the two thermophiles suggest this co-culture can be a valuable consortium for improving second generation biofuel production.

In conclusion, a remaining challenge is that the natural processes found in microbial ecosystems are typically slow compared to those required in industrial bioprocesses, and therefore further research is necessary to eventually have improved control over these processes but at a much faster and efficient rate. 


\section{CHAPTER 4: OVERALL CONCLUSIONS AND FUTURE WORK}

Due to a finite nature of fossil fuels, there is a growing demand for a more sustainable energy source alternative. Bio-ethanol production from CBP technology has been presented as a viable and more environmentally friendly solution. However, efforts in improving this biotechnology and hence increase levels of bioethanol production are still necessary to maximize its economical effectiveness.

The results of this study suggested that the metabolic relationship between $C$.

thermocellum and T. saccharolyticum can contribute to higher ethanol yield and the dynamics of their interaction can be used to further enhance CBP technology. Revisiting the objectives; cell morphology has shown that $T$. saccharolyticum DSM 7060 is generally 3 times larger than $C$. thermocellum and due to this visible morphological difference assessment of monoculture and co-culture physical substrate attachment was possible. The hemicellulolytic organism has shown poor adherence to both cellulosic and lignocellulosic substrates and thus the majority of its sugar utilization does not necessarily depend on direct (physical) contact with the carbon structures. The lack of interaction between $T$. saccharolyticum and carbon material does not influence hydrolysis rates and does confirm cellulosome-directed binding in the case of cellulolytic microbes such as $C$. thermocellum. In addition, $C$. thermocellum is capable of attaching to lignocellulosic material such as switchgrass in a similar fashion as to cellulosic cotton substrates. The relative numbers of the two strains in co-culture when cultivated on cotton or switchgrass suggest that $T$. saccharolyticum is able to utilize sugar produced from $C$. thermocellum's hydrolysis and eventually increase the production of ethanol and, potentially, hydrolysis of carbon material (due to increased fermentation of inhibiting cellobiose). Hydrolysis rates of both 
cellulosic and lignocellulosic material were increased in co-culture experiments. Overall, these results revealed the potential, and need for future work to optimize lignocellulose-to-ethanol conversions. Topics that should be considered for future research include the following:

\section{Co-culture research involving other lignocellulosic substrates}

It is also important to analyze how C.thermocellum and $T$. saccharolyticum interact on other forms of lignocellulosic sources. The results obtained from switchgrass can be used to test the limits of bio-ethanol production and cellulosic hydrolysis on other promising substrates such as corn stover, Miscanthus grass species, wood chips, and municipal waste. For example, Miscanthus giganthus has shown average annual harvestable yields of 45 tonnes per hectare, compared to annual yield of 19.8 tonnes per hectare for switchgrass (Heaton et al., 2008). Thus, it would be interesting to see the comparison between switchgrass and $M$. giganthus with respect to cellulose utilization and bio-ethanol production.

\section{Genetically modified switchgrass}

Research performed by Shen et al. (2013) has demonstrated that overexpression of transcription factor PvMYB4 can reduce carbon deposition into lignin and increase levels of anaerobic thermophilic ethanol production by 2.6-fold. In addition, a study by Yee et al. (2014) has shown that downregulation of the caffeic acid O-methyl transferase (COMT) gene reduced lignin content and increased the $\mathrm{S} / \mathrm{G}$ ratio. Using $C$. thermocellum in their experiments, this group showed a $90 \%$ increase in ethanol yield compared to the wild-type switchgrass. Hence, future research on genetically modified switchgrass with $C$. thermocellum and $T$. saccharolyticum in co-culture may reveal interesting new possibilities. 


\section{Lignin utilization}

A recent study by Beauchet et al. (2012) showed that it is possible to convert 10 to $20 \%$ of lignin by weight into value added products such as catechol, guaiacol, and other phenolic compounds used for bioplastic production. In addition, it was also shown that it is possible to convert part of lignin into a desirable hydrocarbon fuel such as Jet A-type fuels used in the aviation industry (Shabtai et al., 1998). Therefore, further analysing the availability of switchgrass's lignin conversion into desirable end products may lead to more financially feasible processes.

\section{Bio-hydrogen production}

Previous studies have shown that co-culture research has a great potential to increase the production of bio-hydrogen (Weimer and Zeikus, 1977; Liu et al., 2008; Geng et al., 2010). The study performed by Liu and colleagues showed that $C$. thermocellum JN4 strain and Thermoanaerobacterium thermosaccharolyticum GD17 strain, when placed in co-culture on microcrystalline cellulose, caused bio-hydrogen production to increases about 2-fold (from 0.8 $\mathrm{mol} \mathrm{H}_{2}$ to $1.8 \mathrm{~mol} \mathrm{H}_{2}$ ) (Liu et al., 2008). Understanding the nature of this interaction can aid in developing more effective methods to further increase the levels of bio-hydrogen yield.

\section{Solid, liquid, and gas phase carbon utilization in co-culture}

The use of $C$. thermocellum and $T$. saccharolyticum in this study has provided insight on the extent of solid substrate hydrolysis on both cellulose and lignocellulose material. Future research can be open to analyzing the total metabolic activity, including liquid and gas phase carbon. This study would help contribute to determining how much carbon is actually being utilized and provide further insight into the extent of carbon balance analysis in consortium. 


\section{REFERENCES}

Akinosho, H., Yee, K., Close, D., and Ragauskas, A. (2014). The emergence of Clostridium thermocellum as a high utility candidate for consolidated bioprocessing applications. Frontiers in Chemistry. 2:66.

Almarsdottir, A. R., Sigurbjornsdottir, M. A., and Orlygsson, J. (2011). Effects of various factors on ethanol yields from lignocellulosic biomass by Thermoanaerobacterium AK17. Biotechnology and Bioengineering. 109:686-694.

Altaras, N. E., Etzel, M. R., and Cameron, D. C. (2001). Conversion of sugars to 1, 2propanediol by thermoanaerobacterium thermosaccharolyticum HG-8. Biotechnology Progress. 17:52-56.

Anderson, S. T., and Sallee, J. M. (2011). Using loopholes to reveal the marginal costs of regulation: the case of fuel-economy standards. American Economic Review. 101:1375-1409.

Antizar-Ladislao, B., and Turrion-Gomez, J. L. (2008). Second-generation biofuels and local bioenergy systems. Biofuels, Bioproducts, and Biorefineries. 2:455-469.

Argyros, D. A., Tripathi, S. A., Barrett, T. F., Rogers, S. R., Feinberg, L. F., Olson, D. G., Foden, J. M., Miller, B. B., Lynd, L. R., Hogsett, D. A., and Caiazza, N. C. (2011). High ethanol titers from cellulose using metabolically engineered thermophilic, anaerobic microbes. Applied and Environmental Microbiology. 77:8288-8294.

Bai, F. W., Anderson, W. A., and Moo-Young, M. (2008). Ethanol fermentation technologies from sugar and starch feedstocks. Biotechnology Advances. 26:89-105.

Baldan, B., Andolfo, P., Navazio, L., Tolomio, C., and Mariani, P. (2001). Cellulose in algal cell wall: an "in situ" localization. European Journal of Histochemistry. 45:51-56.

Barber, J. (2008). Photosynthetic energy conversion: natural and artificial. RSC Publishing. 38:185-196.

Bardsley, J., Desai, S. G., Hogsett, D. A., Lynd, L. R., Podkaminer, K., Shaw, A. J., and Tyurin, M. V. (2008). U.S. Patent No. WO2007130984A9. Cambridge, MA: USA.

Bartle, J. R., and Abadi, A. (2010). Toward sustainable production of second generation bioenergy feedstocks. Energy and Fuels. 24:2-9.

Basen, M., Rhaesa, A. M, Kataeva, I., Prybol, C. J., Scott, I. M., Poole, F. L., and Adams, M. W. (2014). Degradation of high loads of crystalline cellulose and of unpretreated plant biomass by the thermophilic bacterium Caldicellulosiruptor bescii. Bioresource Technology. 152:384-392. 
Bayer, E. A., Chanzy, H., Lamed, R., and Shoham, Y. (1998). Cellulose, cellulases and cellulosomes. Current Opinions in Structural Biology. 8:548-557.

Bayer, E. A., Kenig, R., and Lamed, R. (1983). Adherence of Clostridium thermocellum to cellulose. Journal of Bacteriology. 156:818-827.

Bayer, E. A., and Lamed, R. (1986). Ultrastructure of the cell surface cellulosome of Clostridium thermocellum and its ineraction with cellulose. Journal of Bacteriology. 167:828-836.

Bayer, E. A., Morag, E., and Lamed, R. (1994). The cellulosome - a treasure- trove for biotechnology. Trends Biotechnology. 12:379-386.

Beauchet R., Monteil-Rivera F., and Lavoie J. M.(2012). Conversion of lignin to aromatic-based chemicals (L-chems) and biofuels (L-fuels). Bioresource Technology. 121:328-334.

Bernstein, H. C., and Carlson, R. P. (2012). Microbial consortia engineering for cellular factories: in vitro to in silico systems. Computational and Structural Biotechnology Journal. 3:112.

Biswas, R., Prabhu, S., Lynd, L. R., and Guss, A. M. (2013). Increase in ethanol yield via elimination of lactate production in an ethanol-tolerant mutant of Clostridium thermocellum. PLOS ONE. 9: e86389.

Briones, A., and Raskin, L. (2003). Diversity and dynamics of microbial communities in engineered environments and their implications for process stability. Current Opinion in Biotechnology. 14:270-276.

Brückner, R., and Titgemeyer, F. (2002). Carbon catabolite repression in bacteria: choice of the carbon source and autoregulatory limitation of sugar utilization. FEMS Microbiology Letters. 209:141-148.

Burkheisser, E. V. (2010). Biological barriers to cellulosic ethanol. New York, NY: Nova Scotia Publishers, Inc.

Burrell, P. C., O’Sullivan, C., Song, H., Clarke, W. P., and Blackall, L. L. (2004). Identification, detection, and spatial resolution of Closridium populations responsible for cellulose degradation in a methanogenic landfill leachate bioreactor. Applied and Environmental Microbiology. 70:2414-2419.

Bungay, R. R. (1982). Biomass refining. Science. 281:643-646.

Cao, G., Zhao, L., Wang, A., Wang, Z., and Ren, N. (2014). Single-step bioconversion of lignocellulose to hydrogen using novel moderately thermophilic bacteria. Biotechnol Biofuels. $7: 82$.

Carere, C. R., Sparling, R., Cicek, N., and Levin, D. B. (2008). Third generation biofuels via direct cellulose fermentation. International Journal of Molecular Sciences. 9:1342-1360. 
Carrard, G., Koivula, A., Soderlund, H., and Beguin, P. (2000). Cellulose-binding domains promote hydrolysis of different sites on crystalline cellulose. PNAS. 97:10342-10347.

Costa, R. C., and Sodre, J. R. (2010). Hydrous ethanol vs. gasoline-ethanol blend: Engine performance and emissions. Fuel. 89:287-293.

Crespi, B. J. (2001). The evolution of social behavior in microorganisms. Trends in Ecology and Evolution. 16:178-183.

Currie, D. H., Herring, C. D., Guss, A. M., Olson, D. G., Hogsett, D. A., and Lynd, L. R. (2013). Functional heterologous expression of an engineered full length CipA from Clostridium thermocellum and Thermoanaerobacterium saccharolyticum. Biotechnology for Biofuels. 6:3243.

Damartzis, T., and Zabaniotou, A. (2011). Thermochemical conversion of biomass to second generation biofuels through integrated process design. Renewable and Sustainable Energy Reviews. 15:366-378.

Dauenhauer, P. J., Dreyer, B. J., and Degenstein, N. J. (2007). Millisecond reforming of solid biomass for sustainable fuels. Angewandte Chemie International Edition. 46:5864-5867.

Davison, B. H., Drescher, S. R., Tuskan, G. A., Davis, M. F., and Nghiem, N. P. (2006). Variation of S/G ratio and lignin content in a Populus family influences the release of xylose by dilute acid hydrolysis. Applied Biochemistry and Biotechnology. 129: 427-435.

Demain, A. L., Newcomb, M., and Wu, J. H. (2005). Cellulase, clostridia, and ethanol. Microbiology and Molecular Biology Reviews. 69:124-154.

Ding, S. Y., Bayer, E. A., Steiner, D., Shoham, Y., and Lamed, R. (1999). A novel cellulosomal scaffoldin from Acetivibrio cellulolyticus that contains a family 9 glycosyl hydrolase. Journal of Bacteriology. 181:6720-6729.

Dror, T. W., Morag, E., Rolider, A., Bayer, E. A., Lamed, R., and Shoham, Y. (2003). Regulation of the cellulosomal celS (cel48A) gene of Clostridium thermocellum is growth rate dependent. Journal of Bacteriology. 185:3042-3048.

Dumitrache, A., Wolfaardt, G., Allen, G., Liss, S. N., and Lynd, L. R. (2013). Form and function of Clostridium thermocellum biofilms. Applied and Environmental Microbiology. 79:231-239.

Evans, J. (1999). Call out the reserves. Chemistry in Britain. 35:38-41.

Fike, J. H., Parrish, D. J., Wolf, D. D., Balasko, J. A., Green, J. T., Rasnake, M., and Reynolds, J. H. (2005). Long-term yield potential of switchgrass-for-biofuel systems. Biomass and Bioenergy. 3:198-206. 
Garcia-Alvarez, B., Melero, R., Dias, M. V., Prates, A. M., Fontes, C., Smith, S. P., Romao, M. J., Carvalho, A. L, and Llorca, O. (2011). Molecular architecture and structural transitions of a Clostridium thermocellum mini-cellulosome. Journal of Molecular Biology. 407:571-580.

Geng, A., He, Y., Qian, C., Yan, X., and Zhou, Z. (2009). Effect of key factors on hydrogen production from cellulose in a co-culture of Clostridium thermocellum and Clostridium thermopalmarium. Bioresource Technology. 101:4029-4033.

Görke, B., and Stülke, J. (2008). Carbon catabolite repression in bacteria: many ways to make the most out of nutrients. Nature Reviews Microbiology. 6:613-624.

Gruno, M., Väljamäe, P., Pettersson, G., and Johansson, G. (2004). Inhibition of the Trichoderma reesei cellulases by cellobiose is strongly dependent on the nature of the substrate. Biotechnology and Bioengineering. 86:503-511.

Hameed, S., and Dignon, J. (1992). Global Emissions of Nitrogen and Sulfur Oxides in Fossil Fuel Combustion 1970-1986. Journal of the Air and Waste Management Association. 42:159163.

He, Q., Hemme, C. L., Jiang, H., He, Z., and Zhou, J. (2011). Mechanisms of enhanced cellulosic bioethanol fermentation by co-cultivation of Clostridium and Thermoanaerobacter spp. Bioresource Technology. 102:9586-9592.

Heaton, E. A., Dohleman, F. G., and Long, S. P. (2008). Meeting US biofuel goals with less land: the potential of Miscanthus. Global Change Biology. 14:2000-2014.

Hilz, H., de Jong, L. E., Kabel, M. A., Verhoef, R., Schols, H. A., and Voragen, A. (2007). Billberry xyloglucan - novel building blocks containing $\beta$-xylose within a complex structure. Carbohydrate Research. 342:170-181.

Himmel, M. E., Ding, S. Y., Johnson, D. K., Adney, W. S., Nimlos, M. R., Brady, J. W., and Foust, T. D. (2007). Biomass recalcitrance: engineering plants and enzymes for biofuel production. Science. 315:804-807.

Igboanugo, A. C., Ajieh, M. U., and Eloka-Eloka, A. C. (2013). Potential for biomass perennial grass as alternative to fuel wood in Niger Delta Region of Nigeria. International Journal of Scientific and Engineering Research. 4:2178-2186.

Inderwildi, O. R., and King, D. A. (2009). Quo vadis biofuels? Energy and Environmental Science. 2:343-346.

International Energy Agency (IEA). (2002). Renewables in global energy supply. Paris, France. Available at http://www.iea.org. 
International Energy Agency (IEA). (2010). Sustainable production of second-generation biofuels. Paris, France. Available at http://www.iea.org.

Jiang, H., He, Q., He, Z., Hemme, C. L., Wu, L., and Zhou, J. (2013). Continuous cellulosic bioethanol fermentation by cyclic fed-batch co-cultivation. Applied and Environmental Microbiology. 79:1580-1589.

Johnson, E. A. (1983). Regulation of cellulase activity and synthesis in Clostridium thermocellum. Ph.D. thesis. Massachusetts Institute of Technology, Cambridge, Mass.

Johnson, E. A., Reese, E. T., and Demain, A. L. (1982). Inhibition of C. thermocellum cellulase by end products of cellulolysis. Journal of Applied Biochemistry. 4:64-71.

Jung, G. A., Shaffer, J. A., Stout, W. L., and Panciera, M. T. (1990). Warm season grass diversity in yield, plant morphology, and nitrogen concentration and removal in the Northeastern USA. Agronomy Journal. 82:21-26.

Kakiuchi, M., Isui, A., Suzuki, K., Fujino, T., Fujino, E., Kimura, T., Karita, S., Sakka, K., and Ohmiya, K. (1998). Cloning and DNA sequencing of the genes encoding Clostridium josui scaffolding protein CipA and cellulose CelD and identification of their gene products as major components of the cellulosome. Journal of Bacteriology. 180:4303-4308.

Kallos, E., and Apostolopoulou, T. (2007). Cellulosic ethanol and the future of biofuels: from carbohydrates to hydrocarbons. University of Southern California.

Kamm, B., Gruber, P. B., and Kamm, M. (2006). Biorefineries - industrial processes and products. Weinheim, Germany: WILEY-VCH.

Kent, P. (2013). Switchgrass could produce more ethanol than corn. Clemson University.

Kephart, K. D., Buxton, D. R., Taylor, E. S. (1992). Growth of C3 and C4 perennial grasses under reduced irradiance. Crop Science. 32:1033-1038.

Kepner, R. L, and Pratt, J. R. (1994). Use of fluorochromes for direct enumeration of total bacteria in environmental samples: past and present. Microbiology and Molecular Biology Reviews. 58:603-615.

Khalil, M., and Rasmussen, R. (1989). Climate-induced feedbacks for the global cycles of methane and nitrous oxides. Tellus. 41:554-559.

Kim, C. H. (1995). Characterization and Substrate Specificity of an Endo-b-1,4-D-Glucanase I (Avicelase I) from an Extracellular Multienzyme Complex of Bacillus circulans. Applied and Environmental Microbiology. 61:959-965.

Koonin, S. E. (2006). Getting serious about biofuels. Science. 311: 435. 
Kumar, M., Goyal, Y., Sarkar, A., and Gayen, K. (2011). Comparative economic assessment of ABE fermentation based on cellulosic and non-cellulosic feedstocks. Applied Energy. 93:193204.

Lacis, L. S., and Lawford, H. G. (1991). Thermoanaerobacter ethanolicus growth and product yield from elevated levels of xylose or glucose in continuous cultures. Applied and Environmental Microbiology. 57:579-585.

Lal, R. (2005). World crop residues production and implications of its use as a biofuel. Environmental International. 31:575-584.

Lamed, R., and Bayer, E. A. (1988). The cellulosome of Clostridium thermocellum. Rehovot, Israel. The Weizmann Institute of Science.

Lamed, R., Setter E., and Bayer, E. A. (1983). Characterization of cellulose-binding, cellulosecontaining complex in Clostridium thermocellum. Journal of Bacteriology. 156:828-836.

Lavoie, J. M., Marie-Rose, S., and Lynch, D. (2012) Non-homogeneous residual feedstocks to biofuels and chemicals via the methanol route. Biomass Conversion and Biorefinery. 3:39-44.

Lee, R. A., and Lavoie, J. M. (2013). From first to third generation biofuels: challenges of producing a commodity from a biomass of increasing complexity. Animal Frontiers. 3:6-11.

Lee, Y. E., Jain, M. K., Lee, C., Lowe, S. E., and Zeikus, G. J. (1993). Taxonomic Distinction of Saccharolytic Thermophilic Anaerobes: Description of Thermoanaerobacterium xylanolyticum gen. nov., sp. nov., and Thermoanaerobacterium saccharolyticum gen. nov., sp. nov. ; Reclassification of Thermoanaerobium brockii, Clostridium thermosulfurogenes, and Clostridium thermohydrosulfiricum ElO0-69 as Thermoanaerobacter brockii comb. nov., Thermoanaerobacterium thermosulfurigenes comb. nov., and Thermoanaerobacter thermohydrosulfuricus comb. nov., Respectively; and Transfer of Clostridium thermohydrosulfuricum 39E to Thermoanaerobacter ethanolicus. International Journal of Systematic Bacteriology. 43:41-51.

Lehmann, D., and Lutke-Eversloh, T. (2011). Switching Clostridium acetobutylicum to an ethanol producer by disruption of the butyrate/butanol fermentative pathway. Metabolic Engineering. 13:464-473.

Lewandowski, I., Sculock, J. M. O., Lindvall, E., and Christou, M. (2003). The development and current status of perennial rhizomatous grasses as energy crops in the US and Europe. Biomass Bioenergy. 25:335-361.

Lima, C. F., Barbosa, L. C. A., Marcelo, C. R., Silverio, F. O., and Colodette, J. L. (2008). Comparison between analytical pyrolysis and nitrobenzene oxidation for determination of syringyl/guaiacyl ratio in Eucalyptus spp. lignin. Bioresources. 3:701-712. 
Limayem, A., and Ricke, S. C. (2012). Lignocellulosic biomass for bioethanol production: current perspectives, potential issues and future prospects. Progress in Energy and Combustion Science. 38:449-467.

Linger, J., and Darzins, A. (2013). Consolidated bioprocessing. In J.W Lee (Eds.), Advanced biofuels and bioproducts (pp.267-280). Norfolk, VA: Springer.

Liu, X., Kim, C. N., Yang, J., Jemmerson, R., and Wang, X. (1996). Induction of apoptotic program in cell-free extracts: requirement for datp and cytochrome c. Cell. 86:147-157.

Liu, Y., Yu, P., Song, X., and Qu, Y. (2008). Hydrogen production from cellulose by co-culture of clostridium thermocellum jn4 and thermoanaerobacterium thermosaccharolyticum gd17. Science Direct. 3:2927-2933.

Lu, Y., Zhang, Y. P., and Lynd, L. R. (2006). Enzyme-microbe synergy during cellulose hydrolysis by Clostridium thermocellum. PNAS. 103:16165-16169.

Lynd, L. R., Grethlein, H. E., and Wolkin, R. H. (1989). Fermentation of cellulosic substrates in batch and continuous culture by Clostridium thermocellum. Applied and Environmental Microbiology. 55:3131-3139.

Lynd, L. R., Laser, M. S., Bransby, D., Dale, B. E., Davison, B., Hamilton, R., Himmel, M., Keller, M., McMillan, J. D., Sheehan, J., and Wyman, C. E. (2008). How biotech can transform biofuels. Nature Biotechnology. 26:169-172.

Lynd, L. R., Van Zyl, W. H., McBride, J. E., and Laser, M. (2005). Consolidated bioprocessing of cellulosic biomass: an update. Current Opinion on Biotechnology. 16:577-583.

Lynd, L. R., Weimer, P. J., Van Zyl, W. H., and Pretorius, I. S. (2002). Microbial cellulose utilization: fundamentals and biotechnology. Microbiology and Molecular Biology Reviews. 66:506-577.

Maddipati, P., Atiyeh, H. K., Bellmer, D. D., and Huhnke, R. L. (2011). Ethanol production from syngas by Clostridium strain P11 using corn steep liquor as a nutrient replacement to yeast extract. Bioresource Technology. 102:6494-6501.

Maki, M., Leung, K. T., and Qin, W. (2009). The prospects of cellulase-producing bacteria for the bioconversion of lignocellulosic biomass. International Journal of Biological Sciences. 5:500-516.

Mazzoli, R. (2012). Development of microorganisms for cellulose-biofuel consolidated bioprocessings: metabolic engineers' tricks. Computational and Structural Biotechnology Journal. 3:19. 
Mechaly, A., Fierobe, H. P., Belaich, A., Belaich, J. P., Lamed, R., Shoham, Y., and Bayer, E. A. (2001). Cohesin-dockerin interaction in cellulosome assembly: a single hydroxyl group of a dockerin domain distinguishes between non-recognition and high affinity recognition. Journal of Biological Chemistry. 276:9883-9888.

Molinier, A. L., Nouailler, M., Valette, O., Tardif, C., and Receveur-Bréchot, V. (2011). Synergy, structure and conformational flexibility of hybrid cellulosomes displaying various inter-cohesins linkers. Journal of Molecular Biology 405: 143-157.

Monti, A. (2012). Switchgrass: a valuable biomass crop for energy. Bologna, Italy: Springer.

Morag, E., Lapidot, A., Govorko, D., Lamed, R., Wilchek, M., Bayer, E. A., and Shoham, Y. (1995). Expression, purification, and characterization of the cellulose-binding domain of the scaffoldin subunit from the cellulosome of Clostridium thermocellum. Applied and Environmental Microbiology. 61:1980-1986.

Morris, R. J., Fox, R. H., and Jung, G. A. (1982). Growth, P uptake, and quality of warm and cool season grasses on a low available P soil. Agronomy Journal. 74:125-129.

Naik, S.N., Goud, V.V., Rout, P. K., and Dalai, A. K. (2010). Production of first and second generation biofuels: a comprehensive review. Renewable and Sustainable Energy Reviews. 14:578597.

Ng, T. K., Ben-Bassat, A., and Zeikus, J. G. (1981). Ethanol production by thermophilic bacteria: fermentation of cellulosic substrates by co-cultures of Clostridium thermocellum and Clostridium thermohydrosulfuricum. Applied and Environmental Microbiology. 41:1337-1343.

Ng, T. K, and Zeikus, J. G. (1982). Differential metabolism of cellobiose and glucose by Clostridium thermocellum and Clostridium thermohydrosulfuricum. Journal of Bacteriology. 150:1391-1399.

Nolling, J., Breton, G., Omelchenko, M. V., Makarova, K. S., Zeng, Q., Gibson, R., Lee, H. M, Dubois, J., Qui, D., Hitti, J., Wolf, Y. I., Tatusoy, R. L., Sabathe, F., Doucette-Stamm, L., Soucaille, P., Daly, M. J., Bennett, G. N., Koonin, E. V., and Smith, D. R. (2001). Genome sequence and comparative analysis of the solvent-producing bacterium Clostridium acetobutylicum. Journal of Bacteriology. 183:4823-4838.

Norsker, M., Bloch, L., and Adler-Nissen, J. (1999). Enzymatic degradation of plant cell wall polysaccharides: the kinetic effect of competitive adsorption. Nahrung. 43:307-310.

Ohra-aho, T., Gomes, F. J. B., Colodette, J. L., and Tamminen, T. (2013). S/G ratio and lignin structure among Eucalyptus hybrids determined by Py-GC/MS and nitrobenzene oxidation. Journal of Analytical and Applied Pyrolysis. 101:166-171.

Olson, D. G., McBride, J. E., Shaw, J. A., and Lynd, L. R. (2012). Recent progress in consolidated bioprocessing. Current Opinion in Biotechnology. 23:396-405. 
Ozkan, M., Desai, S. G., Zhang, Y., Stevenson, D. M., Beane, J., White, E. A., Guerinot, M. L., Lynd, L. R. (2001). Characterization of 13 newly isolated strains of anaerobic, cellulolytic, thermophilic bacteria. Journal of Industrial Microbiology and Biotechnology. 27:275-280.

Pages, S., Belaich, A., Fierobe, H. P., Tardif, C., Gaudin, C., and Belaich, J. P. (1999). Sequence analysis of scaffolding protein CipA and ORFXp, a new cohesion-containing protein in Clostridium cellulolyticum: comparison of various cohesion domains and subcellular localization of ORFXp. Journal of Bacteriology. 181:1801-1810.

Parikka, M. (2004). Global biomass fuel resources. Biomass Bioenergy. 27:613-620.

Patni, N. J., and Alexander, J. K. (1971). Utilization of glucose by Clostridium thermocellum: presence of glucokinase and other glycolytic enzymes in cell extracts. Journal of Bacteriology. 105: $220-225$.

Patzek, T. W., Anti, S. M., Campos, R., Ha, K. W., Lee, J., Li, B., Padnick, J., and Yee, S. A. (2005). Ethanol from corn: clean renewable fuel for the future, or drain on our resources and pockets? Springer. 7:319-336.

Price, D. L., and Casler, M. D. (2014). Divergent selection for secondary traits in upland tetraploid switchgrass and effects on sward biomass yield. Bioenergy Research. 7:329-337.

Raman, B., McKeown, C. K., Rodriguez, M., Brown, S. D., and Mielenz, J. R. (2011). Trnascriptomic analysis of Clostridium thermocellum ATCC 27405 cellulose fermentation. BMC Microbiology. 11:134.

Rani, K. S., Swamy, M. V., Sunitha, D., Haritha, D., and Seenayya, G. (1996). Improved ethanol tolerance and production in strains of Clostridium thermocellum. World Journal of Microbiology and Biotechnology. 12:57-60.

Robertson, G. P, Hamilton, S. K., Del Grosso, S. J., and Parton, W. J. (2011). The biogeochemistry of bioenergy landscapes: carbon, nitrogen, and water considerations. Ecological Society of America Journals. 21:1055-1067.

Rodolfi, L., Zittelli, G. C., Bassi, N., Padovani, G., Biondi, N., Bonini, G., and Tredici, M. R. (2009). Microalgae for oil: strain selection, induction of lipid synthesis and outdoor mass cultivation in a low-cost photobioreactor. Biotechnology and Bioengineering. 120:100-112.

Ronan, P. (2011). Enriching and characterizing an aerotolerant mixed microbial community capable of cellulose hydrolysis and ethanol production. Master's Thesis. Ryerson University. Toronto, ON.

Rosillo-Calle, F. and Johnson, F. X. (2010). Food versus fuel: An informed introduction to biofuels. New York, NY: Zed Books. 
Rydzak, T., Levin, D. B., Cicek, N., and Sparling R. (2011). End-product induced metabolic shifts in Clostridium thermocellum ATCC 27405. Applied Microbiology and Biotechnology. 92:199-209.

Saddler, J. N., Chan, M. K., and Louis-Seize, G. (1981). A one step process for the conversion of cellulose to ethanol using anaerobic microorganisms in mono- and co-culture. Biotechnology Letters. 3:321-326.

Salimi, F., and Mahadevan, R. (2013). Characterizing metabolic interactions in clostridial co-culture for consolidated bioprocessing. BMC Biotechnology. 13:95.

Sanderson, K. (2011). Lignocellulose: a chewy problem. Nature. 474:12-14.

Scragg, A. (2009). Biofuels: Production, application, and development. Cambridge, MA: CABI.

Schmer, M. R., Vogel, K. P., Mitchell, R. B., and Perrin, R. K. (2007). Net energy of cellulosic ethanol from switchgrass. PNAS. 105:464-469.

Schwarz, W. H. (2001). The cellulosome and cellulose degradation by anaerobic bacteria. Applied Microbiology and Biotechnology. 56:634-649.

Shabtai, J., Zmierczak, W., Chornet, E. (1998). Process for conversion of lignin to reformulated hydrocarbon gasoline. The University of Utah Research Foundation.

Shafiee, S., and Topal, E. (2009). When will fossil fuel reserves be diminished?. Energy Policy. 37:181-189.

Shaw, J. A. (2008). Metabolic engineering of high yield ethanol production in Thermoanaerobacterium saccahrolyticum. PhD Dissertation. Dartmouth College. Hanover, NH.

Shaw, J. A., Hogsett, D. A., and Lynd, L. R. (2009). Identification of the [FeFe]-hydrogenase responsible for hydrogen generation in Thermoanaerobacterium saccharolyticum and demonstration of increased ethanol yield via hydrogenase knockout. Journal of Bacteriology. 191:6457-6464.

Shaw, J. A., Jenney, F. E., Adams, M. W., and Lynd, L. R. (2008a). End-product pathways in the xylose fermenting bacterium, Thermoanaerobacterium saccharolyticum. Enzyme and Microbial Technology. 42:453-458.

Shaw, J. A., Podkaminer K. K., Desai, S. G., Bardsley, J. S., Rogers, S. R., Thorne, P. G., Hogsett, D. A., and Lynd, L. R. (2008b). Metabolic engineering of a thermophilic bacterium to produce ethanol at high yield. PNAS. 105:13769-13774.

Shaw, J. A., Tyrin, M., Podkaminer, K., Hogsett, D., and Lynd, L. R. (2006). Metabolic engineering of the xylose-utilizing thermophile Thermoanaerobacterium saccharolyticum jw/slys485 for ethanol production. Conference presentation. Iowa State University. 
Shen, H., Poovaiah, C. R., Ziebell, A., Tschaplinski, T. J., Pattathil, S., Gjersing, E., Engle, N. L., Katahira, R., Pu, Y., Sykes, R., Chen, F., Ragauskas, A. J., Mielenz, J. R., Hahn, M. G., Davis, M., Stewart, C. N., and Dixon, R. A. (2013). Enhanced characteristics of genetically modified switchgrass (Panicum virgatum $\mathrm{L}$.) for high biofuel production. Biotechnology for Biofuels. 6:71.

Shimon, L. J., Pages, S., Belaich, A., Belaich, J. P., Bayer, E. A., Lamed, R., Shoham, Y., and Frolow., F. (2000). Structure of a family III a scaffoldin CBD from the cellulosome of Clostridium cellulolyticum at 2.2 A resolution. Biological Crystallography Journal. 56:1560-1568.

Shoseyov, O., Takagi, M., Goldstein, M. A., and Doi, R. H. (1992). Primary sequence analysis of Clostridium cellulovorans cellulose binding protein A. PNAS. 89:3483-3487.

Sims, R., and Taylor, M. (2008). From first-to-second generation biofuel technologies. Paris, France. International Energy Agency.

Sizova, M. V., Izquierdo, J. A., Panikov, N. S., and Lynd, L. R. (2011). Cellulose-and xylandegrading thermophilic anaerobic bacteria from biocompost. Applied and Environmental Microbiology. 79:2282-2291.

Slonczewski, J. L. (2014). Microbiology: an evolving science. Bellevue, WA: Content Technologies Inc.

Smith, D. K., and Greenfield, S. B. (1979). Distribution of chemical constituents among shoot parts of timothy and switchgrass at anthesis. Journal of Plant Nutrition. 1:81-89.

Sparling, R., Islam., R., Cicek, N., Carere, C., Chow, H., and Levin, D. B. (2006). Formate synthesis by Clostridium thermocellum during anaerobic fermentation. Canadian Journal of Microbiology. 52:681-688.

Suib, S. L. (2013). New and future developments in catalysis: catalytic biomass conversion. Waltham, MA: Elsevier.

Svetlitchnyi, V. A., Kensch, O., Falkenhan, D. A., Korseska, S. G., Lippert, N., Prinz, M., Sassi, J., SchickorA., and Curvers, S. (2013). Single-step ethanol production from lignocelluloses using novel extremely thermophilic bacteria. Biotechnology for Biofuels. 6:31.

Taherzadeh, M., and Karimi, K. (2007). Enzyme-based hydrolysis processes for ethanol from lignocellulosic materials. Bioresource. 2:707-738.

Tojo, S. (2013). Sustainable biomass system. Waltham, MA: Elsevier.

Tripp, V. W., and Rollins, M. L. (1952). Morphology and chemical composition of certain components of cotton fiber cell wall. Analytical Chemistry. 24:1721-1728. 
Tsakraklides, V., Shaw, J. A., Miller, B. B., Hogsett, D. A., and Herring, C. D. (2012). Carbon repression in Thermoanaerobacterium saccharolyticum. Biotechnology for Biofuels. 5:85.

Teugjas, H., and Väljamäe, P. (2013). Product inhibition of cellulases studied with ${ }^{14} \mathrm{C}$-labeled cellulose substrates. Biotechnology for Biofuels. 6:104-118.

Van Breeman, N., Burrough, P. A., Velthorst, E. J., Van Dobben, H. F., De Vit, T., Ridder T.B., and Reijnders H. F. (1982). Soil acidification from atmospheric ammonium sulphate in forest canopy throughfall. Nature. 299:548-550.

Venturi, P. and Venturi, G. (2003). Analysis of energy comparison for crops in European agricultural systems. Biomass Bioenergy. 25:235-255.

Vinuselvi, P., Kim, M. K., Lee, S. K., and Ghim, C. M. (2012). Rewiring carbon catabolite repression for microbial cell factory. BMB Reports. 45:59-70.

Waller, B. H., Olson, D. G., Currie, D. H., Guss, A. M., and Lynd, L. R. (2012). Exchange of type II dockerin-containing subunits of the Clostridium thermocellum cellulosome as revealed by SNAP-tags. FEMS Microbiology Letters. 338:46-53.

Wang, Z. W., and Chen, S. (2009). Potential of biofilm-based biofuel production. Applied Microbiology and Biotechnology. 83:1-18.

Wang, Z. W., Lee, S. H., Elkins, J. G., Li, Y., Hamilton-Brehm, S., and Morrell-Falvey, J. L. (2013). Continuous live cell imaging of cellulose attachment by microbes under anaerobic and thermophilic conditions using confocal microscopy. Journal of Environmental Sciences. 25:849856.

Wang, Z. W., Lee, S. H., Elkins, J. G., and Morrell-Falvey, J. L. (2011). Spatial and temporal dynamics of cellulose degradation and biofilm formation by Caldicellulosiruptor obsidiansis and Clostridium thermocellum. AMB Express. 1:30.

Weimer, P. J., and Zeikus, J. G. (1977). Fermentation of cellulose and cellobiose by Clostridium thermocellum in the absence and presence of Methanobacterium thermoautotrophicum. Applied and Environmental Microbiology. 33:289-297.

Wiegel, J. (1980). Formation of ethanol by bacteria. A pledge for the use of extreme thermophilic anaerobic bacteria in industrial ethanol fermentation process. Experientia. 36:14341446.

Wingender, J., Neu, T. R., and Flemming, H. C. (1999). What are bacterial extracellular polymeric substances? Berlin, Germany: Springer 
Wolf, W., Spiess, W. E. L, and Jung, G. (1984). The water-vapour sorption isotherms of microcrystalline cellulose (MCC) and of purified potato starch.: results of a collaborative study. Journal of Food Engineering. 3:51-73.

Wolfaardt, G. M., Lawrence, J. R., and Korber, D. R. (1999). Function of EPS. In: Wingender J, Neu T. R, Flemming HC, editors. Microbial Extracellular Polymeric Substances. Berlin, Germany: Springer. 171-200.

Wolfaardt, G. M., Lawrence, J. R., Robarts, R. D., Caldwell, S. J., and Caldwell, D. E. (1994). Multicellular organization in degradative biofilm community. Applied and Environmental Microbiology. 60:434-446.

Wright, J.D., Wyman, C.E., and Grohmann, K. (1988). Simultaneous saccharification and fermentation of lignocellulose: process evaluation. Applied Biochemistry and Biotechnology. 18:75-90.

Wu, M., Mintz, M., Wang, M., and Arora, S. (2008). Consumptive water use in the production of bioethanol and petroleum gasoline. Lemont, IL: Argonne National Laboratory.

Wyman, C. E. and Goodman, B. J. (1993). Biotechnology for production of fuels, chemicals, and materials. Applied Biochemistry and Biotechnology. 39:41-59.

Yaniv, O., Frolow, F., Levy-Assraf, M., Lamed, R., and Bayer, E. A. (2012). Chapter thirteen interactions between family 3 carbohydrate binding modules (CBMs) and cellulosomal linker peptides. Methods in Enzymology. 510: 247-259.

Yee, K. L., Rodriguez, M., Thompson, O. A., Fu, C., Wang, Z., Davison, B. H., and Mielenz, J. R. (2014). Consolidated bioprocessing of transgenic switchgrass by engineered and evolved Clostridium thermocellum strain. Biotechnology for Biofuels. 7:75.

Yee, K. L., Rodriguez, M., Tschaplinski, T. J., Engle, N. L., Martin, M. Z., Fu, C., Wang, Z., Hamilton-Brehm, S. D., and Mielenz, J. R. (2012). Evaluation of the bioconversion of genetically modified switchgrass using simultaneous saccharification and fermentation and consolidated bioprocessing approach. Biotechnology for Biofuels. 5:81.

Zavrel, M., Bross, D., Funke, M., Buchs, J., and Spiess, A. C. (2009). High-throughput screening for ionic liquids dissolving (ligno-) cellulose. Bioresource Technology. 100:2580-2587.

Zhang, G. C., Liu, J. J., and Ding, W. T. (2011). Decreased xylitol formation during xylose fermentation in Saccharomyces cerevisiae due to overexpression of water-forming NADH oxidase. Applied and Environmental Microbiology. 78:1081-1086.

Zhang, Y. P., and Lynd, L. R. (2005). Cellulose utilization by Clostridium thermocellum: bioenergetics and hydrolysis product assimilation. PNAS. 102:7321-7325. 
Zou, S., Causey, T. B., Hasona, A., Shanmugam, K. T., and Ingram, L. O. (2003). Production of optically pure D-Lactic acid in mineral salts medium by metabolically engineered Eschericia coli W3110. Applied and Environmental Microbiology. 69:399-407. 